\title{
SINANTROPIA DE CALLIPHORIDAE (Diptera) EM GOIÂNIA, GOIAS
}

\section{MARIA JUDY DE MELLO FERREIRA}

Orientador: Prof. Dr. José Henrique Guimarães

Tese apresentada à Escola Superior de Agricultura "Luiz de Queiroz", dá Universidade de São Paulo, para obtençāo do titulo de Doutor em Agronomia. Area de Concentração: Entomologia

PIRACICABA

Estado de Sào Paulo - Brasil

Outubro - 1980 
Ao Dr. José Henrique Guimarães pela valiosa orientação e dedicação dispensada na elaboração do presente trabalho.

Ao corpo docente do Departamento de Entomologia da ESALQ-USP, em nome do seu chefe Prof. Dr. Domingos Gallo, pelos ensinamentos adquiridos.

A Universidade Federal de Goiās.

A Coordenação de Aperfeiçoamento de Pessoal do Ensino Superior (CAPES).

A todos os colegas dos diversos pontos do Brasil pela coleta e remessa de moscas.

Aos amigos que ajudaram e incentivaram durante a realização deste trabalho. 


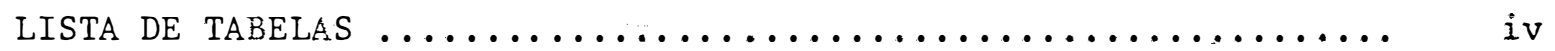

- LISTA DE FIGURAS $\ldots \ldots \ldots \ldots \ldots \ldots \ldots \ldots \ldots \ldots \ldots \ldots \ldots \ldots \ldots \ldots \ldots \ldots \ldots \ldots \ldots \ldots$

RESUMO $\ldots \ldots \ldots \ldots \ldots \ldots \ldots \ldots \ldots \ldots \ldots \ldots \ldots \ldots \ldots \ldots \ldots \ldots \ldots \ldots \ldots \ldots \ldots \ldots \ldots$

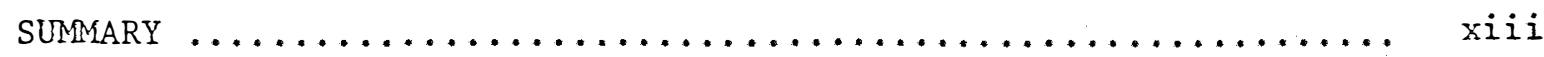

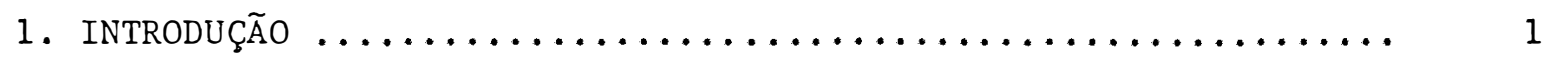

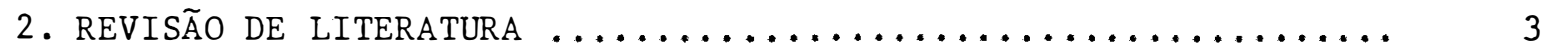

2.1. Sinantropia $\ldots \ldots \ldots \ldots \ldots \ldots \ldots \ldots \ldots \ldots \ldots \ldots \ldots \ldots \ldots$

2.2. Notas sobre o comportamento dos califorídeos .......... 8

2.3. Aspectos médico e sanitärio .................... 10

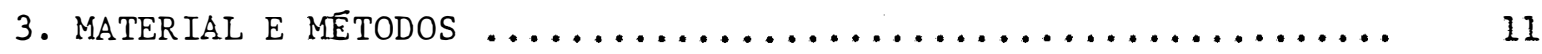

3.1. Coleta de moscas $\ldots \ldots \ldots \ldots \ldots \ldots \ldots \ldots \ldots \ldots \ldots \ldots \ldots \ldots \ldots$. 11

3.1.1. Período de coleta .................... 12

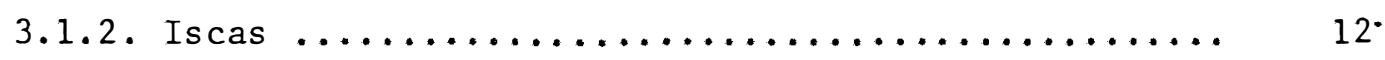

3.1.3. Preservação do material coletado ............. 13

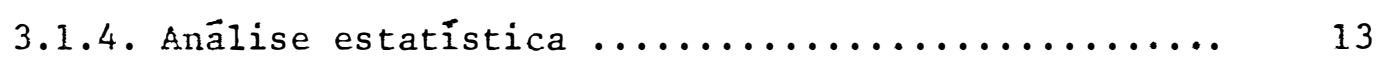

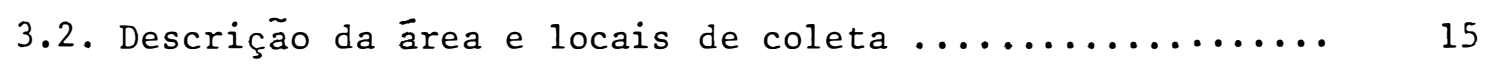

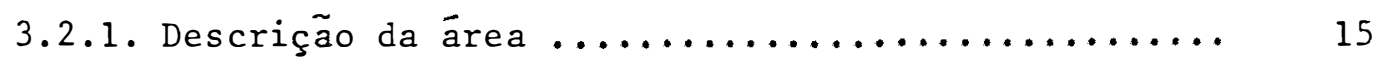

3.2.2. Locais de coleta ...................... 16

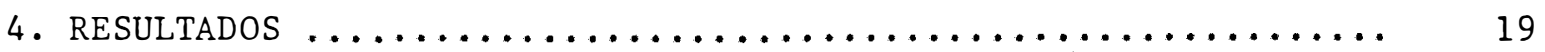

4.1. Espécies coletadas ........................... 19

4.2. Ocorrência da espécie Chrysomya chloropyga, até setembro de 1979 (baseados em GUIMARÃES et alii, 1979) ......... 20 
Pàg.

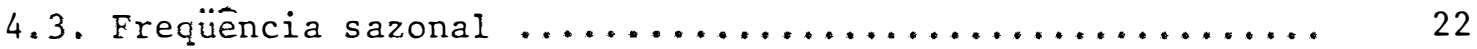

4.4. Indice de Sinantropia ..................... 22

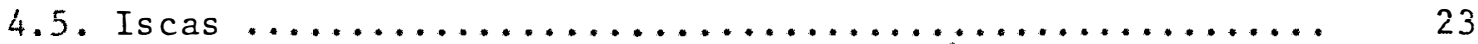

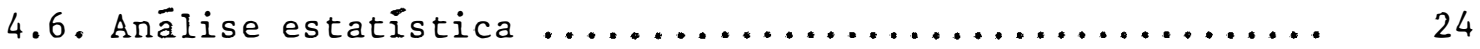

4.7. Distribuição e comportamento das espécies estudadas ..... 29

4.8. Freqüência sazonal ...................... 45

4.9. Indice de Sinantropia .................... 45

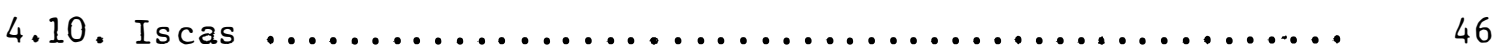

4.11. Distribuição e comportamento das espécies estudadas .... 51

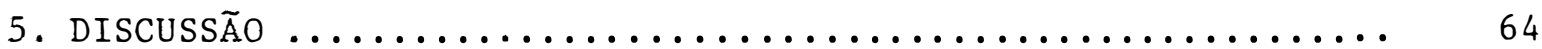

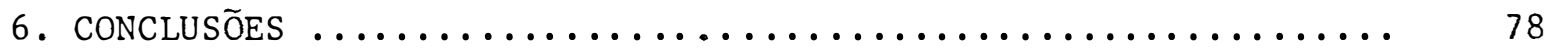

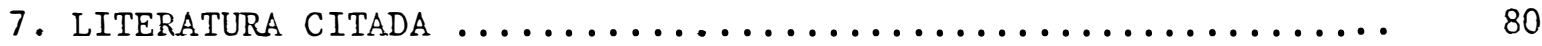

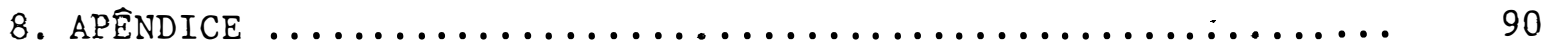


TABELA 1 - Esquema da anālise de variância............

TABELA 2 - Comparação da abundância de califorídeos coletados em peixe cru, fígado de ave e fezes humanas, em Goiânia, no período de agosto de 1975 a julho de 1976. . . .

TABELA 3 - Valores do "Teste F" e Coeficiente de Variação, relativos às espécies de califorídeos coletadas em Goiâ nía, no período de 1975-1976. . . . . . . . .

TABELA 4 - Valores do Teste de Tukey, referentes às espécies de califorídeos coletados em Goiânia, no período de 1975-

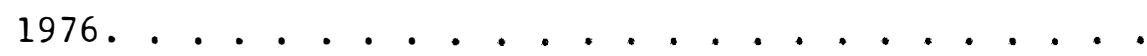

TABELA 5 - Valores do Teste de Tukey para as eficiências de iscas utilizadas na coleta dos califorídeos em Goiânia, no período de 1975-1976. . . . . . . . . . .

TABELA 6 - Valores do Teste de Tukey para as médias de iscas de peixe cru, fígado de ave e fezes humanas dentrodas es pécies de califorídeos coletadas em Goiânia, no perío do de 1975-1976................

TABELA 7 - Comparação da abundância de califorídeos coletados em peixe cru, fígado de ave e fezes humanas, em Goiânia, nos períodos de julho e dezembro de 1978 e janeiro-fe vereiro de 1979 . . . . . . . . . . . . .

TABELA 8 - Valores do "Teste F" e Coeficiente de Variação, relativos às espécies de califorídeos coletadas em Goiânia, no período de 1978-1979........... . 
TABELA 9 - Valores do Teste de Tukey para as espécies de califo rídeos coletadas em Goiânia, no período de 1978 1979 . . . . . . . . . . . . . . .

TABELA 10 - Valores do Teste de Tukey, para as eficiências de is cas utilizadas na coleta de califorídeos, em Goiânia, no período de 1978-1979 . . . . . . . .

TABELA 11 - Valores do Teste de Tukey para as médias de iscas de peixe cru, fígado de ave e fezes humanas dentro das espécies de califorídeos coletadas em Goiânia, no pe ríodo de 1978-1979 . . . . . . . . . . . .

TABELA 12 - Indice sinantrópico de califorídeos coletados em Goiâ nia, nos períodos de 1975-1976 (agosto a julho) e 1978 a 1979 (julho e dezembro, janeiro e fevereiro), para comparação com os índices de espécies que ocorrem em Curitiba, Campinas e o indice de $P$. sericata calcula do por NUORTEVA (1963), relativo à Finlândia, Tchecoslovãquia, Hungria e Suécia. . . . . . . . . 
FIGURA 1 - Armadilha para dípteros, instalada no campo .... .

FIGURA 2 - Aspecto gẹal do local de coleta - (I) Zona urbana. .

FIGURA 3 - Aspecto geral do local de coleta-(II) Zona rural..

FIGURA 4 - Aspecto geral do local de coleta-(III) Zona de mata.

FIGURA 5 - Distribuição geral de Calliphoridae no período de agosto de 1975 a julho de 1976 em Goiânia - Goiās. . .

FIGURA 6 - Indices de Sinantropia das espécies de Calliphoridae no período de agosto de 1975 a julho de 1976, em Goiânia, Goiās. . . . . . . . . . . . . .

FIGURA 7 - Freqüência relativa (\%) das espécies de Calliphoridae em iscas de Peixe cru, Fígado de ave e Fezes humanas, no período de 1975-1976, em Goiânia - Goiās . . . .

FIGURA 8 - Relação entre o Indice de Sinantropia e o Grau de Pre ferência por Fezes humanas, das espécies de Calliphoridae de Goiānia, no período de agosto de 1975 a jutho de 1976 .

FIGURA 9 - Freqüência relativa (\%) das espécies de Calliphoridae, no período de agosto de 1975 a julho de 1976, em Goiānia, Goiās. . . . . . . . . . . . . 
Pàg.

FIGURA 10 - Distribuição anual de P. eximia no período de 19751976, em Goiânia, Goiās. . . . . . . . . .

FIGURA 11 - Distribução anual de P. sericata no período de 19751976, em Goiânia, Goiās. . . . . . . . . . .

FIGURA 12 - Distribuição anual de H. segmentaria no período de 1975-1976, em Goiānia, Goiás .. . . . . . .

FIGURA 13 - Distribuição anual de H. flavifacies no período de 1975-1976, em Goiânia, Goiās . . . . . . . .

FIGURA 14 - Distribuição anual de C. macellaria no período de 1975-1976, em Goiânia, Goiās . . . . . . . .

FIGURA 15 - Distribuição anual de M. fulvinota no período de 1975-1976, em Goiânia, Goiās . . . . . . . .

FIGURA 16 - Frequência relativa (\%) das espécies de Calliphoridae, na z. urbana; z. rural e z. de mata, no período de agosto de 1975 a julho de 1976, em Goiânia-GO . .

FIGURA 17 - Freqüência relativa (\%) das espécies de Calliphoridae em iscas de: (A) Peixe cru; (B) Fígado de ave e (C) Fezes humanas, no período de agosto de 1975 a ju lho de 1976, em Goiânia, Goiās . . . . . . . .

FIGURA 18 - Freqüência relativa (\%) das espécies de Calliphoridae, coletados em iscas de: (A) Peixe cru; (B) Fígado de ave e (C) Fezes humanas, na $z$. urbana; z. rural e z. de mata, no período de agosto de 1975 a julho de 1976, em Goiânia, Goiās . . . . . . . . 
FIGURA 19 - Variação na freqüência dos sexos das espécies de Cạ liphoridae, na $z$. urbana (I); $z$, rural (II) e $z$. de mata (III), coletados no período de agosto de 1975 a julho de 1976, em Goiânia, Goiās . . . . . . .

FIGURA 20 - Distribuição geral de Calliphoridae no período de ju tho e dezembro de 1979 e janeiro-fevereiro de 1979, em Goiânia, Goiās . . . . . . . . . . . .

FIGURA 21 - Indices de Sinantropia das espécies de Calliphoridae, no período de julho a dezembro de 1978 e janeiro-fevereiro de 1979, em Goiânia, Goiās. . . . .

FIGURA 22 - Freqüência relativa (\%) das espécies de Calliphoridae, em iscas de Peixe cru, Fígado de ave e Fezes hu manas, no período de julho e dezembro de 1978 e janeiro-fevereiro de 1979, em Goiânia, Goiás . . . .

FIGURA 23 - Relação entre o Indice de Sinantropia e o Grau de Pre ferência por Fezes humanas, das espécies de Calliphoridae de Goiânia, no período de julho e dezembro de 1978 e janeiro e fevereiro de 1979.

FIGURA 24 - Freqüência relativa (\%) das espécies de Calliphoridae, no período de julho e dezembro de 1978 e janeiro-fevereiro de 1979, em Goiânia, Goiàs. . . . .

FIGURA 25 - Variação na ocorrência de $P$. eximia no período de ju tho e dezembro de 1978 e janeiro-fevereiro de 1979 , em Goiânia, Goiās. . . . . . . . . . . . . 
Pág.

FIGURA 26 - Variação na ocorrência de $P$. sericata no período de julho e dezembro de 1978 e janeiro-fevereiro de 1979, em Goiânia, Goiās. . . . . . . . . . . . .

FIGURA 27 - Variação na ocorrência de C. macellaria no período de julho e dezembro de 1978 e janeiro-fevereiro de 1979, em Goiânia, Goiās. . . . . . . . . . .

FIGURA 28 - Variação na ocorrência de H. segmentaris no período de julho e dezembro de 1978 e janeiro-fevereiro de 1979, em Goiânia, Goiás. . . . . . . . . .

FIGURA 29 - Variação na ocorrência de C. chloropyga no período de julho e dezembro de 1978 e janeiro-fevereiro de 1979, em Goiânia, Goiās. . . . . . . . . . .

FIGURA 30 - Freqüência relativa (\%) das espécies de Calliphoridae, coletados na $z$. urbana; $z$, rural e z. de mata no período de 1978-1979, em Goiânia, Goiás. . . . .

FIGURA 31 - Freqüência relativa (\%) das espécies de Calliphoridae em iscas de: (A) Peixe cru, (B) Fígado de aves e (C) Fezes humanas, no período de julho-dezembro de 1978 e janeiro-fevereiro de 1979, em Goiânia, Goiás.

FIGURA 32 - Freqüência relativa (\%) das espécies de Calliphoridae, coletados em iscas de: (A) Peixe cru, (B) Fígado de ave e (C) Fezes humanas, na z. urbana, z. rural e $z$. de mata, no período de julho-dezembro de 1978 e janeiro-fevereiro de 1979, em Goiânia, Goiás. 
FIGURA. 33 - Variação na frequência do sexo das espécies de Calli phoridae, coletados na $z$. urbana (I); z. rural (II) e $z$. de mata (III), no período de julho-dezembro 1978 e janeiro-fevereiro de 1979, em Goiânia, Goiās . . .

FIGURA 34 - Comparação de fréqüência relativa (\%) das espécies de Calliphoridae, no período de 1975-1976 e 1978-1979, em Goiânia, Goiās . . . . . . . . . . . .

FIGURA 35 - Comparação entre o Indice de Sinantropiadas espécies de Calliphoridae encontrados em Goiânia, Goiás, nos períodos de 1975-1976 e 1978-1979. . . . . . .

FIGURA 36 - Distribuição das espécies de Calliphoridae encontradas em Goiânia, Goiās, nos períodos de 1975-1976 e - 1978-1979, na Eubiocenose, Agrobiocenose e Antropo biocenose (Esquema baseado nos critérios de NUORTEVA, 1963 e POVOLNY, 1971 ). . . . . . . . . . .

FIGURA 37 - Dispersão de C. Chloropyga, no Brasil, até setembro de 1979 . . . . . . . . . . . . . 


\section{SINANTROPIA DE CALLIPHORIDAE (DIPTERA) \\ EM GOIÂNIA - GOIÁS}

Maria Judy de Mello Ferreira Orientador: Prof. Dr. José Henrique Guimarães

RESUMO

Avaliou-se o grau de preferência por āreas habitadas pelo ho mem, para sete espécies de Diptera - Calliphoridae: Phaenicia eximia (Wiedemann, 1819), Phaenicia sericata (Meigen, 1826), Cochliomyia macellaria (Fabricius, 1775), Chrysomya chloropyga (Wiedemann, 1818), Hemilucilia segmentaria (Fabricius, 1775), Hemilucilia flavifacies (Engel, 1931), Myiolucilia fulvinota (Walker, 1849), que são atraídas por substratos de peixe cru, fígado de ave e fezes humanas na Região de Goiânia - Goiās. A avaliação foi feita determinando-se o Indice de Sinantropia para cada uma delas (se gundo a metodologia de NUORTEVA, 1963). Para tal houve necessidade de coletas simultâneas em três āreas ecológicas distintas: zona urbana, zona rural e zona de mata.

O trabalho foi realizado em duas etapas: a primeira no período de agosto de 1975 a julho de 1976, quando foi realizado um levantamento da fauna nativa da Região e, a segunda, em julho e dezembro de 1978 e janeiro e fevereiro de 1979, após a constatação da introdução no Brasil, da espécie Chrysomya chloropyga, originäria do Velho Mundo. 
xii.

Comprovou-se uma forte competição da espécie introduzida com as espécies nativas, ocasionando drástica queda nas populações de C. macella ria que era dominante durante a primeira etapa.

Considerou-se também a distribuição anual das espécies, uma vez que as coletas foram realizadas mensalmente, durante a primeira etapa. Ve rificou-se que os picos máximos populacionais ocorreram em setembro, janeiro, e maio e as quedas de população em dezembro, fevereiro, março, julho e agosto.

O efeito das iscas na atração das moscas, também foi observado. Fígado de ave foi estatisticamente preferido para as espécies sinantrópicas e hemissinantrópicas. As espécies assinantrōpicas mostraram - se mais freqüentes em iscas de fezes.

A freqüência dos sexos tambēm foi considerada.'As fêmeas são sem pre mais freqüentes em todos os tipos de substrato e em todas as āreas de coleta.

Finalmente, foi feita uma anālise do comportamento ecológico das espécies nativas antes e após a introdução da espécie exótica. C. chlo ropyga mostrou ser uma espécie de fácil adaptação e ampla distribuição no território brasileiro, uma vez que tendo sido introduzida em 1975 já ocor ria em diversos Estados até setembro de 1979. 


\section{SYNANTHROPY OF-CALLIPHORIDAE (DIPTERA)}

IN GOIÂNIA - STATE OF GOIÁS

Maria Judy de Mello Ferreira

Advisor: Prof. Dr. Josē Henrique Guimarães

\section{SUMMARY}

It is well known that the occurrence of several species of dipterous calliphorids is dependent on human settlement. This dependence, known as synanthropy has been investigated by calculating synanthropic indices, for different species in several ecological areas. In this work the author determines the synanthropic indices for 7 calliphorids species occurring in the city of Goiânia, State of Goiás. The following species were captured in the area: Phaenicia eximia (Wiedemann, 1819); Phaenicia seri cata (Meigen, 1826), Cochliomyiamaccllaria (Fabricius, 1775), Chrysomya chloropyga (Wiedemann, 1818), Hemilucilia segmentaria (Fabricius, 1775), Hemilucilia flavifacies (Engel, 1931), Myiolucilia fulvinota (Walker, 1849). The calculation of synanthropic indices (NUORTEVA, 1963) was based on comparative trapping in a town, a rural area and in an undisturbed forested zone. The baits used were bird liver, fresh fish and human faeces. The flies were trapped in two distinct periods. In the first period (August 1975 to July 1976), it was conducted a preliminary survey of calliphorid fauna of Goiânia; in the second period (July and December, 
1978 and January to February, 1979), another trapping was performed, after the introduction of Chrysomya chloropyga in the area. The population of Cochliomyia macellaria, a native species prevalent in the first trapping period, was drastically reduced after the introduction of $C$. chloropyga. The annual frequency to each species was determined. The flies reached their highest populational density in September, January and May, and the lowest density in December, February, March, July and August. The comparative effect of the baits in attracting the flies was also investigated. Poultry liver was highly attractive to synanthropic and hemisynanthropic species whereas human faeces was more attractive to asynanthropic ones. The females were more abundant and collected in all the substracts. The status of dispersal and distribution of $\mathrm{C}$. chloropyga in Brazil, and the effect on both natural and agroecosystem that resulted from the invasion of this species was herewith reviwed. After its introduction in 1975 , C. Chloropyga has dispersed to long distances, and has been being recorded from Belém (State of Parā) southward to State of Rio Grande do Sul. 


\section{INTRODUÇÃO}

Entre os dípteros de interesse médico e sanitärio que ocor rem em āreas metropolitanas, ou seja, em ambientes modificados pelo homem, destacam-se os muscóideos, que assumem importante papel não só no cam po da ecologia, como também no campo da Saúde Pública, pois os adultos são vetores mecânicos de patógenos para o homem e animais domésticos.

Os muscóideos representados pelos califorídeos, muscídeos, sar cofagídeos, faniídeos e outros constituem um grupo em que o fenômeno de si nantropia é definido, por se desenvolverem em substratos que estão sempre associados com o homem; excrementos, carcaças de animais, lixo urbano,etc. Considerando-se os aspectos evidenciados, propõem-se a es tudar, do ponto de vista ecológico, as espécies de Calliphoridae de Goiânia-Goiās, determinando-lhes o indice sinantrópico, para estabelecer o seu relacionamento quantitativo e qualitativo com o ambiente humano, através de uma adaptação da metodologia de NUORTEVA (1963).

0 presente trabalho foi desenvolvido em duas etapas: a primei 
ra, durante o biênio $1975 / 76$ através de um levantamento da fauna nativa regional e, a segunda, no período de 1978/79 quando se constatou a introdução de uma espécie de califorídeo do Velho Mundo em Goiânia, Chrysomya chloropyga, citada pela primeira vez no Brasil em 1975 por IMBIRIBAet alii (1977), na cidade de Curitiba e posteriormente em São Paulo por GUIMARÃES et alii (1978).

A introdução da espécie em referência, neste País, ocasionou grandes modificações no comportamento das espécies nativas, mudanças essas que serão desenvolvidas e discutidas neste trabalho.

Concomitantemente às observações sobre ocorrência e comportamento de C. Chloropyga, procederam-se estudos gerais acerca de sua introção e dispersão, até o presente. 


\section{REVISÃO DE LITERATURA}

\subsection{SINANTROPIA}

Segundo GREGOR e POVOLNY (1958), moscas sinantrópicas, consideradas no amplo sentido, são definidas como sendo aquelas que mantêm relações puramente ecológicas, obrigatórias ou facultativas com o homem e seu ambiente, não se considerando o aspecto higiênico epidemiológico des ta relação. No sentido restrito, moscas sinantrópicas são aquelas que estão relacionadas com o ambiente microbiologicamente contaminado e com o homem e seu ambiente imediato (alimento e artigos manuseados). Neste sentido, o termo sinantropia fica limitado às espécies de importância higiênica e epidemiológica. Conforme o mesmo autor, esta corrente é adotada pelos pesquisadores russos.

PETERS (1960) conceituou moscas sinantrópicas como sendo aque las que apresentam capacidade de se adaptarem às condições criadas pelo ho mem.

NUORTEVA (1963) considerou moscas sinantrópicas aquelas que 
têm capacidade de utilizar as condições favoráveis criadas pelo homem. De acordo com este conceito, ele criou e utilizou o Indice de Sinantropia (I.S.), para analisar as relações entre os califorídeos e o homem, e suas preferências por āreas colonizadas. Este índice é aplicado quando se comparam dados quantitativos de uma determinạda espécie em três áreas ecológicas distintas: a) ārea urbana; b) ārea rural (perto de uma casa isolada) e c) área de mata ou florestada, usando-se o mesmo método de coleta (NUORTEVA, 1963, 1966, 1971), (NUORTEVA e LAURIKAINEN, 1964), (NUORTEVA e VESIKARI, 1966), (NUORTEVA e RÄSÄNEM, 1968).

POVOLNY (1959) acredita que a sinantropia geral das moscas não pode ser considerada como uma adaptação direta do ambiente humano no que diz respeito às modificações deste ambiente, mas sim, como um grau de aproveitamento das condições favoráveis, que é dado pela valência ecológi ca das diferentes espécies, e classifica as formas sinantrópicas em dois grupos: eusinantrōpicas e hemissinantrōpicas.

DERBENEVA-UKHOVA (1962) classifica como sinantrópico todo inseto associado com o homem e animais domésticos. De acordo com este tipo de associação propõe três tipos de formas sinantrōpicas: a) formas pastoris; b) formas de ambiente rural (semicolonizado), e c) formas de ambiente urbano (colonizado).

De acordo com NUORTEVA (1971), a transformação do ambiente na tural em área urbana provoca modificações radicais na fauna e na flora, com adaptações de muitas espécies a estas transformações, passando assim, a se beneficiarem do material orgānico aí acumulado. Em um levantamento quanti tativo de pássaros em ambiente de mata, zona de campos cultivados e zona urbana, observou-se um acentuado acréscimo na biomassa desses animais na 
ārea urbana, decorrente da perturbação ecológica causada pelo transporte de matéria biológica das matas e campos cultivados em direção às cidades. NUORTEVA (1963) refere-se à influência de fatores ambientes na composição das populações animais, entre os quais as moscas sinantrópicas. Os detritos e excrementos de origem humana e de animais domésticos, assim como o tratamento dado a este material em diferentes condições urba nas e rurais, são fatores determinantes do grau e modo de sinantropia de diferentes espécies de moscas.

FRANKIE e EHLFR (1978) ressaltam o aspecto da adaptabilidade de populações de insetos a novos ambientes criados pelo homem, e a consequiente necessidade de estudos ecológicos destes insetos em ambientes urbanos.

- MIHÁLY (1967 c) propõe também uma classificação para os dîpteros sinantrópicos, dividindo-os em dois subgrupos: rural e urbano. A fau na sinantrópica rural, segundo esse autor, constituir-se-ia das espécies de dípteros muscóideos que se desenvolvem a partir das fezes de animais do mésticos. Secundariamente, poderiam usar outros substratos, tais como, li xo urbano, carcaças, etc., enquanto que, a fauna urbana seria formada por espécies que se alimentariam ou se desenvolveriam a partir de fezes humanas.

POVOLNY in Greenberg (1971) considera o ambiente humano ou am biente da residência humana como uma antropobiocensose e as espécies ani-mais que aí vivem, excetuando-se o próprio homem e seus animais domésticos, são constituídas daquelas espécies capazes de se adaptarem às novas condições surgidas, devido à sua grande valência ecológica. Pode-se mesmo dizer que algumas espécies tornam-se melhor adaptadas às condições cria- 
das pelo homem e que não se constituem mais em populações importantes em seu ambiente natural. Segundo este autor, a antropobiocenose é constituída por três componentes animais: a) o homem, seu criador; b) os animais do mésticos introduzidos e mantidos pelo homem e, c) os animais sinantrópicos, como membros espontâneos, mas indesejāveis para o homem.

O mesmo autor considera ainda um terceiro tipo de biocenose agrobiocenose - como intermediārio entre o ambiente original (eubiocenose) e a antropobiocenose. Esse ambiente transitório é por ele considerado como sendo fundamental para o aparecimento e desenvolvimento da sinantropia, pois funciona como seletor das espécies que apresentam capacidade adaptativa às novas condições. Posteriormente viria o desenvolvimento dos dípteros que se criam em fezes de animais domésticos que aos poucos vão sendo introduzidos no ambiente, e de produtos decorrentes da atividade agrícola. Portanto, afirma o autor, são poucas as espécies que passam dire tamente de uma eubiocenose para uma antropobiocenose.

Procurando levar em consideração fatores de ordem ecológica,e conômica e sanitäria, POVOLNY (loc. cit.) propõe a classificação que se segue para as moscas sinantrōpicas.

1 - Eusinantrōpicas: são moscas associadas à antropobiocenose e se desenvolvem principalmente nesse ambiente. Algumas espécies tendendo ao cos mopolitismo. Neste tipo de moscas encontram-se as formas endófilas, que estão relacionadas à antropobiocenose por estreitos laços de natu reza trófica e microclimática, e fora deste ambiente são incapazes de se constituĩrem em populações importantes e, formas exōfilas, que tam bém estão associadas à antropobiocenose, mas não necessitam, obrigato riamente, do ambiente humano para se desenvolverem. 
2 - Hemissinantrópicas: são espécies que existem independentemente da antropobiocenose. Vivem em ambientes naturais, e com a gradual evolução da biocenose modificada, as moscas originais dessa região mostram ten dência crescentemente assinantrōpica com o aumento de suas populaf̧ões. Uma espécie hemissinantrōpiça pode evoluir para uma forma exō fila de sinantropia. Por esta razão, uma espécie pode ser considerada eusinantrōpica em uma localidade e hemissinantrōpica em outra.

3 - Assinantrópicas: neste grupo são incluídas as espécies que não preenchem os requisitos para serem consideradas hemissinantrópicas ou eusinantrōpicas.

4 - Simbovinas: são moscas ligadas ao homem através de excretas de ruminantes domésticos. As formas pastoris encontram-se em altas densidades nas pastagens, mas não dependem da antropobiocenose para seu desenvolvimento e sobrevivência. As formas de estábulos encontram-se nos locais de confinamento dos animais domésticos.

5 - Causadoras de miíases: são de grande importância veterinária, como cau sadoras de miliases e consideradas em separado dos demais grupos.

6 - Comunicativas: moscas que oscilam entre o ambiente, microbiologicamen te contaminado, e o ambiente humano.

GREGOR (1972) questiona a possibilidade de aplicação do indice de sinantropia de NUORTEVA (1963) às espécies que vivem em condif̧ões tropicais, devido à influência de fatores abióticos limitantes, como a temperatura nas latitudes norte.

Os dípteros muscóideos têm sido pouco estudados nas regiões tropicais. Podemos salientar apenas os trabalhos de GREGOR (1972, 1975) 
realizados com sarcofagídeos, califorídeos e muscídeos de Cuba. No Brasil, destacamos as contribuições de FERREIRA (1975,. 1978, 1979) em Curitiba-Paraná e LINHARES (1979) em Campinas - São Paulo.

\subsection{NOTAS SDBRE O COMPORTAMENTO DOS CALIFORIDEOS}

SCHOOF et alii (1954), SIVERLY e SCHOOF (1955 b,c) mostraram que o potencial reprodutivo de moscas varia consideravelmente com o nível sócio-econômico das populações de uma ärea metropolitana. Esta correlação foi analisada levando-se em consideração o tipo de lixo e a maneira como era acondicionado. Inegavelmente, como tem sido demonstrado por SILVERLY e SCHOOF (1955 a), SAVAGE e SCHOOF (1955), SIVERLY e SCHOOF (1955 b), SCHOOF et alii (1954) e WILTON (1961), os depósitos urbanos de lixo assumem importante papel como substrato de criação de móscas sinantrópicas em áreas metropolitanas.

Areas higienicamente menos favorecidas chegam a produzir duas vezes ma1s moscas do que locais urbanos onde ocorre coleta sistemática de lixo (SIVERLY e SCHOOF, 1955 b).

SCHOOF e SAVAGE (1955); SAVAGE e SCHOOF (1955) realizaram estudos comparativos em cinco cidades dos Estados Unidos nos anos de 1949 e 1950 e mostraram que as condições climáticas são fatores que determinam o grau de incidência de uma dada espécie de mosca em área urbana. Esta rela ção também foi observada por NUORTEVA (1960) com referência à Finlândia. SCHOOF et alii (1954), WILLIAM (1954), nos Estados Unidos, mostraram a in fluência de condições higiênicas em áreas metropolitanas na regulação da incidência de populações de moscas.

De acordo com STEWART e ROESSLER (1942) fatores bióticos po- 
dem obscurecer o efeito direto de fatores climáticos na incidência de mos cas em áreas metropolitanas.

Estudos de dispersão de moscas, realizados nos Estados Unidos por QUARTERMAN et alii (1954 a,b) mostraram que a população daquelas moscas em uma ärea urbana não é constituída ex̣clusivamente de espécies que aí se de senvolvem, mas tambēm por espécies de dispersão contínua e em todas as di reções, atraídas de fontes originárias de criação, tais como matadouros, leiterias, depósitos de lixo, etc., localizadas próximos às cidades. Observações de dispersão de califorídeos foram também feitas por BISHOPP e LAAKE (1921), LINDQUIST et alii (1951), SCHOOF et alii (1952), SCHOOF e MAIL (1953).

A dispersão de vôo de Cochliomyia macellaria em āreas urbanas foi estudada por QUARTERMAN et alii (1949) que constataram sua capacidade de realizar migrações à cerca de 10 milhas. Estes autores demonstram também a importância do saneamento municipal como forma de controlar a pro dução urbana de moscas.

A incidência e distribuição de moscas sinantrōpicas estão intimamente relacionadas com a sazonalidade, como demonstraram DEONIER (1942), STEWART e ROESSLER (1942), ARADI e MIHALLYI (1971), SAVAGE e SCHOOF (1955), SIVERLY e SCHOOF (1955 b), SCHOOF et alii (1956), FERREIRA (1975, 1978, 1979) e LINHARES (1979). Assim, diferentes espécies de moscas estão regidas por fatores ambientes, sendo suas populações alteradas em diferen tes épocas do ano.

Segundo NUORTEVA (1960), a incidência diāria de califorídeos na Finlândia é atribuída a fatores abióticos, tais como: temperatura, umi dade e luminosidade. 
Diferentes condições geogrä́ficas também estão relacionadas co mo fatores que interferem na composição populacional de moscas "varejeiras" (NUORTEVA, 1963), MacLEOD e DONELLY (1958).

A heliofilia de califorídeos sinantrópicos foi observada por NUORTEVA (1963) na Finlândia, ẹ a este fato foi atribuído grande importân cia do ponto de vista higiênico. De um modo geral, as espécies mais heliō filas parecem ser mais sinantrópicas. Dados referentes à heliofilia das es pécies tropicais são ressaltados por FERREIRA $(1975,1978)$ e LINHARES (1979) .

\subsection{ASPECTOS MEDICO E SANITARIO}

A importância médico-sanitária e econômica das moscas sinantrópicas foi ressaltada por vários autores, pois as formas adultas são transmissoras de patógenos para o homem e suas larvas causam miíases no ho mem e animais domésticos (ARADI e MIHALYI, 1971), (JAMES, 1948), (LINDSAY e SCCUDER, 1956), (MIHÁLYI, 1965; 1967 a,c), (ZUMPT, 1965). Uma relação dos organismos veiculados por moscas foi dada por GREENBERG (1971, 1973). NUORTEVA (1958; 1959 a,b,c,d; 1960), NUORTEVA e SKAREN (1960) associaram a maior incidência de poliomielite, na Finlândia, com picos po pulacionais de moscas "varejeiras", sobretudo no que diz respeito a Lucilia sericata (=Phaenicia sericata). Esta correlação foi também comprovada por NUORTEVA (1959) na Inglaterra. Ainda TRASK et alii (1943) mostraram que as "varejeiras" estariam, provavelmente relacionadas com a transmissão de pólio nos Estados Unidos.

Três espécies do gênero Chrysomya, originārias do Velho Mundo, e.recentemente introduzidas no Brasil, também estariam associadas com a transmissão de polioviroses e enterobacteriose (GUIMARÃEs et alii, 1978). 


\section{MATERIAIS E MÉTODOS}

\subsection{COLETAS DE MOSCAS}

As moscas foram capturas com armadilhas para dípteros construídas com latas de coloração preta, medindo $11 \mathrm{~cm}$ de diâmetro e $12 \mathrm{~cm}$ de altura, com oito aberturas laterais na parte inferior, para permitirem a entrada de insetos. No interior da lata foi colocado um cone de tela aberto nas extremidades. As latas foram envolvidas por sacos plásticos na parte superior, onde as moscas ficaram retidas. As armadilhas com as iscas, eram penduradas a uma altura de $20 \mathrm{~cm}$ do solo, aproximadamente (Figura 1). Essa armadilha foi anteriormente utilizada por, FERREIRA (1975, 1978, 1979) e LINHARES (1979).

Adotou-se a armadilha de coloração preta com base nos resulta dos de ORI et alii (1960), no Japão, segundo os quais os califorídeos são mais atraídos por armadilhas escuras (azul e preta) e repelidos por armadilhas de coloração clara (branca), em condições de clima quente, ocorren do o inverso em condições de clima frio. 


\subsubsection{PERIODO DE COLETA}

Este trabalho foi realizado em duas etapas, ocorrendo a primeira no período de 17 de agosto de 1975 a 8 de julho de 1976 (agosto: 17-23; setembro: 10-16; outubro: 14-20; novembro: 12-18; dezembro: 13-19; janeiro: 15-21; fevereiro: 25-29; março: 15-21; abril: 7-13; maio: 14-20; junho: 10-16; julho: 01-07). A segunda etapa desenvolveu-se no período de 13 de julho de 1978 a 12 de fevereiro de 1979 (julho: 13-19; dezembro: 12-18; janeiro: 22-28; fevereiro: 6-12). Todas as coletas foram procedi das mensalmente: no primeiro período, por 12 meses, e apenas durante 4 me ses no segundo período. Em cada mês as coletas eram efetuadas durante sete dias, simultaneamente em três äreas ecológicas distintas, zonas urbana, rural e de mata, na região de Goiânia - Goiás, totalizando 1.512 cole tas na primeira étapa, e 504 na segunda.

Os dados meteorológicos de todo o período de coleta, estão re gistrados nos Apêndices I, II, III e IV.

\section{1 .2 . ISCAS}

Foram utilizadas as seguintes iscas:

a) Peixe cru - em cada armadilha foram colocados $50 \mathrm{~g}$ de sardinha crua, a proximadamente,

b) Fígado de galinha - cada armadilha continha cerca de 50 g de vísceras, c) Fezes humanas - cerca de $50 \mathrm{~g}$ de material fresco.

Essas iscas representam algumas daquelas sugeridas por NUORTEVA (1963) e usadas por FERREIRA (1975, 1978, 1979). Tomando como base as pesquisas de KAWAI e SUENAGA (1960), no Japão, os quais ao compararem o 
grau ideal de putrefação de peixe na atração de moscas concluíram que o peixe envelhecido um dia exerce maior atração e estabeleceram o tempo de 24 h para a isca permanecer na armadilha. Entretanto, este periodo varia de acordo com diversos autores e finalidade do trabalho.

Em cada local de coleta foram colocadas seis armadilhas, duas a duas com o mesmo tipo de isca, num total de 18 armadilhas instaladas por dia.

\subsubsection{PRESERVAÇÃO DO MATERIAL COLETADO}

Em laboratório, as moscas mortas com éter ou clorofórmio, fo ram separadas por espécie e sexo, contadas e acondicionadas em mantas, al finetadas ou conservadas em álcool etílico $70 \%$.

3.1.4. ANALISE ESTATISTICA

o Indice de Sinantropia (I.S.), a seguir, para cada espécie, foi calculado pela fórmula de NUORTEVA (1963), já utilizada por FERREIRA - (1975, 1978, 1979) e LINHARES (1979):

$$
\text { I.S. }=\frac{2 a+b-2 c}{2} \text {, em que, }
$$

$a=$ percentagem de uma determinada espécie coletada na zona urbana em relação a esta mesma espécie, coletada na zona rural e zona de ma ta (ou florestada);

$\mathrm{b}=$ percentagem da mesma espécie coletada na zona rural;

$c=$ percentagem da mesma espécie coletada na zona de mata (ou flores tada). 
Para a determinação deste índice, portanto, se fazem necessārias coletas em três ambientes ecológicos distintos. O Índice varia de +100 a -100 , onde os valores positivos indicam maior associação das espécies com o ambiente humano, e os valores negativos, intolerância a este ambiente.

Para a avaliação estatística dos dados de ocorrência das seis espécies, atratividade das iscas, interação das espécies e iscas, nas três āreas de coleta, aplicou-se a análise de variância utilizando-se os valores numéricos, relativos apenas às fêmeas, e transformados em $\sqrt{x+0,5}$, conforme o esquema da Tabela 1. A diferença entre as médias foi definida pelo Teste de Tukey ao nível de $5 \%$ de probabilidade.

As anālises estatísticas foram desenvolvidas no Computador da Unidade de Processamento de Dados, anexo ao Departamento de Matemática e Estatística da ESALQ-USP.

TABELA 1 - Esquema da anālise de variância.

\begin{tabular}{lc} 
Causas de Variação & G.L. \\
\hline Iscas (I) & $I-1$ \\
Espécies (E) & $E-1$ \\
Interação (I x E) & $(I-1) \times(E-1)$ \\
\hline Tratamentos & $I \times E-1$ \\
Meses (M) & $M-1$ \\
Resíduo & $(I-1 \times E-1) \times(M-1)$ \\
\hline Total & $I \times E \times M-1$ \\
\hline
\end{tabular}




\subsection{DESCRIÇÃO DA AREA E LOCAIS DE COLETA}

\subsubsection{DESCRIÇÃO DA Æ̊REA}

RIZZO et alii (1972) dá a seguinte descrição da ārea:

0 'município de Goiânia localiza-se entre $16^{\circ} 40^{\prime} 21^{\prime \prime}$ de latitu-

de Sul e 49 $15^{\prime} 28^{\prime \prime}$ de longitude Oeste de Greenwich. Assenta-se em um planalto que se estende em ondulações suaves, sobressaindo-se entre os acidentes geogräficos, os morros de Serrinha com $891 \mathrm{~m}$, o do Mendanha com 814 m e o morro Santo Antonio, com 890 m de altitude.

Situa-se na Região Sul do Estado de Goiās, o solo, de maneira geral, é sílico-argiloso e bastante fértil. O clima apresenta-se com características tropicais. A precipitação pluviométrica condiciona a formação de duas estações: seca e chuvosa. A estação seca prolonga-se, geralmente, de abril a setembro (inverno) e a chuvosa tem início em outubro. A temperatura média anual é de $21,4^{\circ} \mathrm{C}$ e sua variação durante o ano estā em torno de $17,6^{\circ} \mathrm{C}$, registrados em julho e $22,9^{\circ} \mathrm{C}$ em outubro. Dados climatológicos de Goiânia (desde o período de 1960 a 1979), encontram-se no Apên dice I.

Ainda RIZZO et alii (op. cit.) define o Cerrado como sendo uma formação constituída por ārvores e aṛbustos contorcidos e com , cascas grossas, de folhas comumente coriáceas e duras. Essa vegetação distribuise, em geral, sobre revestimento de gramíneas e pequenas plantas lenhosas ou herbáceas, ocorrendo com grande freqüência Qualea grandiflora, 2 . parviflora, Byrsonima crassifolia, Hymenaea stigonocarpa e Dimorphandra mollis, as duas ūltimas, de porte mais elevado. O revestimento graminoso é formado em grande parte por Echinolaena inflexa e Melinis minutiflora. A 
Mata Caducifólia Tropical, pertence ao "Mato Grosso de Goiás" e é composta por árvores altas, médias e arbustos, formando assim, três estratos. As ārvores mais altas são representadas por Apuleia mollaris, Cariniana estrellensis, Piptadenia peregrina e Hymenaea.stilbocarpa.

\subsubsection{LOCAIS DE COLETA}

Zona Urbana - As armadilhas foram colocadas no quintal de uma residência (Fig. 2) situada na Vila Cosme, entre o Bairro Feliz e a Aveni da Independência. O local encontra-se à cerca de $4 \mathrm{~km}$ do centro comercial de Goiânia, Cidade que contava com uma população estimada em 518.469 habi tantes, em 1975, 551.485 em 1976, com 623.960 em 1978 e com 623.960 habitantes em 1979, segundo dados fornecidos pelo IBGE.

Zona Rural - As armadilhas foram colocadas próximas a uma casa isolada em um local modificado pelo homem, para criação de gado, distante cerca de $10 \mathrm{~km}$ do centro comercial da cidade. 0 local está à margem direita da rodovia que liga Goiânia a Nerópolis. 0 aspecto geral da ārea pode ser observado na Fig. 3 .

Zona Florestada (Zona de Mata) - o local escolhido é uma mata primária, localizada nas proximidades do Campus Universitário II a $14 \mathrm{~km}$ do centro comercial, aproximadamente. Nesta mata predomina as espécies de grande porte, jā citadas no item anterior (4.2.1.). 0 aspecto geral é mos trado na Fig. 4. 
17.

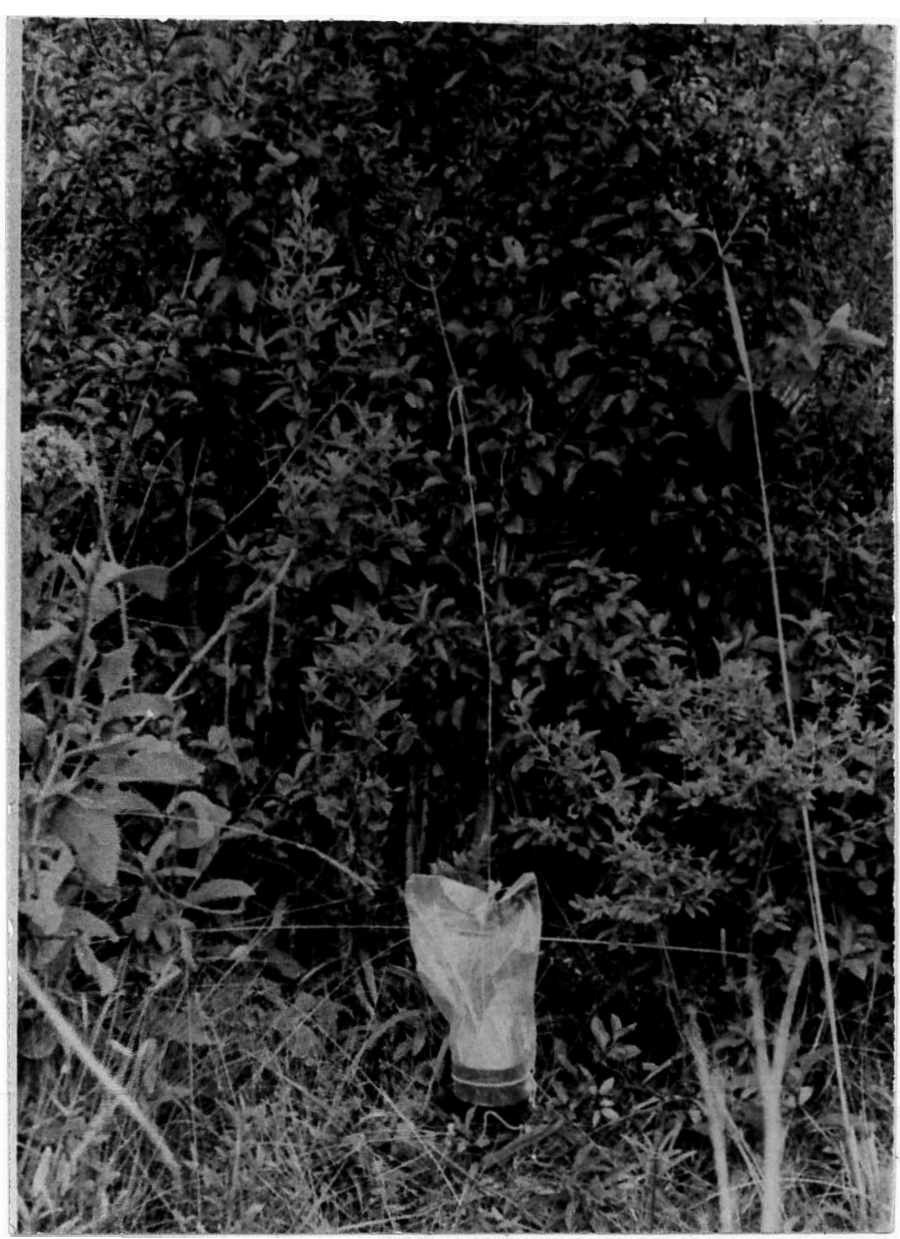

FIG. 1 - Armadilha para dípteros, instalada no campo.

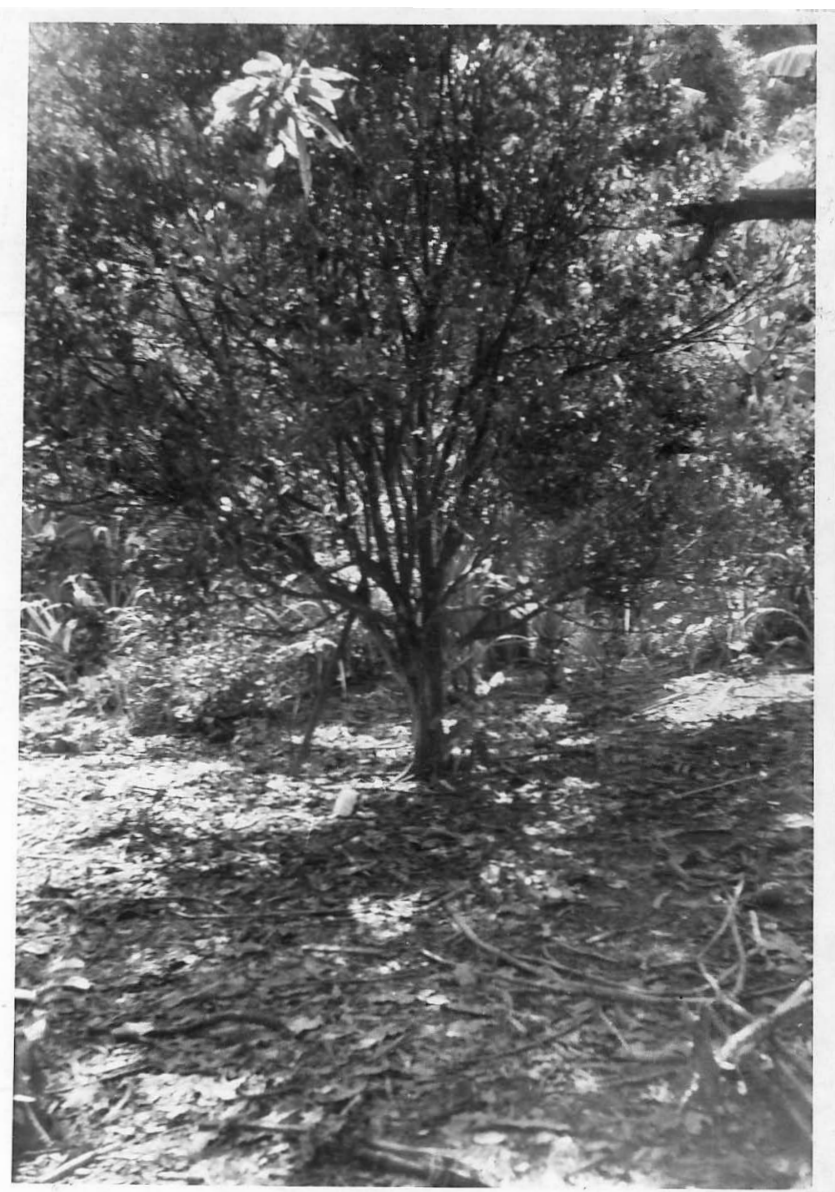

FIG. 2 - Aspecto geral do local de coleta - (I) Zona urbana. 
18.

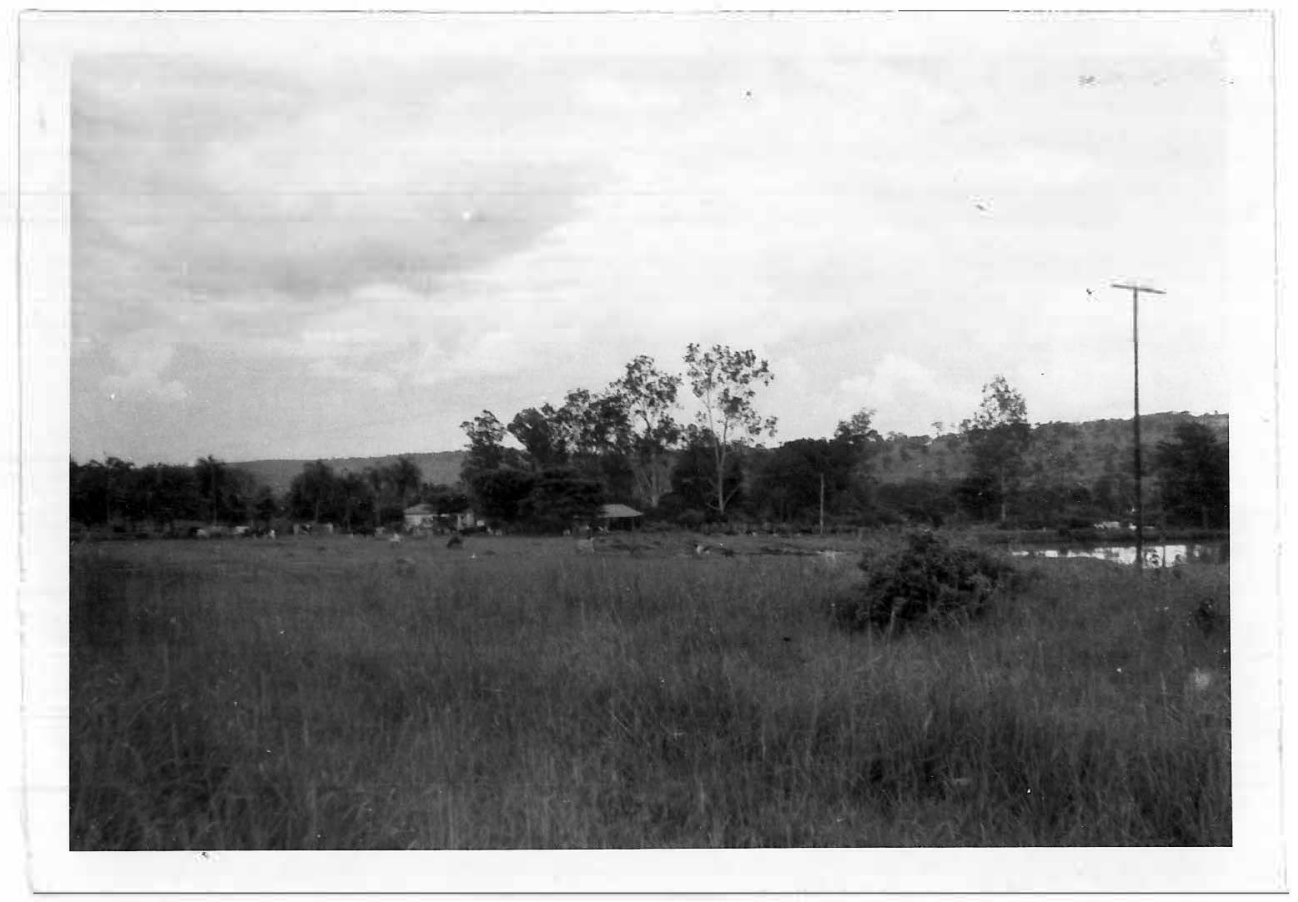

FIG. 3 - Aspecto geral do local de coleta - (II) Zona rural.

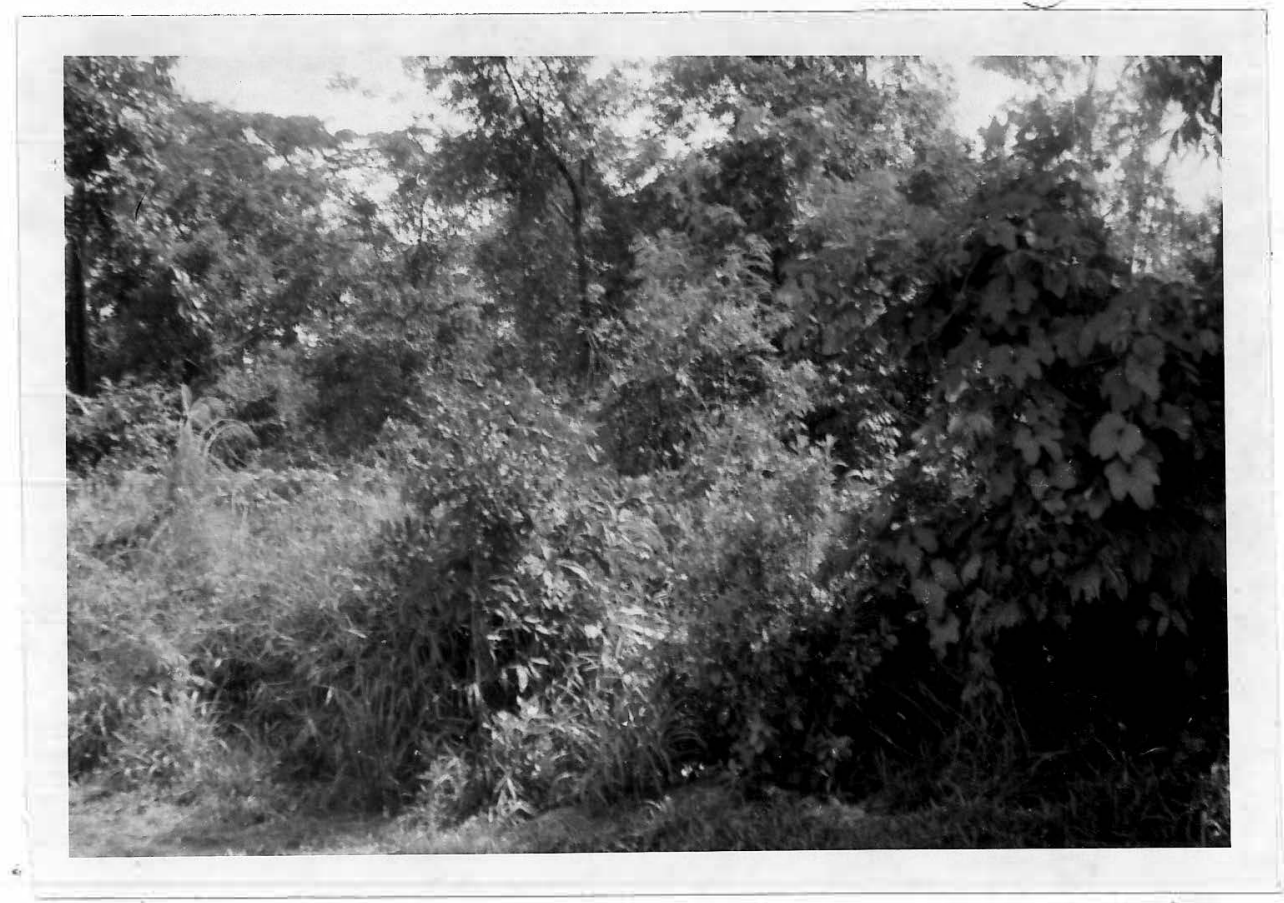

FIG. 4 - Aspecto geral do local de colta - (III) Zona de mata. 
4. RESULTADOS

Tendo em vista que o presente trabalho foi desenvolvido em dois períodos, todos os itens dos resultados serão, conseqüentemente, apresentados separadamente, evidenciando-se as duas etapas. A primeira, compreen dendo o período de agosto de 1975 a julho de 1976, e a segunda, o período de julho e dezembro de 1978 e janeiro e fevereiro de 1979.

\subsection{ESPECIES COLETADAS}

Nas áreas estudadas foram coletadas sete espécies de dípteros muscóideos da família Calliphoridae, que são atraídos por material em decomposição (peixe, vísceras de aves e fezes humanas). Na primeira etapa foram coletados 24.474 exemplares, no período de 12 meses, e na segunda $\underline{\text { e }}$ tapa, 17.620, no período de quatro meses. 


\section{Família Calliphoridae}

Subfamília

Chrysomyinae

Tribo *

Chrysomyini

1. Cochliomyia macellaria (Fabricius, 1775)

* 2. Chrysomya chloropyga (Wiedemann, 1818)

3. Hemilucilia segmentaria (Fabricius, 1775)

4. Hemilucilia flavifacies (Engel, 1931)

** 5. Myiolucilia fulvinota (Walker, 1849)

\section{Calliphorinae}

Luciliini

6. Phaenicia eximia (Wiedemann, 1819)

7. Phaenicia sericata (Meigen, 1826)

A espécie Chrysomya chloropyga, indicada por um asterisco (*), ocorreu apenas na segunda etapa da pesquisa, pois se trata de uma espécie recentemente introduzida no Brasil. A espécie Myiolucilia fulvinota, indicada por dois asteriscos $(* *)$, ocorreu apenas na primeira etapa.

4.2. OCORRENCIA DA ESPECIE Chrysomya chloropyga NO BRASIL, ATE SETEMBRO DE 1979. (Baseado em GUIMARĀEs et alii, 1979)

Bahia, Cruz das Almas, VIII. 1978. A.S. Nascimento, col., atraído por arma dilha de mosca de frutas. 
Maranhão, Imperatriz (584 km ao Sul de Belém), A.G. Bandeira, col., em feí ras-livres visitando peixe e carne.

Mato Grosso do Norte, Cuiabá, X.1978. Air José Martins col., em lixo, carne e peixe em decomposição.

Mato Grosso do Sul, Ponta-Porã, III.1979. W.S. Dias, col. - SUCEN.

Mato Grosso do Sul, Itiquira, VII. 1979. W.S. Dias, col. - SUCEN.

Mato Grosso do Sul, Várzea Grande, VIII. 1979. W.S. Dias, col., em depós $\underline{i}$ tos de lixo.

Minas Gerais, Lavras, IX. 1978. Silvio Gilberto Bertoloti, col., com ví dro caça-mosca.

Pará, Belém, I. 1979. A.G. Bandeira, col., em ārea urbana.

Paraná, União da Vitória, II. 1979, Geraldo M. Buralli, col.

Paraná, Curitiba, XII. 1975, Arlete Imbiriba, col.

Santa Catarina, Tubarão, II. 1979, Geraldo M. Buralli, col., em lixo de restaurante em ārea urbana.

São Paulo, Campinas, XII. 1976, Ivan Sazima, col.

Rio Grande do Sul, Porto Alegre, II. 1979, Geraldo M. Buralli, col., em de pósitos de lixo.

Rio Grande do Sul, Santa Maria, XII. 1978, H. Souza Lopes, col., armadiTha de moscas (isca: melaço e isca de banana), ocorrendo em área metropolitana.

Locais onde ainda não ocorre C. chloropyga (até set. 1979).

Nos locais, abaixo relacionados, foram realizadas coletas de mos ca, mas não foi encontrada $C$. chloropyga.

Amazonas, Manaus, 28.IV.1979, Lúcia M. Feitosa, col., CEASA. 
Bahia, Joazeiro, I.1979, Arício X. Pinheiro, col., em mercado e lixo na á rea urbana.

Cearā, Fortaleza, 1.1979, Arício X. Pinheiro, em mercado e sobre peixe morto na praia.

Pernambuco, Recife e Olinda, I e II.1979, Maria Judy de Mello Ferreira, col., em mercado de peixe, feiras-livres, lixo da zona urbana.

Piauí, Picos, Osmar Pires, col., em iscas de fezes.

\section{PRIMEIRA ETAPA}

4.3. FREQUENCIA SAZONAL

A distribuição geral de califorídeos encontra-se na Fig. 5 onde se pode observar que a maior ocorrência de indivíduos se deu no mês de jạ neiro (4.589 exemplares), e a menor no mês de março (apenas 372 indiví duos). Os picos populacionais ocorreram em setembro, janeiro e maio, e as quedas de população, em dezembro, fevereiro, março, julho e agosto.

Os dados numéricos gerais dos califorídeos coletados nas três á reas estão representados nos Apêndices V, VI e VII, constatando-se que a mai-or ocorrência de indivíduos se deu na zona urbana, e a menor na zona de mata.

4.4. INDICE DE SINANTROPIA

o Indice de sinantropia, calculado para as seis espécies, está representado na Fig. 6. Observa-se aí dois grupos distintos: o primeiro, 
constituído das espécies C. macellaria, $P$. eximia e $P$. sericata, que apre sentam preferência por āreas habitadas pelo homem, com indice de sinantro pia variando de +27.5 ( $P$. sericata) a +47.9 (C. macellaria); o segundo, constituído de $H$. segmentaria, $H$. flavifacies e $M$. fulvinota, espécies as sinatrōpicas, completamente ausentes em äreas habitadas. O Indice neste grupo variou de -83.4 (H. segmentaria) a -93.8 (H. flavifacies).

4.5. ISCAS

Verificou-se uma variação na atratividade exercida pelas iscas. De um modo geral, fígado de ave foi consideravelmente mais atrativo para este grupo de moscas, enquanto que peixe, o menos atrativo (Fig. 7).

A atratividade exercida para cada espécie e em cada área de coleta é considerada especificamente.

A preferência por isca para cada espécie, e a percentagem de es pécimes em substrato de fezes estão indicadas na Tabela 2, e de acordocom os dados desta Tabela 2 e da Fig. 6 foi construído um gráfico, mostrando a correlação entre a preferência por fezes e o índice.de sinantropia para cada espécie. 
TABELA 2 - Comparação da abundância de califorídeos coletados em peixe cru, fígado de ave e fezes humanas, em Goiânia, no período de agosto de 1975 a julho de 1976.

\begin{tabular}{|c|c|c|c|c|c|}
\hline \multirow{2}{*}{ Espécies } & \multicolumn{3}{|c|}{ ISCAS } & & \multirow{2}{*}{$\begin{array}{l}\text { \% de } \\
\text { espécimes } \\
\text { em fezes } \\
\text { humanas }\end{array}$} \\
\hline & $\begin{array}{c}\text { Peixe } \\
\text { cru }\end{array}$ & $\begin{array}{l}\text { Fígado } \\
\text { de ave }\end{array}$ & $\begin{array}{c}\text { Fezes } \\
\text { humanas }\end{array}$ & Total & \\
\hline P. eximia & 380 & 2890 & 768 & 4038 & 19,0 \\
\hline P. sericata & 0 & 48 & 21 & 69 & 30,4 \\
\hline C. macellaria & 1519 & 14793 & 2566 & 18878 & 13,6 \\
\hline H. segmentaria & 10 & 276 & 237 & 523 & 45,3 \\
\hline H. flavifacies & 13 & 81 & 102 & 196 & 52,0 \\
\hline M. fulvinota & 173 & 255 & 342 & 770 & 44,4 \\
\hline TOTAL & 2095 & 18343 & 4036 & 24.474 & \\
\hline
\end{tabular}

Pelo exame à Fig. 8, percebe-se a existência de dois tipos de comportamento: as espécies com I.S. superior a +20.0 mostraram menor preferência por substrato de fezes, enquanto que as espécies com índices superiores a -80.0 parecem ter menor preferência por este tipo de substrato, indicando assim, haver uma correlação negativa entre I.S. e a prefe rência por material fecal.

\subsection{ANĀLISE ESTATISTICA}

Nos Apêndices V.III, IX e X encontram-se os valores numéricos pạ ra as fêmeas constatadas nas três äreas durante todo o ano.

Os valores do "Teste F" e o coeficiente de variação estão na Ta bela 3. As médias das espécies encontram-se na Tabela 4, as médias das is cas, na Tabela 5 e as médias da interação das iscas, dentro das espécies, na Tabela 6 . 
Através destes dados observa-se que houve diferença significativa para todos os itens considerados, menos para a ocorrência das espécies $H$. segmentaria, H. flavifacies e M. fulvinota. A espécie $P$. sericata não foi considerada para efeito estatístico devido ao pequeno número de indivíduos encontrados.

A espécie C. macellaria difere significativamente das demais es pécies nas zonas urbana e rural, enquanto na zona de mata não difere de P. eximia (Tabela 4).

Com relação às iscas, fígado difere de peixe e fezes em todas as äreas (Tabela 5). 


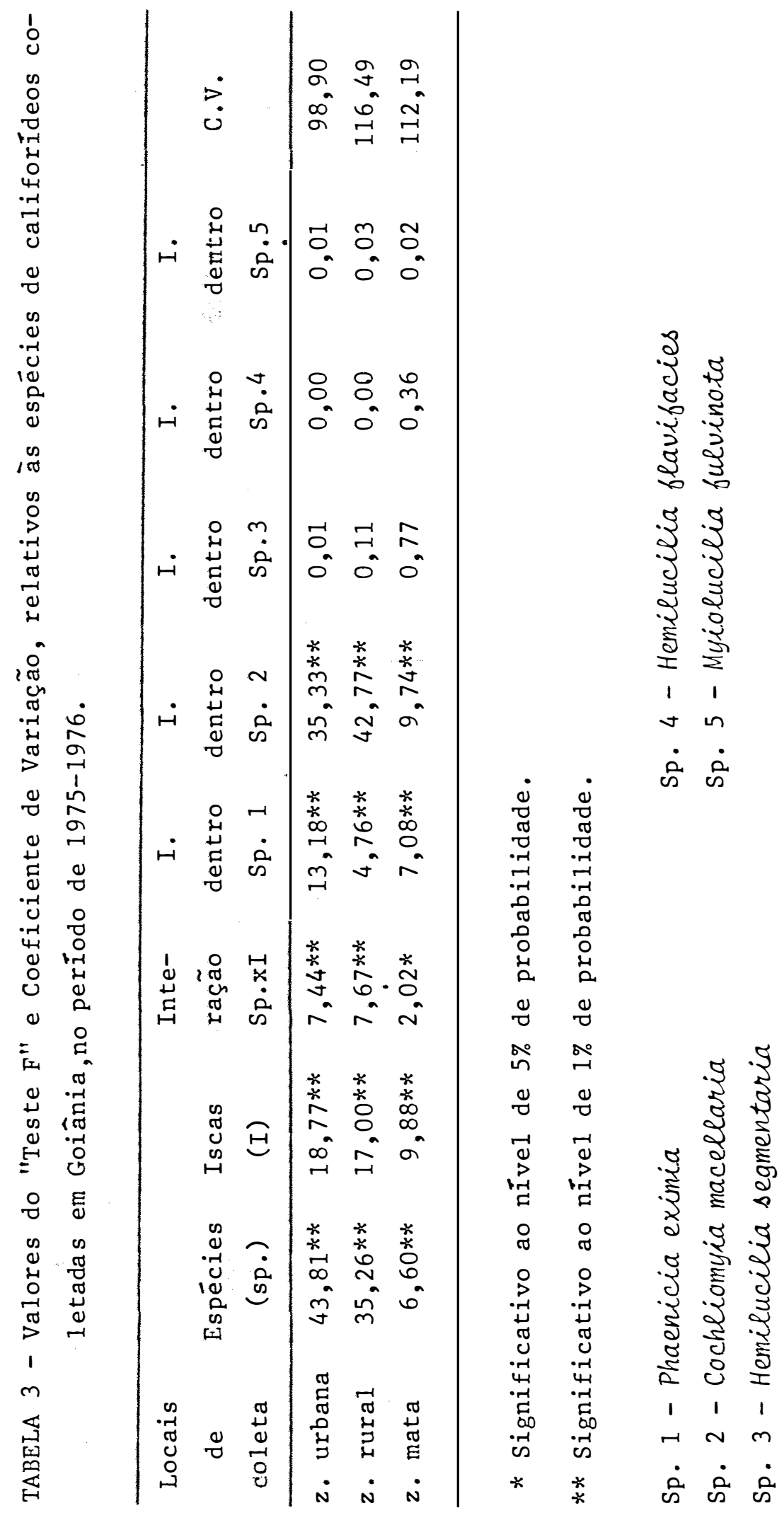


TABELA 4 - Valores do Teste de Tukey, referentes às espécies de califorídeos coletadas em-Goiânia, no período de 1975-1976.

Locais

Espécies

Sp. $1 \quad$ Sp. $2 \quad$ Sp. $3 \quad$ Sp. $4 \quad$ Sp. 5

$\begin{array}{lllllll}\text { z. urbana } & 5,83 \mathrm{~b} & 8,69 a & 0,80 c & 0,70 c & 0,86 c & 2,18 \\ \text { z. rural } & 4,06 \ldots b & 9,16 a & 0,91 c & 0,74 c & 0,89 c & 2,40 \\ \text { z. mata } & 3,71 a b & 4,98 a & 1,84 b & 1,73 b & 2,30 b & 2,13\end{array}$

$\Delta=$ Diferença mínima significativa obtida pelo Teste de Tukey ao nível de $5 \%$ de probabilidade.

As médias com as mesmas letras não diferem estatisticamente entre si.

TABELA 5 - Valores do Teste de Tukey para as eficiências de iscas utiliza das na coleta dos califorídeos em Goiânia, no período de 19751976.

\begin{tabular}{lcccc}
\hline \multirow{2}{*}{ Locais } & \multicolumn{3}{c}{ Iscas } \\
\cline { 2 - 4 } & $\begin{array}{c}\text { Peixe } \\
\text { cru }\end{array}$ & $\begin{array}{c}\text { Fígado } \\
\text { de ave }\end{array}$ & $\begin{array}{c}\text { Fezes } \\
\text { humanas }\end{array}$ & $\Delta$ \\
\hline z. urbana & $2,12 \mathrm{~b}$ & $5,53 \mathrm{a}$ & $2,49 \mathrm{~b}$ & 1,45 \\
z. rural & $1,98 \mathrm{~b}$ & $5,41 \mathrm{a}$ & $2,07 \mathrm{~b}$ & 1,59 \\
z. mata & $1,62 \mathrm{~b}$ & $4,27 \mathrm{a}$ & $2,84 \mathrm{~b}$ & 1,42 \\
\hline
\end{tabular}

$\Delta=$ Diferença mínima significativa obtida pelo Teste de Tukey ao nível de $5 \%$ de probabilidade.

As médias com a mesma letra não diferem entre si. 


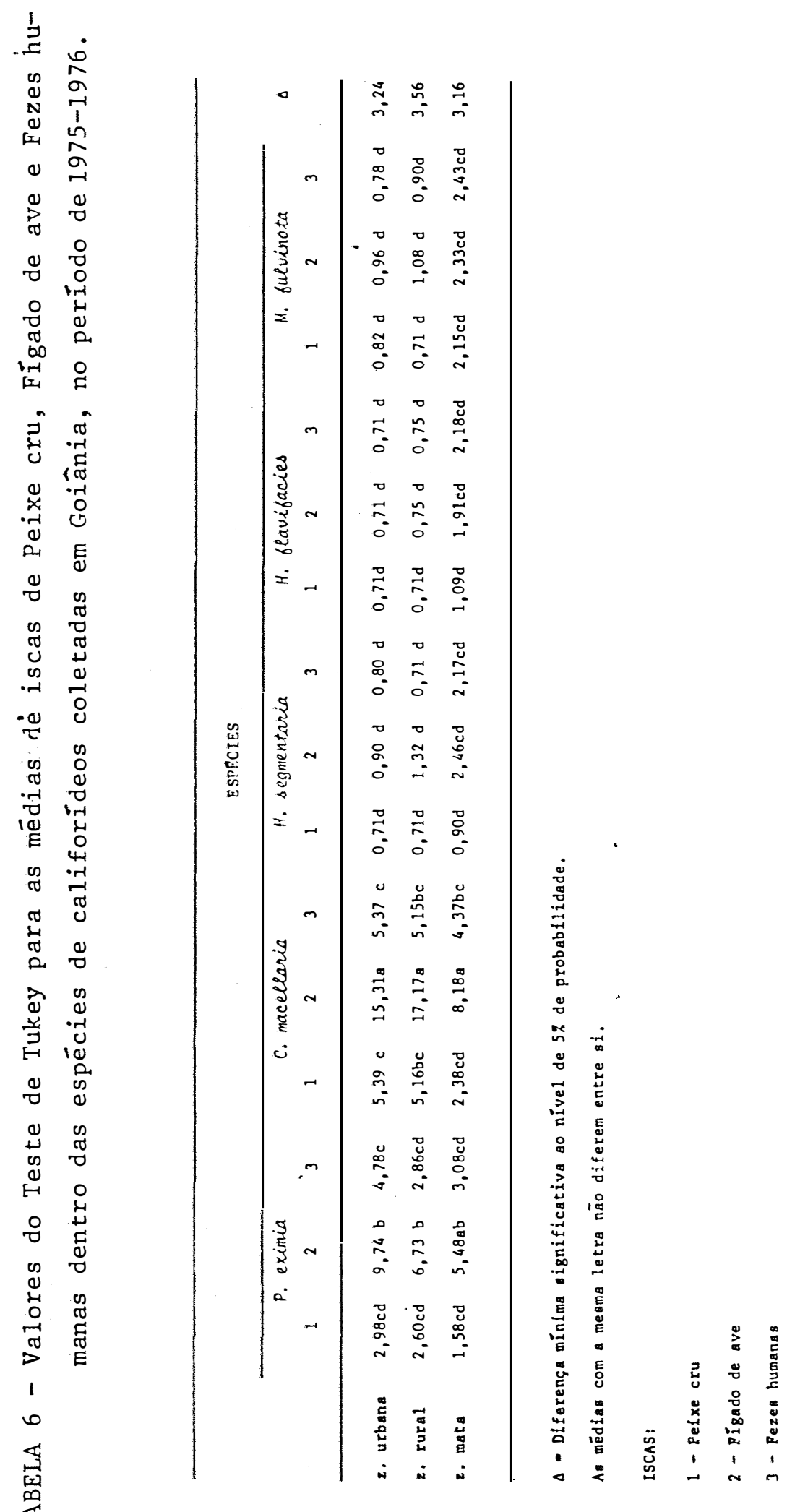




\subsection{DISTRIBUIÇÃO E COMPORTAMENTO DAS ESPECIES ESTUDADAS}

A frequência de ocorrência dos califorídeos, está representada na Fig. 9.

A distribuição geográfica dos califorídeos é citada de acordo com JAMES (1970).

Phaenicia eximia (Wied.) - Distribuição geogrä́ica: América Tro pical, ocorrendo desde o Sudeste dos Estados Unidos (Texas) até a Argenti na, Chile e Antilhas. De acordo com MELLO (1961), no Brasil, sua ocorrência foi registrada no Pará, Bahia, Guanabara, Rio de Janeiro, São Paulo, Rio Grande do Sul, Minas Gerais, Goiās e Mato Grosso.

Entre 24.474 califorídeos coletados, 4.038 pertencem a esta espécie, representando assim $16,50 \%$ do total, e deste modo, a segunda espécie em freqüência (Fig. 9).

A variação anual de $P$. eximia consta na Fig. 10 , onde se verifí ca maior ocorrência no mês de janeiro.

Houve também uma diversidade da freqüência nas três äreas de co leta (Fig. 16). Na zona urbana foi mais freqüente, enquanto na zona de ma ta representou apenas $21,86 \%$ (Apêndice XI). O indice de sinantropia igual $a+42.9$ mostra que esta espécie apresenta preferência por āreas habitadas pelo homem. (Fig. 6).

A frequêencia do sexo da espécie nas três áreas de coleta é apre sentada na Fig. 19 e Apêndice XIII.

Com referência a iscas atrativas, a de fígado foi mais eficiente para $P$. eximia que a de peixe (Apêndice XII, Fig. 17), com 71,57\%. Na Fig. 18 observa-se a preferências pelas iscas, separadamente, para cada á rea de coleta, sendo que em todas, as de fígado mostraram-se mais eficien- 
tes.

Phaenicia sericata (Meig.) - Distribuição geogräfica: Cosmopolita. Na Europa, o limite Norte de distribuição, citado por NUORTEVA (1963), è o Sul da Finlândia. Na América elà ocorre desde o Canadá até a Argentina .

Foi a espécie que ocorreu com menor incidência, representando $\underline{a}$ penas 0,28\% (69 indivíduos) (Fig. 9). Destes 69 indivíduos, 41 restringiram-se à zona urbana $(59,42 \%)$ e apenas 4 ocorreu na zona rural $(5,8 \%)$ (Fi gura 16, Apêndice XI). Seu Índice de sinantropia foi de +27.5 , o que demonstra sua preferência por āreas habitadas (Fig. 6).

Na Fig. 11 observa-se sua distribuição ao longo do período, e na Fig. 16 sua freqüência nas três äreas de coleta, evidenciando sua predomi nância na zona urbana.

$\mathrm{Na}$ Fig. 19 e Apêndice XIII émostrada a freqüência dos sexos, tam bẻm nas três āreas de coleta, nas quais a predominância de fêmeas é evidenciada.

P. sericata foi mais atraída por isca de fígado, $89,57 \%$, não ocorrendo exemplares em isca de peixe (Fig. 17). Através da Fig. 18, evidencia-se que apenas na zona de mata esta espécie foi mais atraídapor fezes. Para esta espécie não foi feita análise estatística devido à pequena incidência de indivíduos.

Cochliomyia macellaria (Fab.) - Distribuição geogräfica: Desde - Sul do Canadā (Quebec), Estados Unidos, até a Argentina (Patagônia), Chi le, Ilhas Galápagos e Antilhas.

Foi a espécie mais comum, ocorrendo durante todo o período de coleta, com um total de 18.878 indivíduos, representando $77,13 \%$ das espé- 
freqüência dos sexos é apresentada na Fig. 19 e no Apêndice XIII.

A isca de fígado foi mais atrativa $(52,77 \%)$, seguida pela de fe zes. A atração exercida por peixe foi insignificante do ponto de vista nu mérico (Fig. 17, Apêndice XII). A Fig. 18 indica o grau de preferência por substrato atrativo nas três áreas de çoleta, não tendo sido constatada di ferença significativa na atratividade entre as iscas (Tabela 5).

Hemilucilia flavifacies (Enge1) - Distribuição geogrāfica: Méxí co ao Equador, Bolívia, Brasil (até o Rio Grande do Sul), Paraguai e Trin dad.

No decorrer de todo o ano (Fig. 13) só ocorreu 196 indivíduos, representando $0,80 \%$.

Pelos dados do Apêndice XI e da Fig. 16 nota-se claramente que esta é uma espécie assinantrópica evitando completamente áreas habitadas. Sua freqüência na mata foi de 95,92\%, não ocorrendo nenhum indivíduo na zo na urbana. Seu Índice de sinantropia foi de -93.8 , sendo esta a espécie menos sinantrōpica entre todas (Fig. 6).

A Fig. 19 representa a freqüência dos sexos nas três áreas de co leta.

Quanto à isca atrativa, mostrou preferência por fezes $(52,04 \%)$, seguida por fígado (Figs. 17 e 18). Não houve diferença significativa para os diversos substratos atrativos.

Myiolucilia fulvinota (Bigot) - Distribuição geogräfica: Neotro pical - vai desde o México ao Brasil e Chile.

Ocorreram 770 indivíduos, correspondendo a.3,15\% (Fig. 9). E uma espécie dominante em zona de mata $(92,99 \%)$, havendo ocorrido em número 
muito reduzido nas zonas urbana e rural (Apêndice XI, Fig. 16). 0 índice de sinantropia foi de -87.53 sendo classificada como uma espécie que se mostra ausente em āreas habitadas pelo homem (Fig. 6).

Na Fig. 15 estā representada a distribuição da espécie durante tọdo o período. A frequêencia dos sexos nas três āreas de coleta é mostrada na Fig. 19.

Isca de fezes exerceu maior atração $(44,41 \%)$, seguida de pela de fígado (Fig. 17). A preferência por substrato atrativo para cada ārea è mostrada na Fig. 18. A anālise estatística não revelou diferença em prefe rência de atratividade nas três áreas de coleta. 


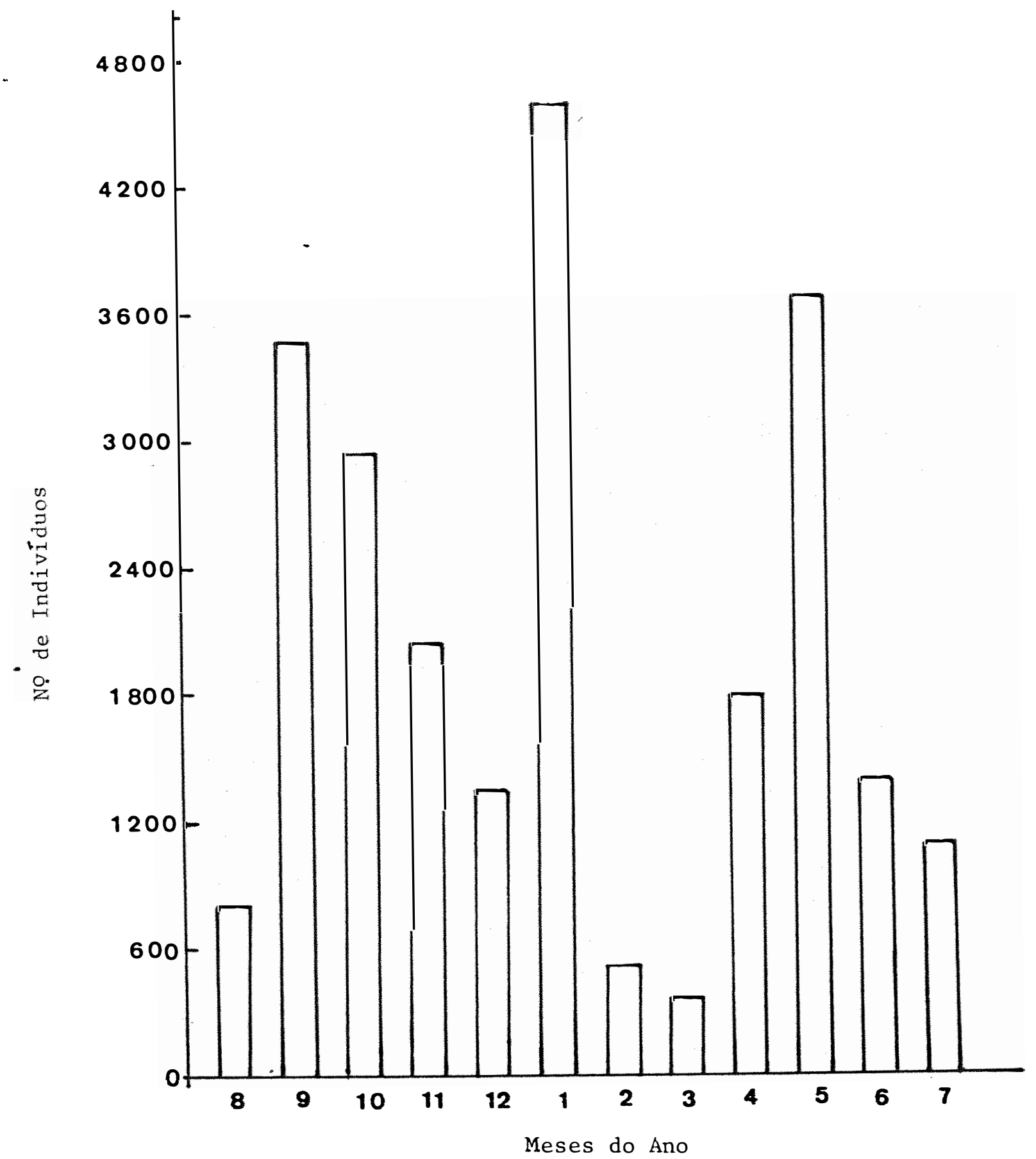

FIG. 5 - Distribuição geral de Calliphoridae no período de agosto de 1975 a julho de 1976 em Goiânia - Goiās. 


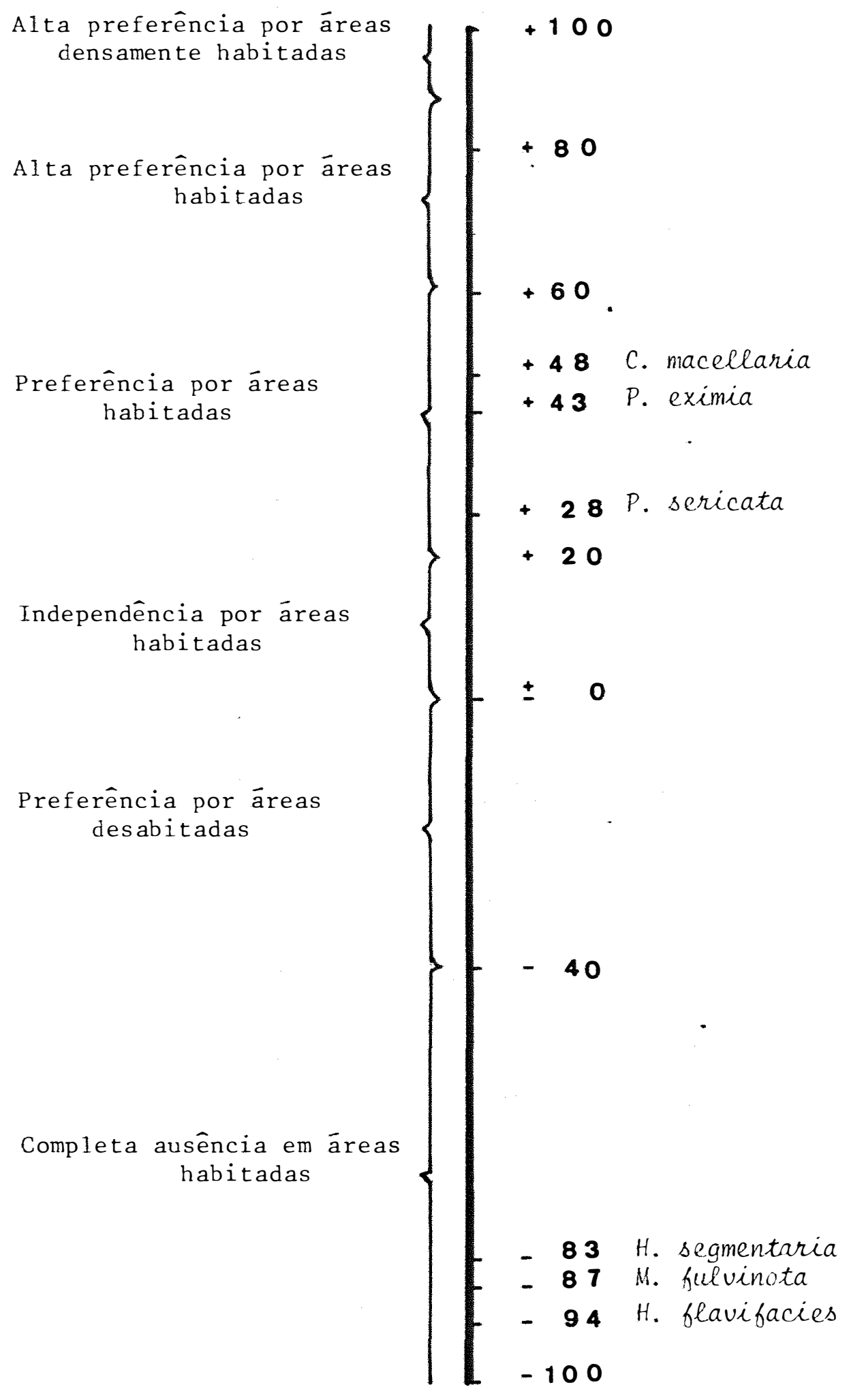

FIG. 6 - Indices de Sinatropia das espécies de Calliphoridae no período de agosto de 1975 a julho de 1976, em Goiânia - Goiás. 


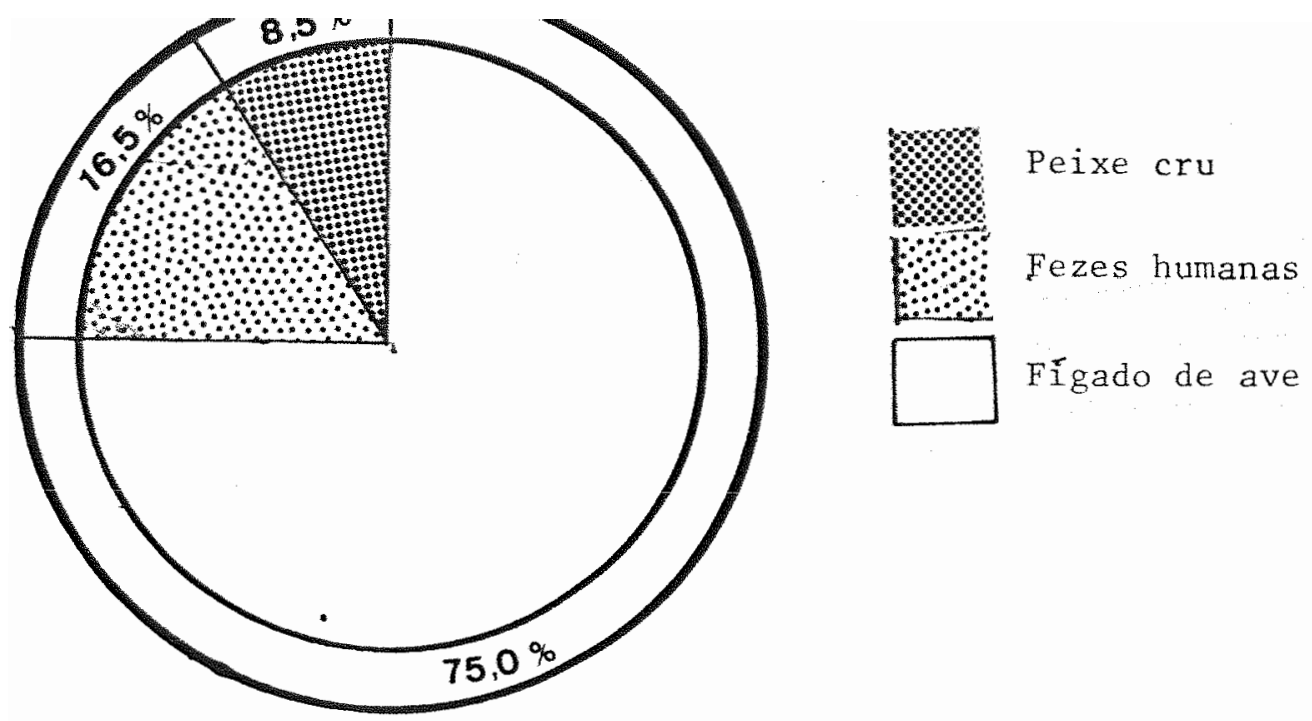

FIG. 7 - Frequência relativa (\%) das espécies de Calliphoridae, em iscas de Peixe, Fígado de ave e Fezes humanas, no período de 1975-1976, em Goiânia - Goiás.

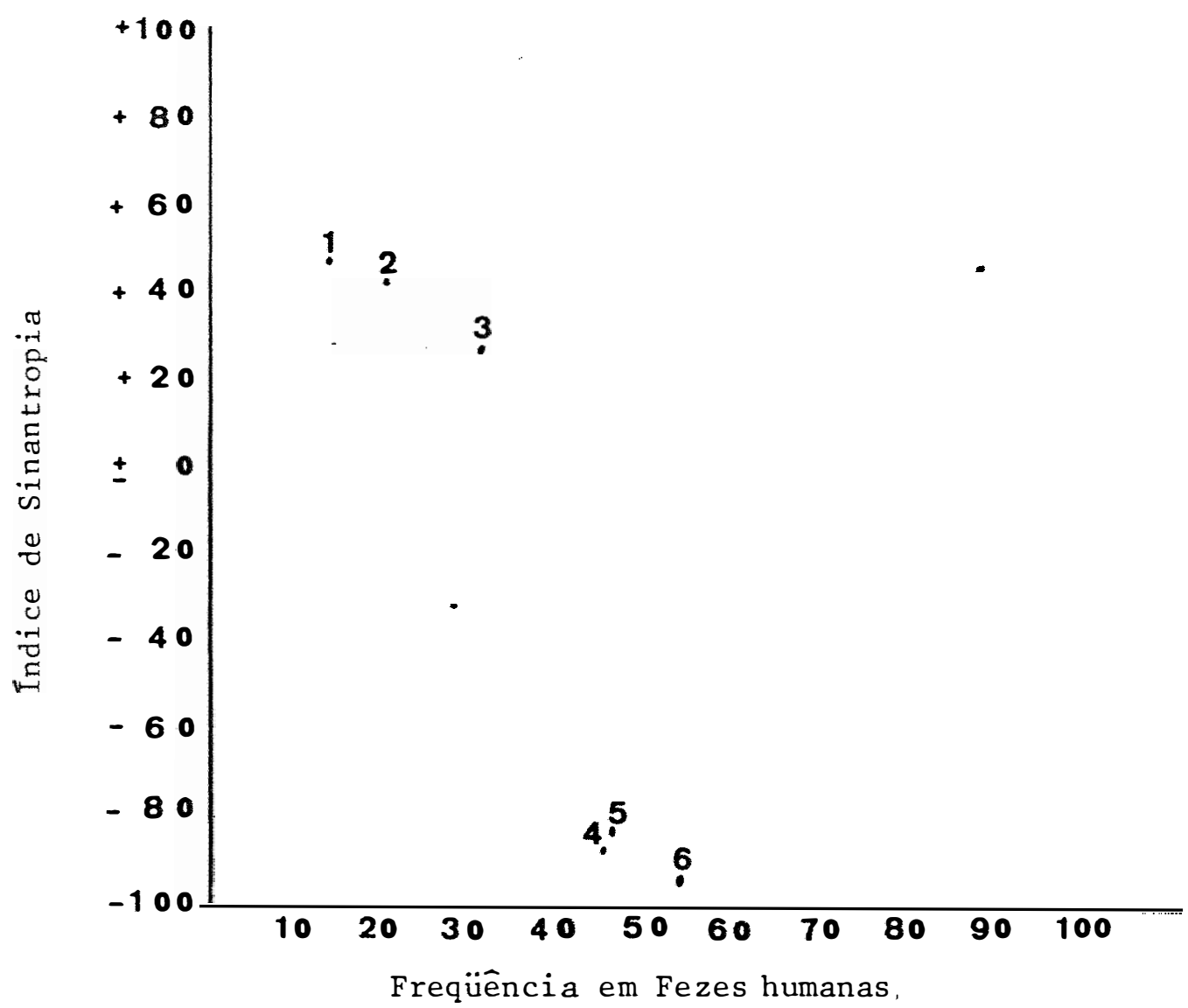

FIG. 8 - Relação entre o Indice de Sinantropia e o Grau de Preferência por Fezes humanas, das espécies de Calliphoridae de Goiânia, no perío do de agosto de 1975 a julho de 1976.

1 - C. macellaria; 2 - P. eximia; 3 - P. sericata;

4 - M. fulvinota; 5 - H. segmentaria; 6 - H. flavifacies 


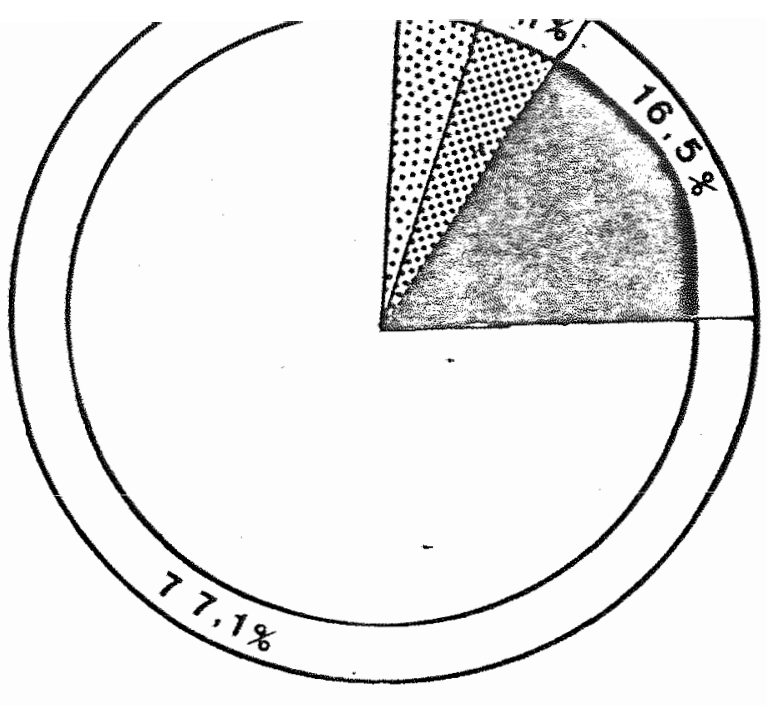

37.

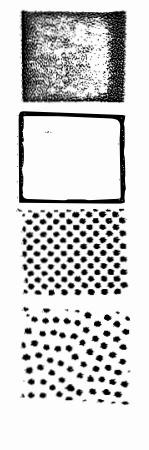

P. eximis

C. macellaria

M. fulvinota

P. sericata

$\therefore$ H. segmentaria

H. flavifacies

FIG. 9 - Frequêencia relativa (\%) das espécies de Calliphoridae, no período de agosto de 1975 a julho de 1976, em Goiânia - Goiās.

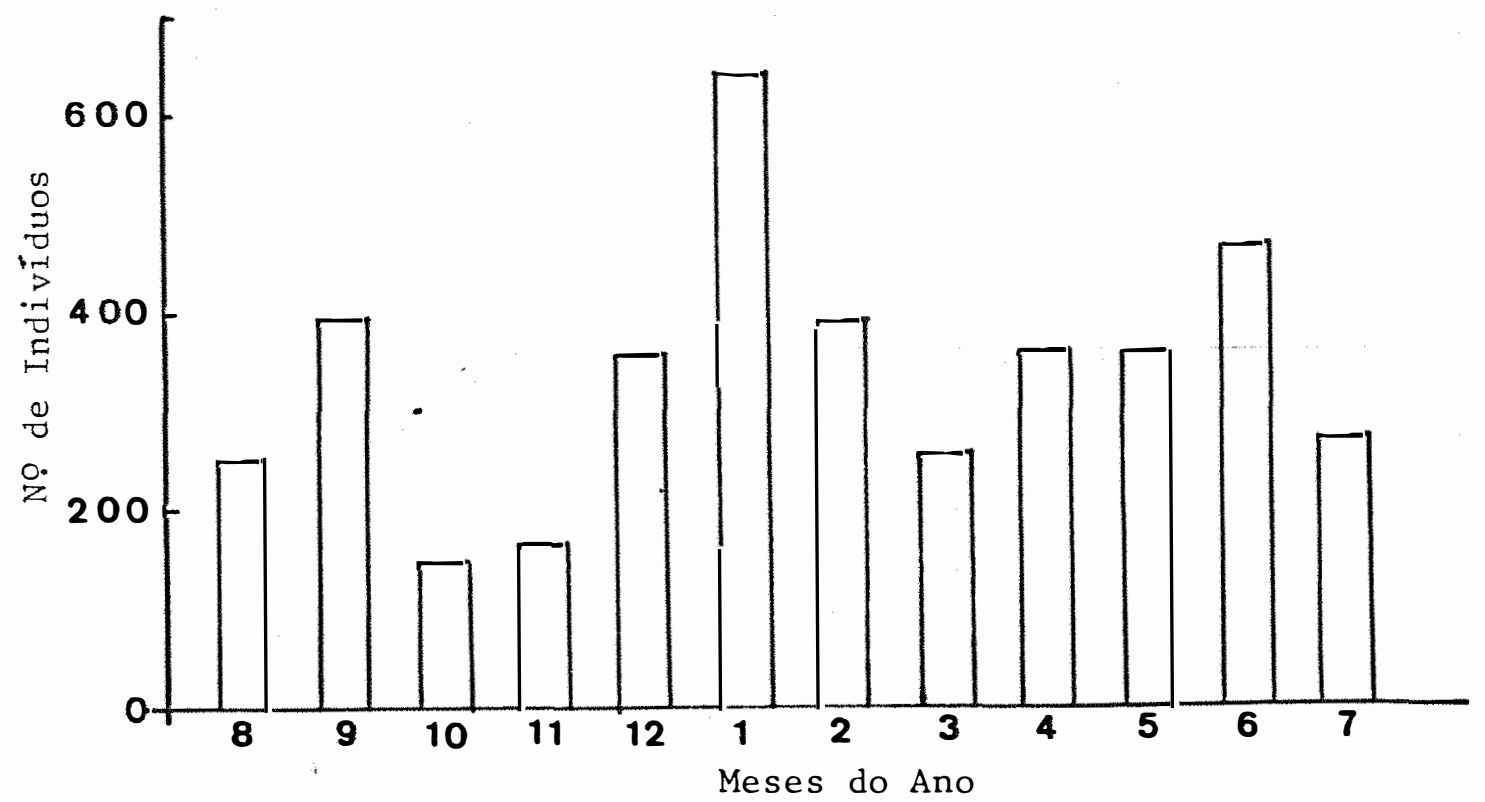

FIG. 10 - Distribuição anual de P. eximia no período de 1975-1976 em Goiâa nia - Goiàs.

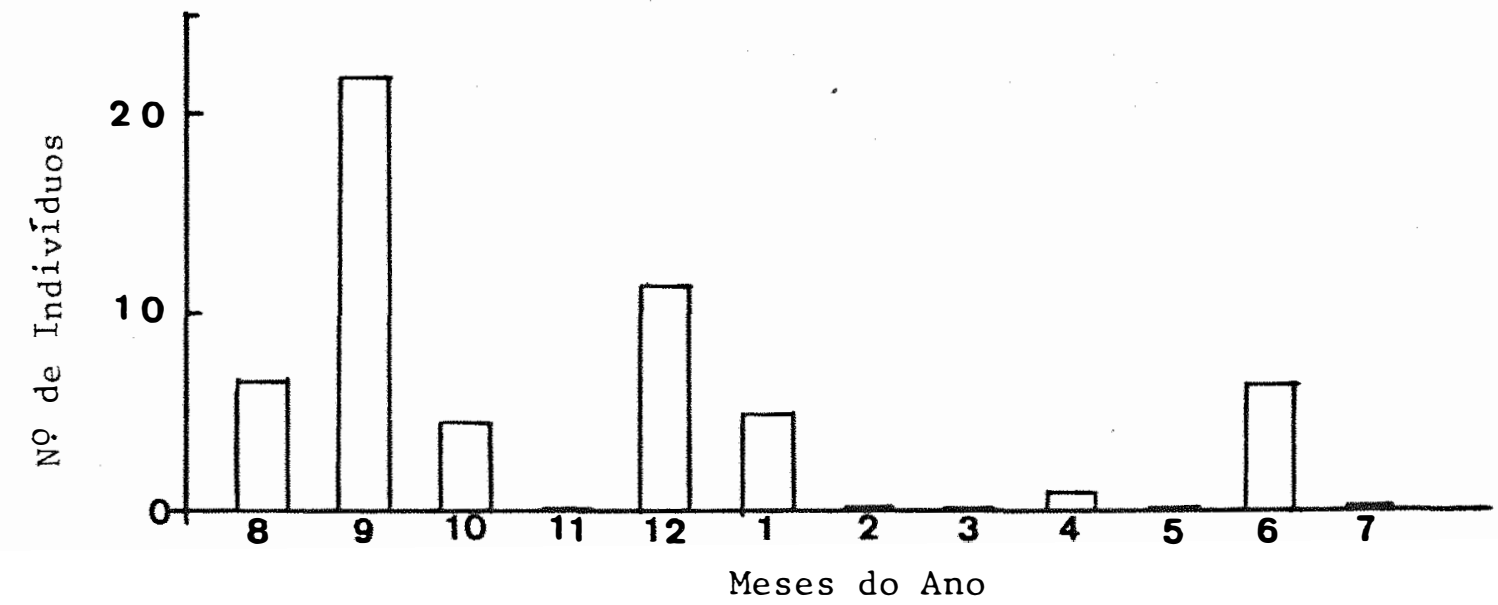

FIG. 11 - Distribuição anual de P. sericata no período de 1975-1976 em Goiânia - Goiās. 


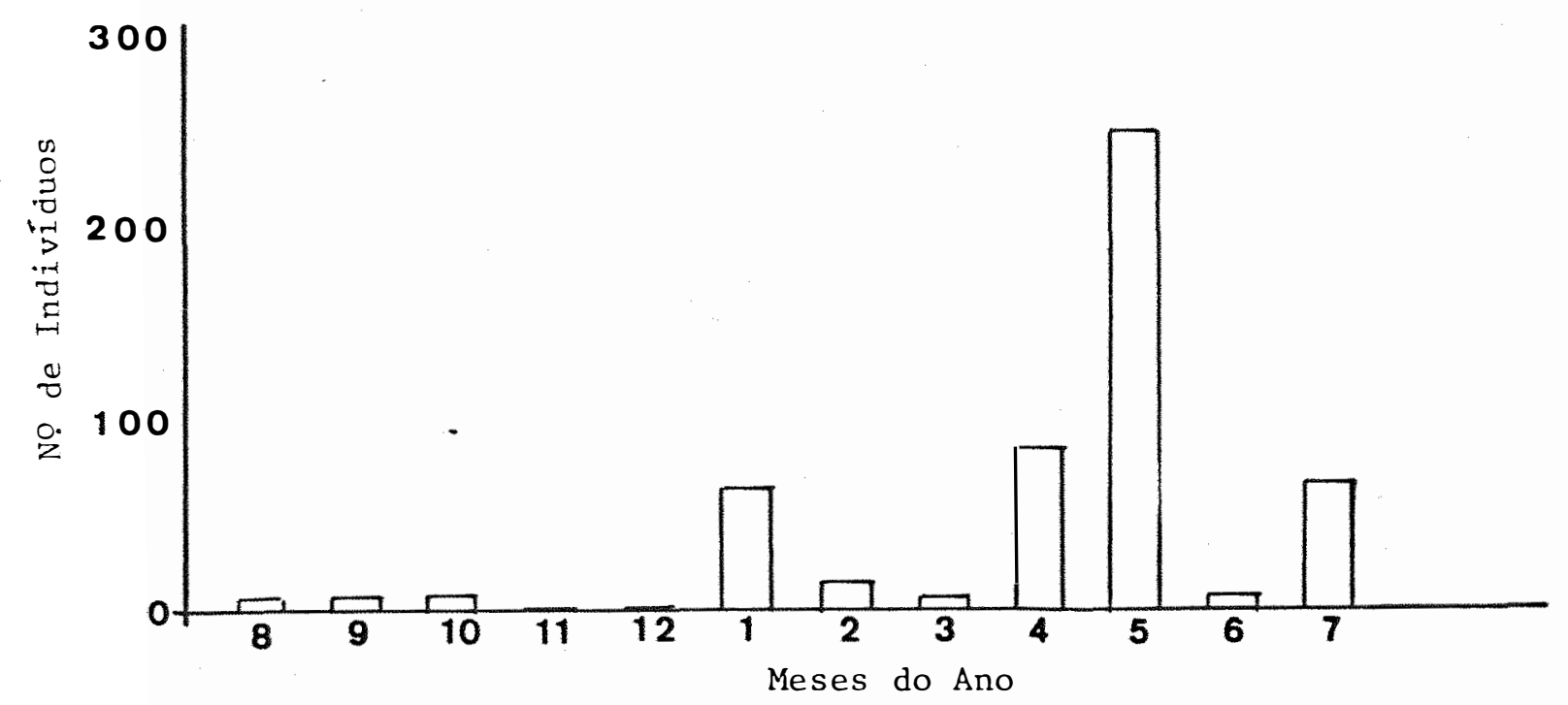

FIG. 12 - Distribuição anual de H. segmentaria no período de 1975-1976 em Goiânia - Goiàs.

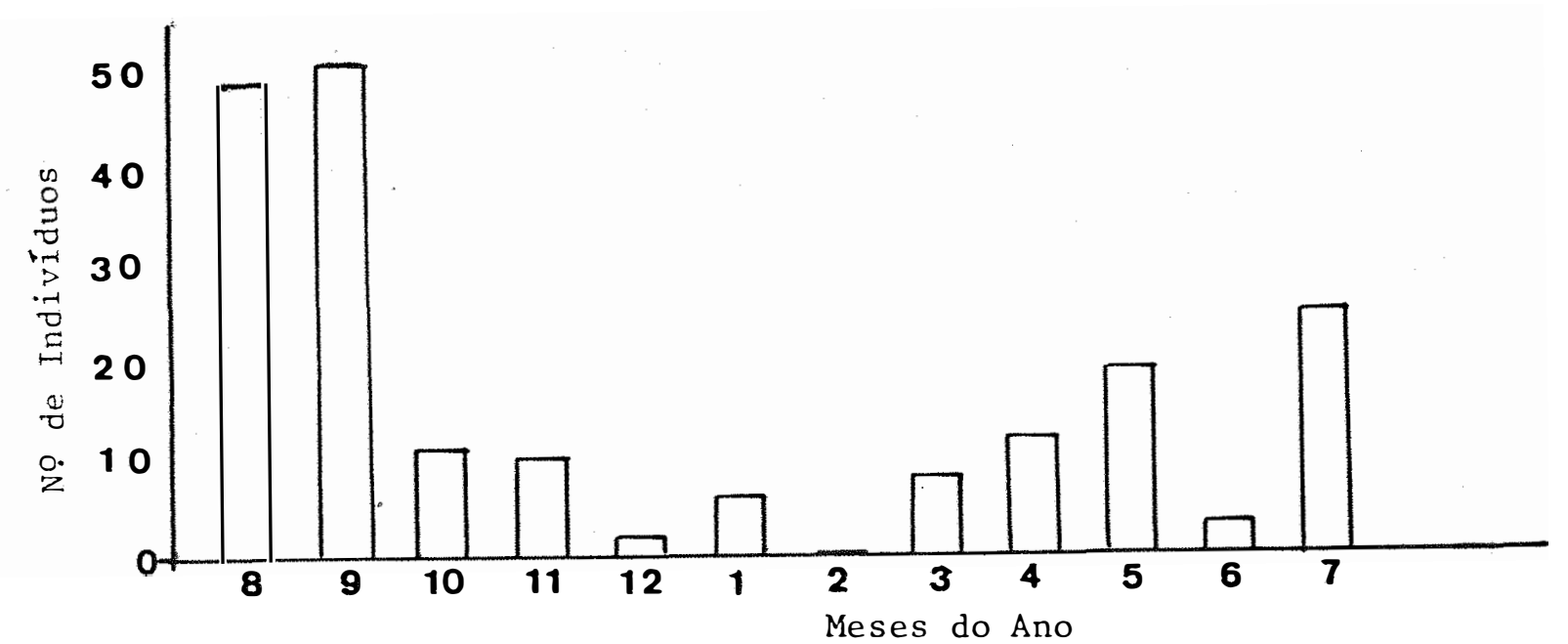

FIG. 13 - Distribuição anual de H. flavifacies no período de 1975-1976 em Goiânia - Goiās. 
39.

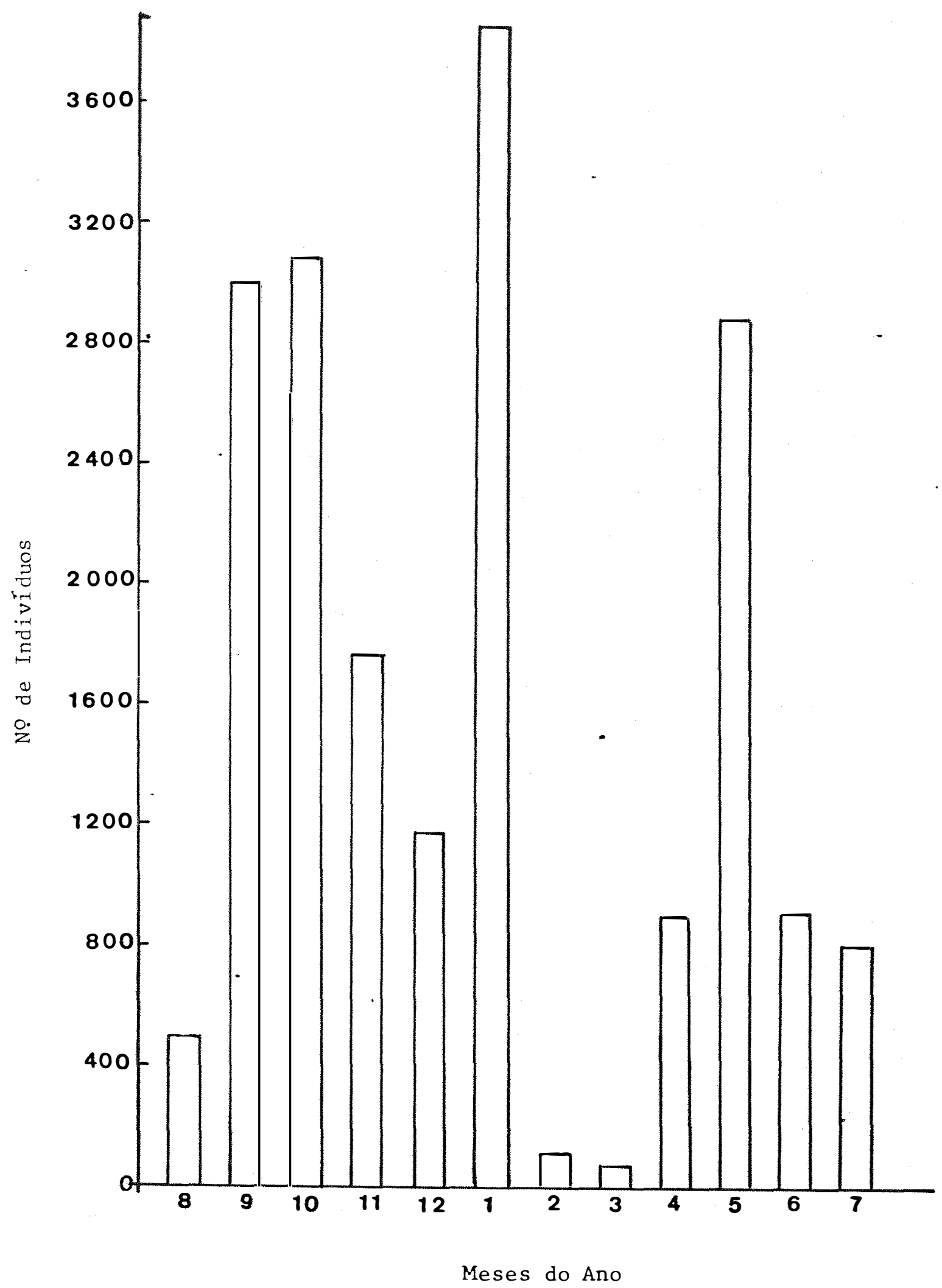

FIG. 14 - Distribuição anual de C. macellaria no período de 1975-1976, em Goiānia - Goiās. 
40.

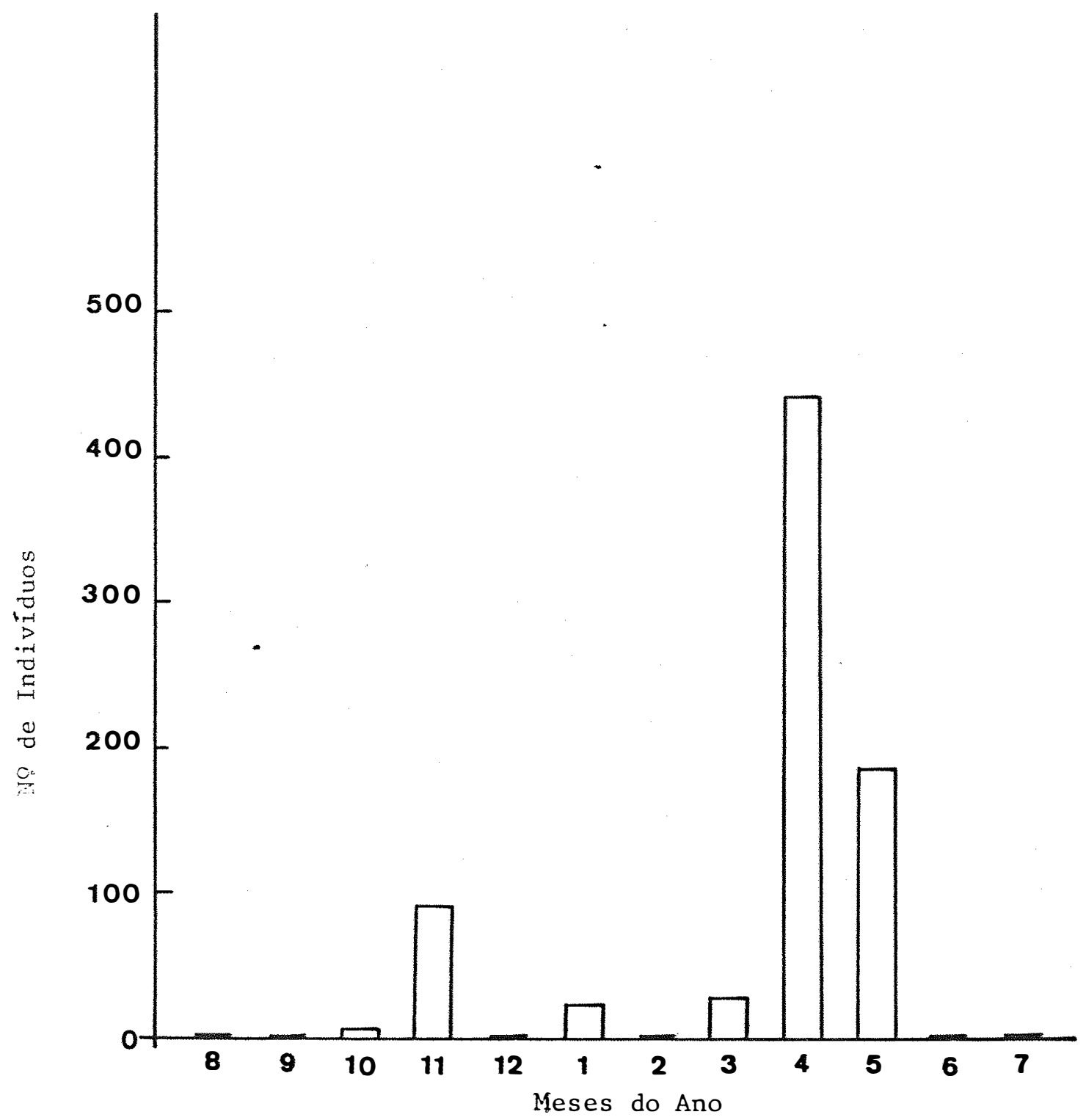

FIG. 15 - Distribuição anual de M. fulvinota no período de 1975-1976, em Goiânia - Goiās. 


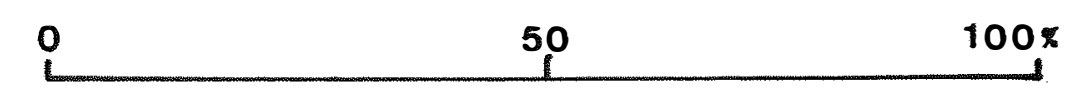

P. eximia

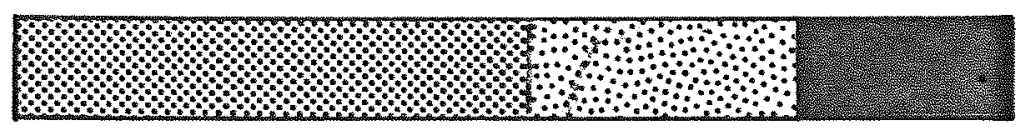

P. sericata

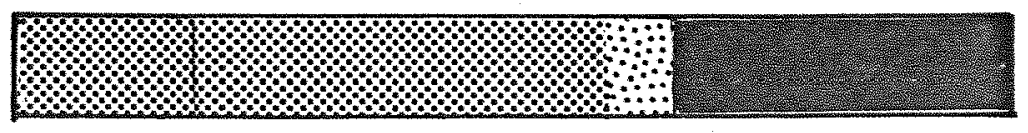

C. macellaria

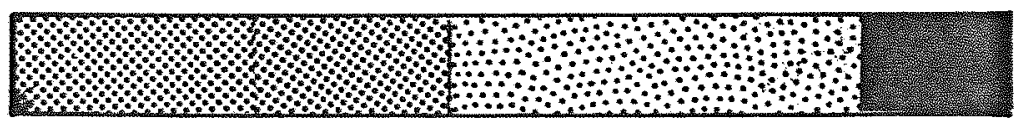

H. segmentaria

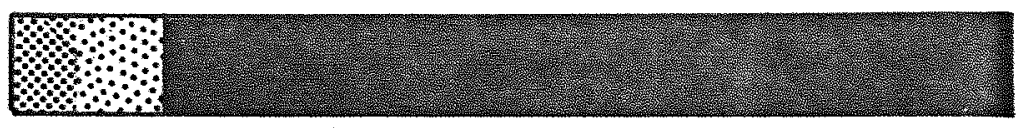

H. flavifacies

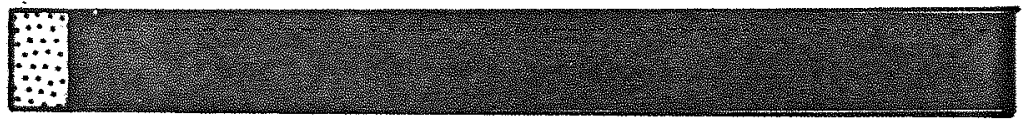

M. fulvinota
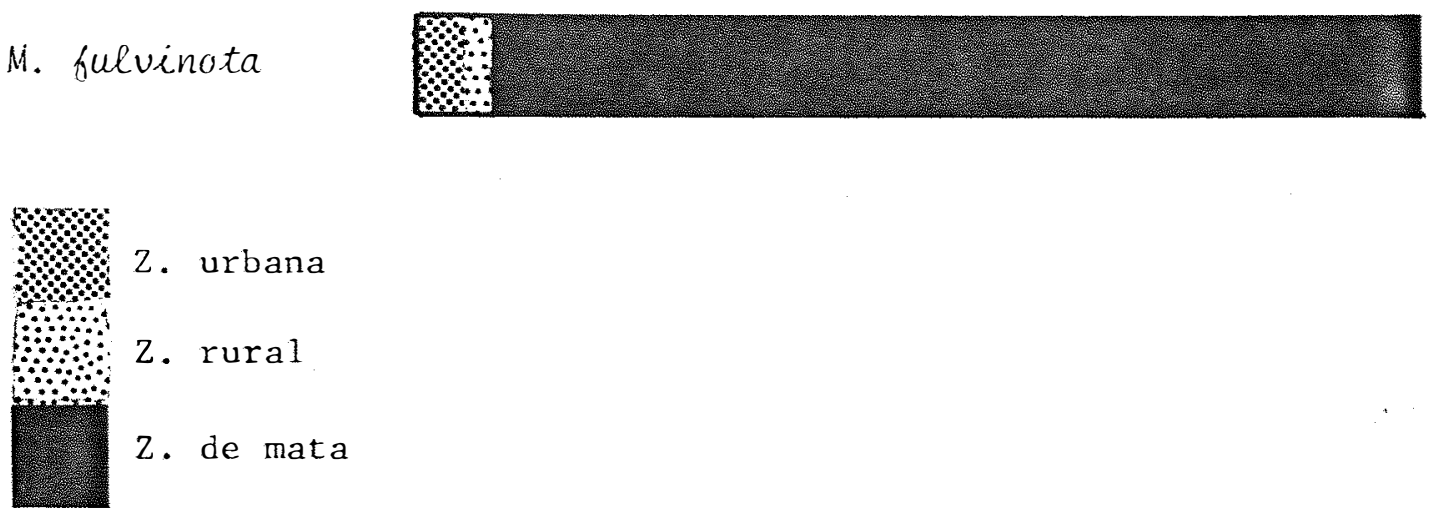

FIG. 16 - Frequência relativa (\%) das espëcies de Calliphoridae, na z. ur bana; z. rural e z. de mata, no perî́odo de agosto de 1975 a julho de 1976 em Goiânia - Goiàs. 
P. eximia

$$
q
$$

P. sericata

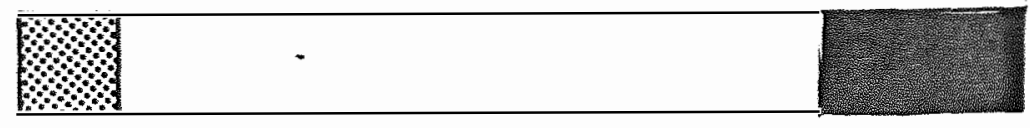

c. macellaria

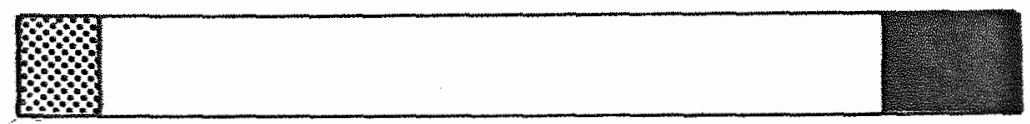

H. segmentaria

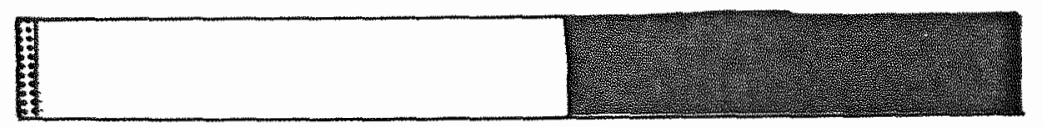

H. flavifacies

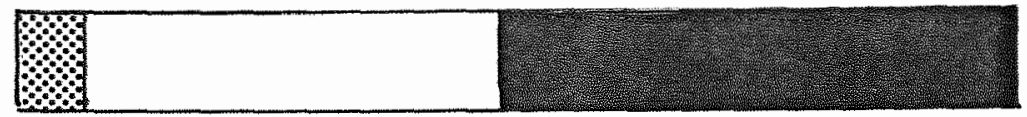

M. fulvinata

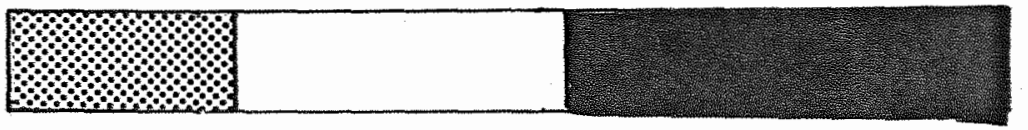

\%

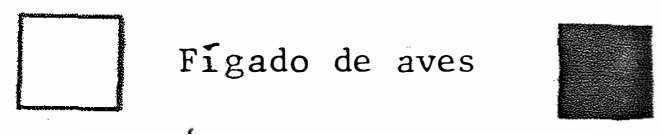

Fezes humanas

FIG. 17 - Freqüência relativa (\%) das espécies de Calliphoridae em iscas de (A) Peixe cru; (B) Fígado de aves e (C) Fezes humanas, no período de agosto de 1975 a julho de 1976 em Goiânia - Goiás. 
P. eximia

$P$. sericata

c. macellaria

H. segmentaria

H. flavifacies

M. fulvinota

P. eximia

P. sericata

C. macellaria

H. segmentaria

H. hlavifacies

M. fulvinota

P. eximia

$P$. sericata

C. macellaria

H. segmentaria

H. Glavifacies

M. fulvinota
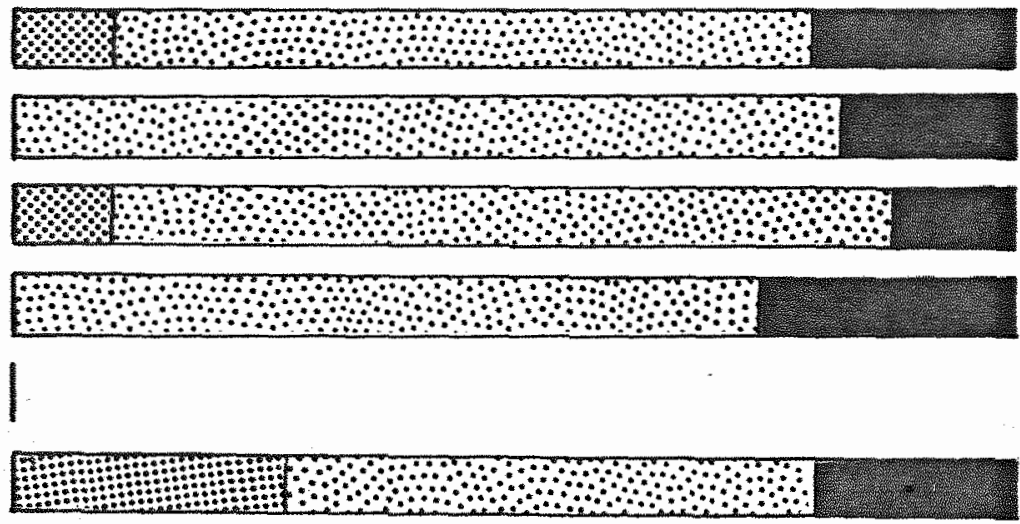

2. urbana
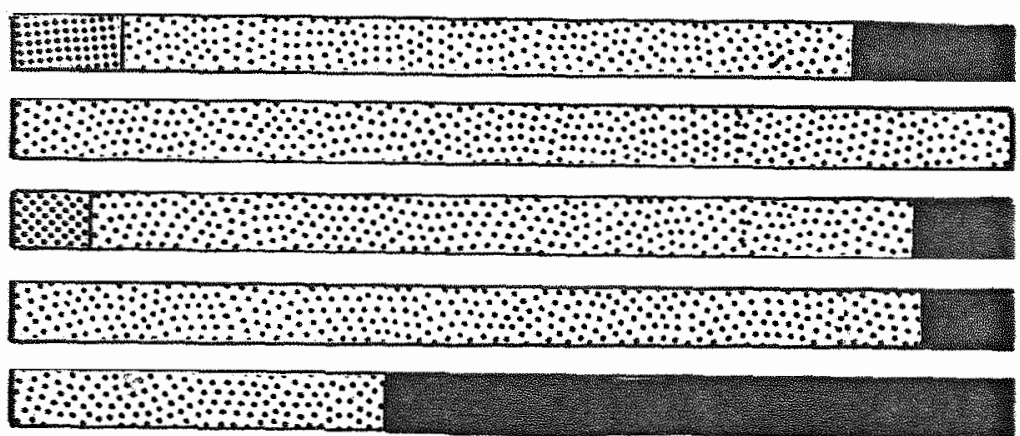

6

2. rural.

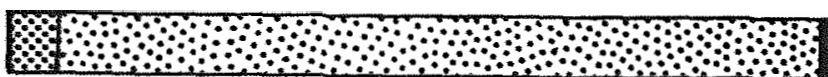

O

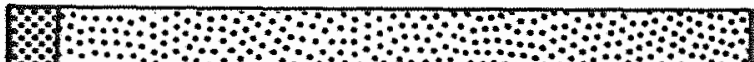

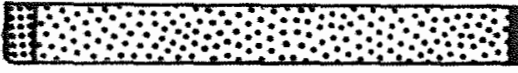

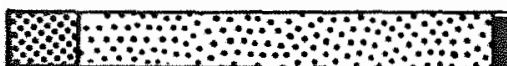

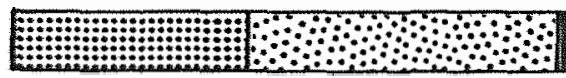

$z$. de mata

6 Peixe cru

$\because: \because$ Fígado de aves

Fezes humanas

FIG. 18 - Frequêencia relativa (\%) das espécies de Calliphoridae, coletados em 1scas de: (A) Peixe cru; (B) Fígado de aves e (C) Fezes humanas, na $z$. urbana; $z$. rural e z. de mata, no período de agosto de 1975 a julho de 1976 em Goiânia - Goiás. 
P. eximia

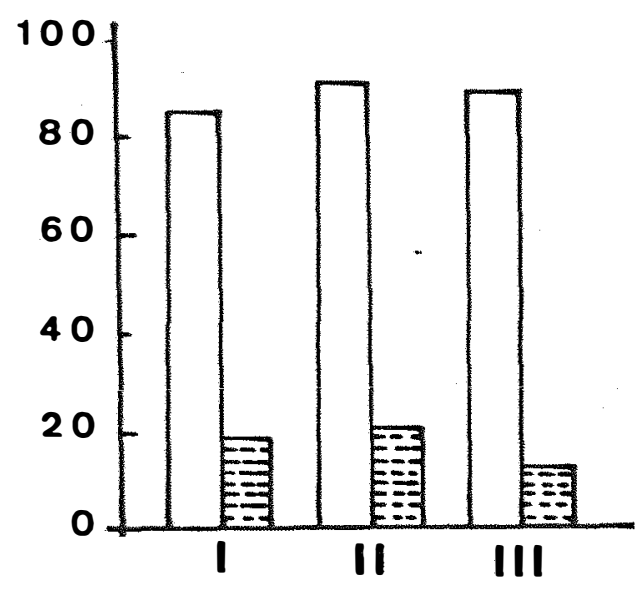

C. macellaria
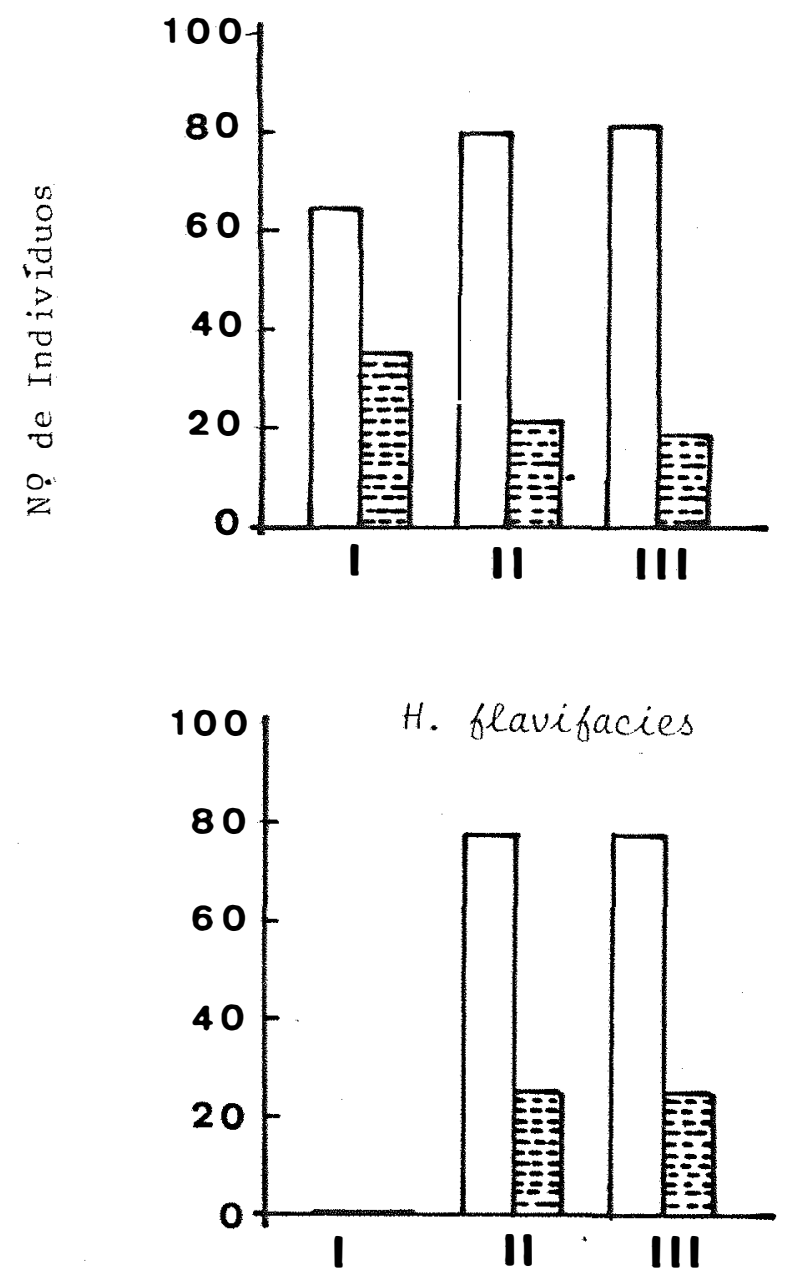

\section{P. sericata}

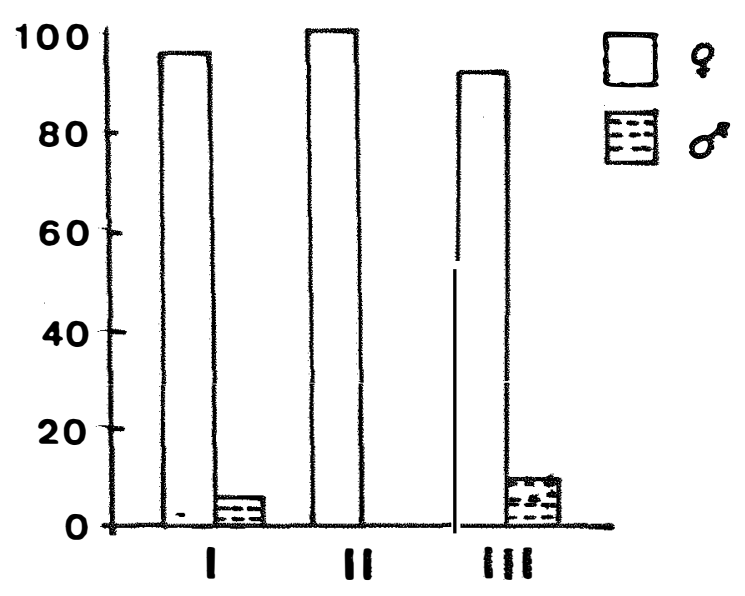

H. segmentaria
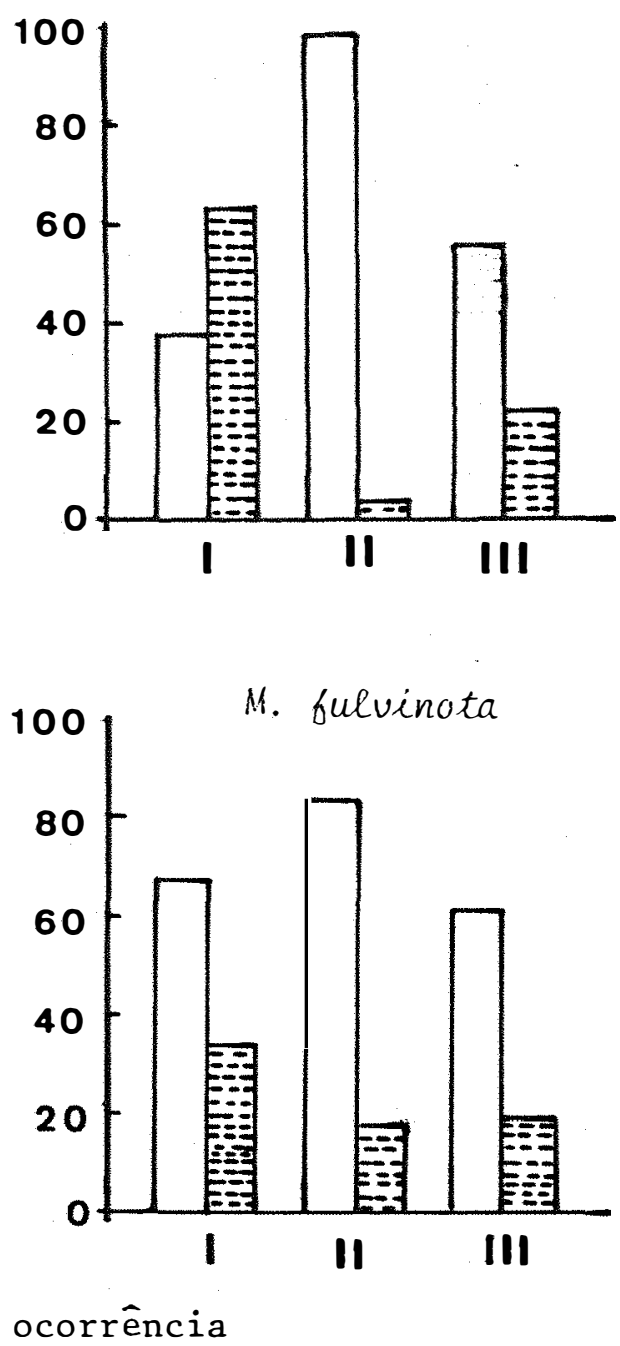

FIG. 19 - Variação na frequêencia dos sexos das espécies de Calliphoridae, na z. urbana (I); z. rural (II) e z. de mata (III), coletadas no período de agosto de 1975 a julho de 1976, em Goiânia - Goiás. 
4.8. FREQÜEิNCIA SAZONAL

Como se observa na Fig. 20, a maior freqüência dos califorídeos deu-se no mês de janeiro. Ocorreu uma variação numërica durante os meses de coleta, porém, esta variação não foi muito pronunciada. A menor ocorrência registrou-se no mês de julho de 1978. Os dados numéricos gerais, referentes aos califorídeos coletados nas três āreas consideradas, dis tribuem-se nos Apêndices XIV, XV e XVI. A maior ocorrência foi na $z$. urba na, representando $77,83 \%$ e a menor na zona de mata, com apenas $6,61 \%$.

\subsection{INDICE DE SINANTROPIA}

o indice de sinantropia, calculado para as seis espécies, está representado na Fig. 21. As espécies constituem três grupos distintos: o primeiro, formado por C. chloropyga, C. macellaria e P. sericata, que mos tram alta preferência por āreas habitadas, com índice sinantrópico varian do de $+62,0$ (C. macellaria) a +88.4 (C. chloropyga); o segundo, formado $\underline{a}$ penas por $P$. eximia, revela independência por āreas habitadas, com índice +12.2; o terceiro grupo, está constituído pelas espécies assinantrópícas: H. segmentaria e H. flavifacies, completamente ausentes em āreas habitadas, tendo o indice variando de -85.4 (H. segmentaria) a -100.0 (H. Glavi facies). 
Observou-se uma variação na atratividade exercida pelas iscas. De um modo geral, fígado de ave foi consideravelmente mais atrativo para este grupo de dípteros, enquanto que peixe foi menos atrativo (Fig. 22). o efeito das iscas na atração de cada espécie é considerado separadamente.

Através da Tabela 7 evidencia-se a preferência por isca para ca da espécie e a percentagem de espécimes em substrato de fezes.

TABELA 7 - Comparação da abundância de califorídeos coletados em peixe cru ?" fígado de ave e fezes humanas, em Goiânia, nos perío dos de julho e dezembro de 1978 e janeiro-fevereiro de 1979.

\begin{tabular}{|c|c|c|c|c|c|}
\hline \multirow{2}{*}{ Espécies } & \multicolumn{4}{|c|}{ Iscas } & \multirow{2}{*}{$\begin{array}{l}\text { \% de espécimes } \\
\text { em fezes humanas }\end{array}$} \\
\hline & $\begin{array}{l}\text { Peixe } \\
\text { cru }\end{array}$ & $\begin{array}{l}\text { Fígado } \\
\text { de ave }\end{array}$ & $\begin{array}{c}\text { Fezes } \\
\text { humanas }\end{array}$ & Total & \\
\hline & & - & & & \\
\hline P. eximia & 90 & 940 & 324 & 1354 & 23,9 \\
\hline P. sericata & 0 & 24 & 2 & 26 & 7,7 \\
\hline C. macellaria & 107 & 405 & 172 & 684 & 25,1 \\
\hline C. chloropyga & 3972 & 9184 & 2150 & 15306 & 14,0 \\
\hline H. segmentaria & 4 & 47 & 179 & 230 & 77,8 \\
\hline H. blavifacies & 0 & 14 & 6 & 20 & 30,0 \\
\hline M. fulvinota & 0 & 0 & 0 & 0 & 0 \\
\hline TOTAL & 4173 & 10614 & 2833 & 17620 & \\
\hline
\end{tabular}


De acordo com o estudo de correlação entre preferência por mate rial fecal e I.S. (Tabela 7 e Fig. 21), um grupo de espécies com valores sinantrópicos positivos apresentou baixa preferência por matéria fecal; a espécie assinantrópica, como H. segmentaria ao contrário manifestou alta preferência, por este substrato. Entretanto $H$. flavifacies também assinantrōpica mostrou baixa preferência por este material (Fig. 23). A ausência de correlação entre estes dois parâmetros, para esta espécie, pode ser atribuída ao pequeno número de indivíduos coletados.

Os valores numéricos dos indivíduos fêmeas que ocorreram nas três áreas, durante os períodos de julho e dezembro de 1978 e janeiroe fe verefro de 1979, constam nos Apêndices XVII, XVIII e XIX.

Os valores do "Teste F" e o Coeficiente de Variação estão indicados na Tabela 8 .

Os valores do Teste de Tukey para as espécies, iscas e atrativi dade das iscas, dentro das espécies constam, respectivamente, nas Tabelas 9, 10 e 11. Os dados nos indicam que houve diferença estatística, signifi cativa para todos os itens considerados, menos para a ocorrência das espécies $H$. segmentaria e H. flavifacies.

A espécie C. chloropyga diferiu estatisticamente de todas as ou tras espécies nas três áreas consideradas, menos de $P$. eximia na zona de mata.

A isca de fígado exerceu maior atratividade com relação às outras duas nas zonas urbana e rural. Na mata não diferiu da isca de fezes. 


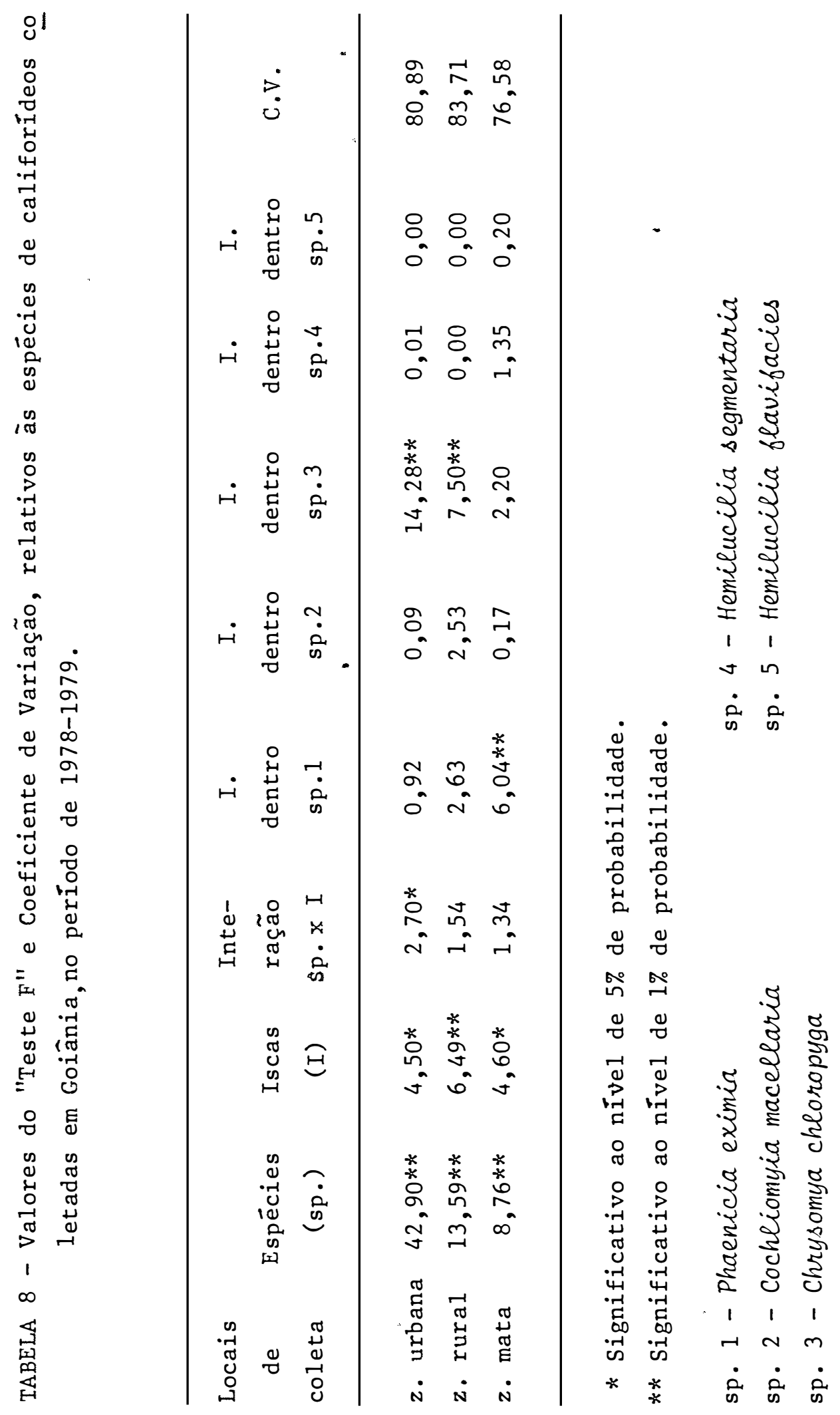


TABELA 9 - Valores do Teste de Tukey para as espécies de califorídeos coletadas em Goiânia; no período de 1978-1979.

\begin{tabular}{|c|c|c|c|c|c|c|}
\hline \multirow{2}{*}{ Locais } & \multicolumn{5}{|c|}{ ESPECIES } & \multirow{2}{*}{$\Delta$} \\
\hline & sp. 1 & sp. 2 & sp.? & sp. 4 & sp. 5 & \\
\hline z. urbana & $4,79 b$ & $3,29 b$ & $27,89 a$ & $0,95 \mathrm{~b}$ & $0,71 b$ & 7,09 \\
\hline z. rural & $4,97 \mathrm{~b}$ & $4,06 b c$ & $9,53 a$ & $0,93 \mathrm{c}$ & $0,71 \mathrm{c}$ & 3,94 \\
\hline z. mata & $4,94 a$ & $1,19 b$ & $4,86 a$ & $2,30 a b$ & $1,15 b$ & 3,14 \\
\hline
\end{tabular}

$\Delta=$ Diferença mínima significativa obtida pelo Teste de Tukey ao nível de $5 \%$ de probabilidade.

As médias com as mesmas letras não diferem estatisticamente entre si.

TABELA 10 - Valores do Teste de Tukey, para as eficiências de iscas utili zadas na coleta de califorídeos, em Goiânia, no período de 1978-1979.

\begin{tabular}{|c|c|c|c|c|}
\hline \multirow[b]{2}{*}{ Locais } & \multicolumn{3}{|c|}{ ISCAS } & \multirow[b]{2}{*}{$\Delta$} \\
\hline & $\begin{array}{c}\text { Peixe } \\
\text { cru }\end{array}$ & $\begin{array}{l}\text { Fígado } \\
\text { de ave }\end{array}$ & $\begin{array}{c}\text { Fezes } \\
\text { humanas }\end{array}$ & \\
\hline z. urbana & $6,11 \mathrm{~b}$ & $10,85 a$ & $5,62 \mathrm{~b}$ & 4,68 \\
\hline z. rural & $3,23 \mathrm{~b}$ & $6,24 a$ & $2,65 \mathrm{~b}$ & 2,60 \\
\hline z. mata & $1,96 a$ & $4,04 a$ & $2,66 a$ & 2,16 \\
\hline
\end{tabular}

$\Delta=$ Diferença mínima significativa obtida pelo Teste de Tukey ao nível de $5 \%$ de probabilidade.

As médias com as mesmas letras não diferem estatisticamente entre si. 
50.

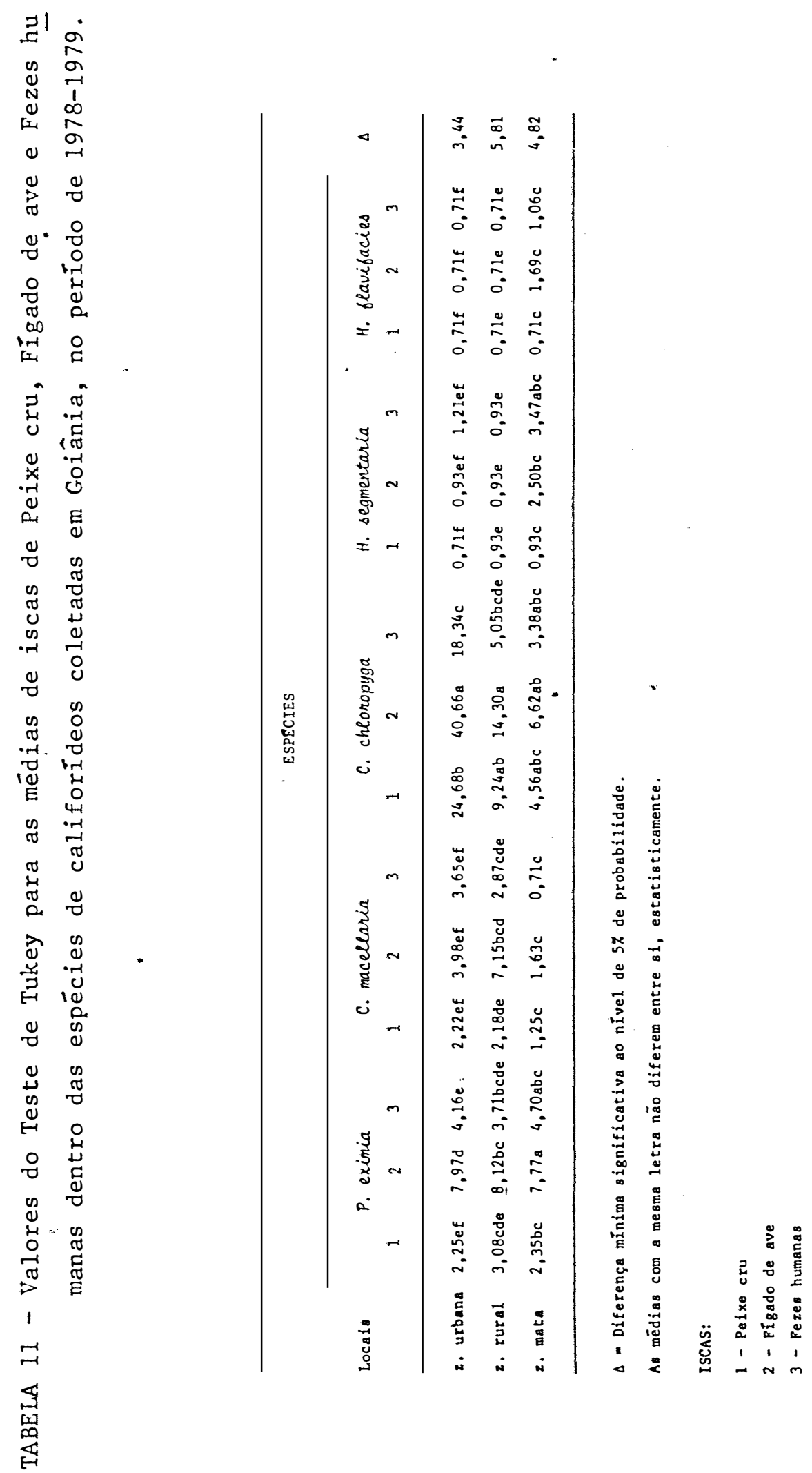




\subsection{DISTRIBUIÇÃO E COMPORTAMENTO DAS ESPECIES ESTUDADAS}

Phaenicia eximia - Foram coletados 1.354 indivíduos, que representaram 7,68\% do total, sendo a segunda espécie mais freqüente (Fig.24). Sua distribuição de ocorrência, durante o período, está ilustrada na Figura 25, e a frequência de ocorrência nas três āreas pode ser observada na Fig. 30, que indicam não haver predominância em nenhuma ārea (ver Apên dice $X X)$.

0 Índice de sinantropia foi de +12.2 (Fig. 21).

A frequência dos sexos nas três áreas é apresentado da Fig. 33 e Apêndice XXII.

A preferência por isca atrativa, nos três locais de coleta, está indicada nas Figs. 31 e 32 , respectivamente, onde se evidencia que a isca de fígado exerceu maior atratividade, seguida da isca de fezes (Apên dice XXI).

Phaenicia sericata - Espécie pouco abundante. Coletaram-se apenas 26 exemplares representando $0,15 \%$ do total (Fig. 24). Sua distribuição no período de coleta encontra-se assinalada na Fig. 26.

Esta espécie foi mais abundante na zona rural (Fig. 30) e apresentou um Indice de sinantropia de +73.0 (Fig. 21), mostrando preferência por äreas habitadas pelo homem.

A frequência dos sexos está indicada na Fig. 33; a preferência

por iscas atrativas, e esta preferência para as três äreas de coleta, estão registradas nas Figs. 31 e 32 , respectivamente.

Cochliomyia macellaria-Coletaram-se apenas 684 indivíduos, representando 3,88\% (Fig. 24). Ocorreu em maior número no mês de julho, con 
forme indica a Fig. 27.

Mais abundante na $z$, rural $(60,09 \%)$, ver Fig. 30 . 0 seu indice de sinantropia é de +62.0 (Fig. 24), significando ser uma espécie com alta preferência por āreas habitadas.

A frequência dos sexos, para cada ārea, consta na Fig. 33 e Apêndice XXII. Isca de fígado exerceu maior atratividade (59,21\%), enquanto a de peixe mostrou-se menos atrativa (Figs. 31 e 32).

Chrysomya chloropyga-Distribuição geogräfica: de acordo com JA MES (1948) esta espécie ocorre na Região Etiópica: Congo Belga, Angola, Ke nya, Rodésia, Sudeste da África, Transvaal, Natal, Cabo da Boa Esperança. No Brasil, sua ocorrência foi registrada, inicialmente, na cidade de Curi tiba, em 1975, por IMBIRIBA et alii (1977) e em São Paulo, no ano de 1978 (GUIMARĀES et alii, 1978).

Foi a espécie dominante neste período, com 15.306 indivíduos, representando $86,87 \%$ (Fig. 24). Sua distribuição ao longo do período de co leta consta na Fig. 29, que evidencia ocorrência maior no mês de janeiro. Mais freqüente na $z$. urbana, com $85,03 \%$ e muito escassa na $z$. de mata (Figura 30). O Indice de sinantropia de +88.39 (Fig. 21), indica ser uma espécie altamente sinantrópica, vivendo em áreas densamente povoadas pelo ho mem.

A freqüência dos sexos encontra-se na Fig. 33 e Apêndice XXII. Fígado é a isca atrativa preferida $(60,0 \%)$, seguida pela de peixe (Fig.31 e 32, Apêndice XXI).

Hemilucilia segmentaria - Ocorreram apenas 230 exemplares desta espécie, representando $1,31 \%$ (Fig. 24), com maior incidência registrada em julho (Fig. 28). 
E uma espécie que ocorre, preferencialmente, em z. de mata $(92,17 \%)$ (Fig. 30). O Indice de sinantropia de -85.6 (Fig. 21) indica sua completa ausência em áreas habitadas pelo homem.

A freqüência dos sexos é mostrada na Fig. 33, Apêndice XXII.

A espēcie é altamente atraịda por substrato de fezes, com $77,83 \%$ (Figs. 31 e 32 e Apêndice XXI).

Hemilucilia flavifacies - Com 20-exemplares, apenas, comparada às demais è a espécie de menor ocorrência participando com $0,11 \%$ (Fig. 24). Foi coletada apenas nos meses de julho e janeiro e exclusivamente na zona de mata (Fig. 30), indicando ser uma espécie assinantrōpica com índi ce de sinantropia de $-100,0$ (Fig. 21).

A freqüência dos sexos consta na Fig. 33 e Apêndice XXII. A pre ferência por iscas atrativas, nas Figs. 31 e 32 e Apêndice XXI. 


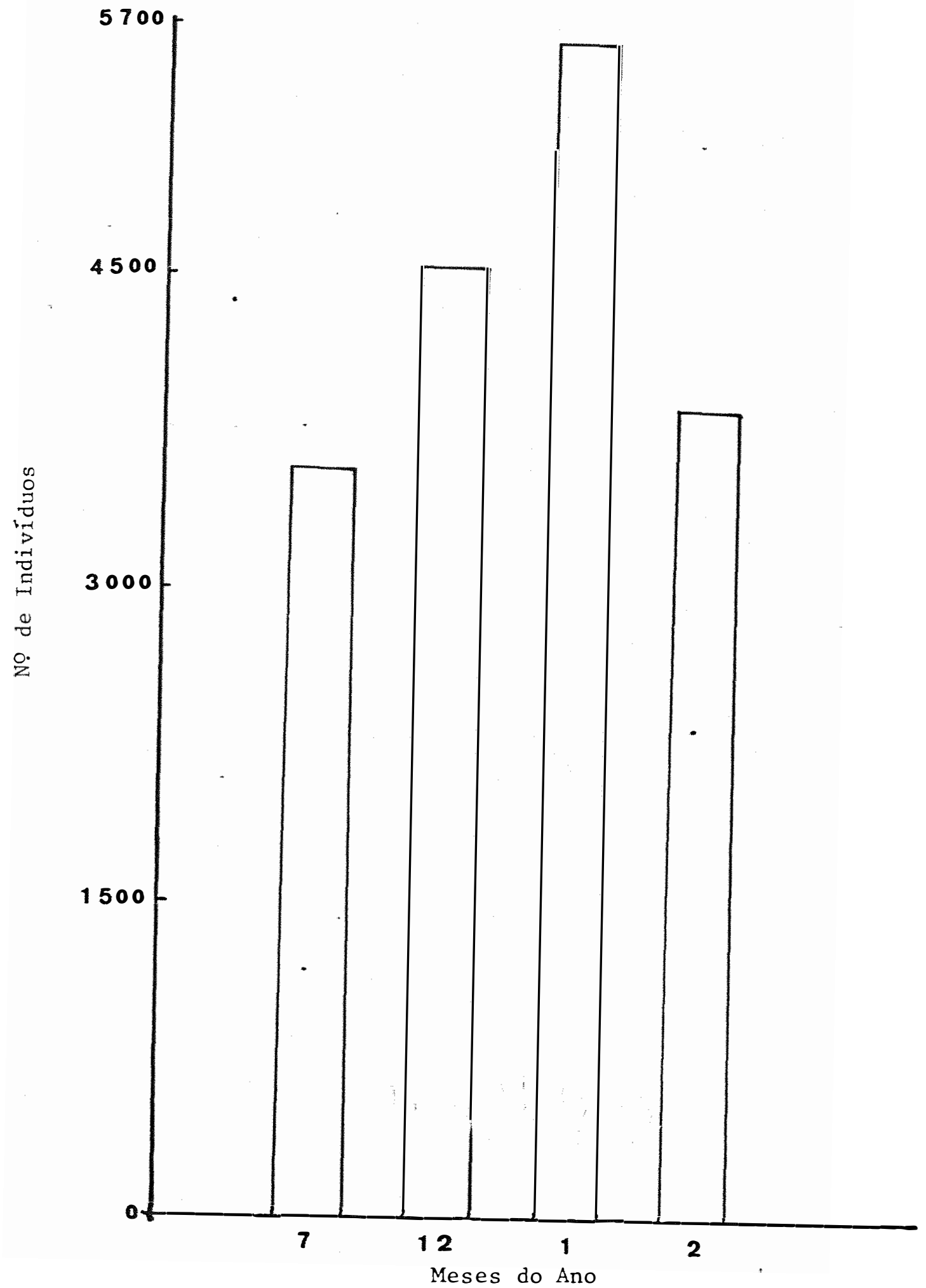

FIG. 20 - Distribuição geral de Calliphoridae no período de julho e dezem bro 1979 e janeiro-fevereiro de 1979 em Goiânia - Goiās. 


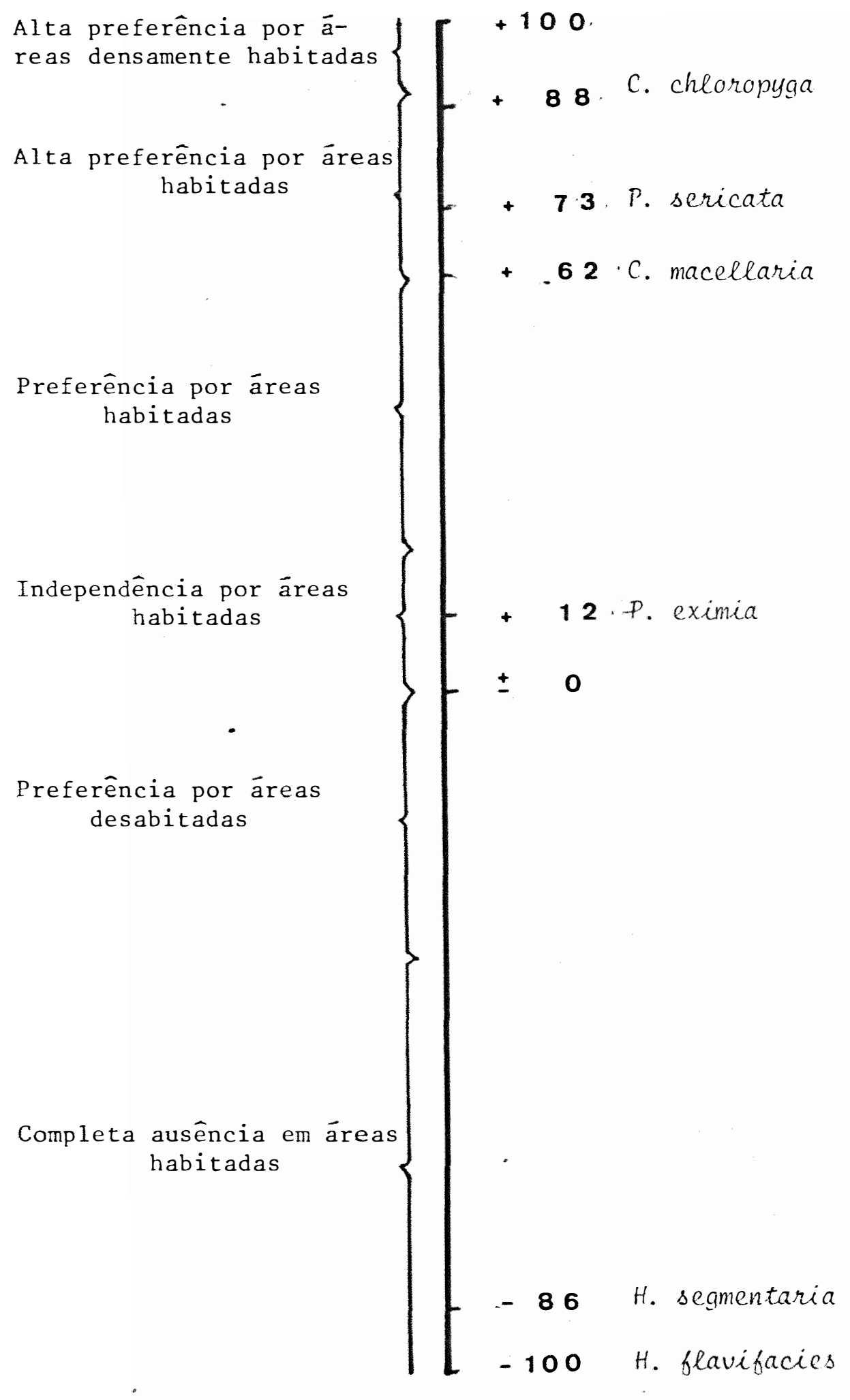

FIG. 21 - Indices de Sinantropia das espécies de Calliphoridae, no período de julho a dezembro de 1978 e janeiro-fevereiro de 1979, em Goiâ nia - Goiàs. 


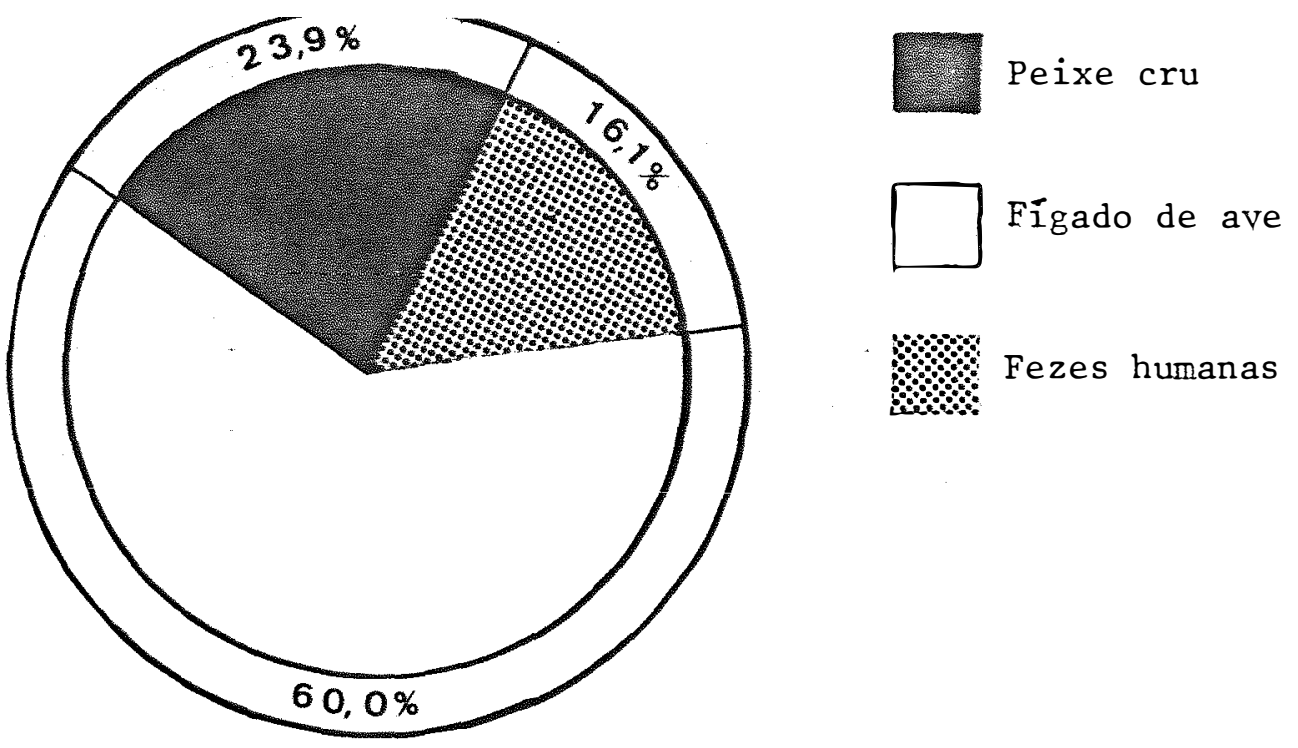

FIG. 22 - Freqüência relativa (\%) das espécies de Calliphoridae, em iscas de Peixe, Fígado de ave e Fezes humanas, no período de julho dezembro de 1978 e janeiro-fevereiro de 1979, em Goiânia, Goiás.

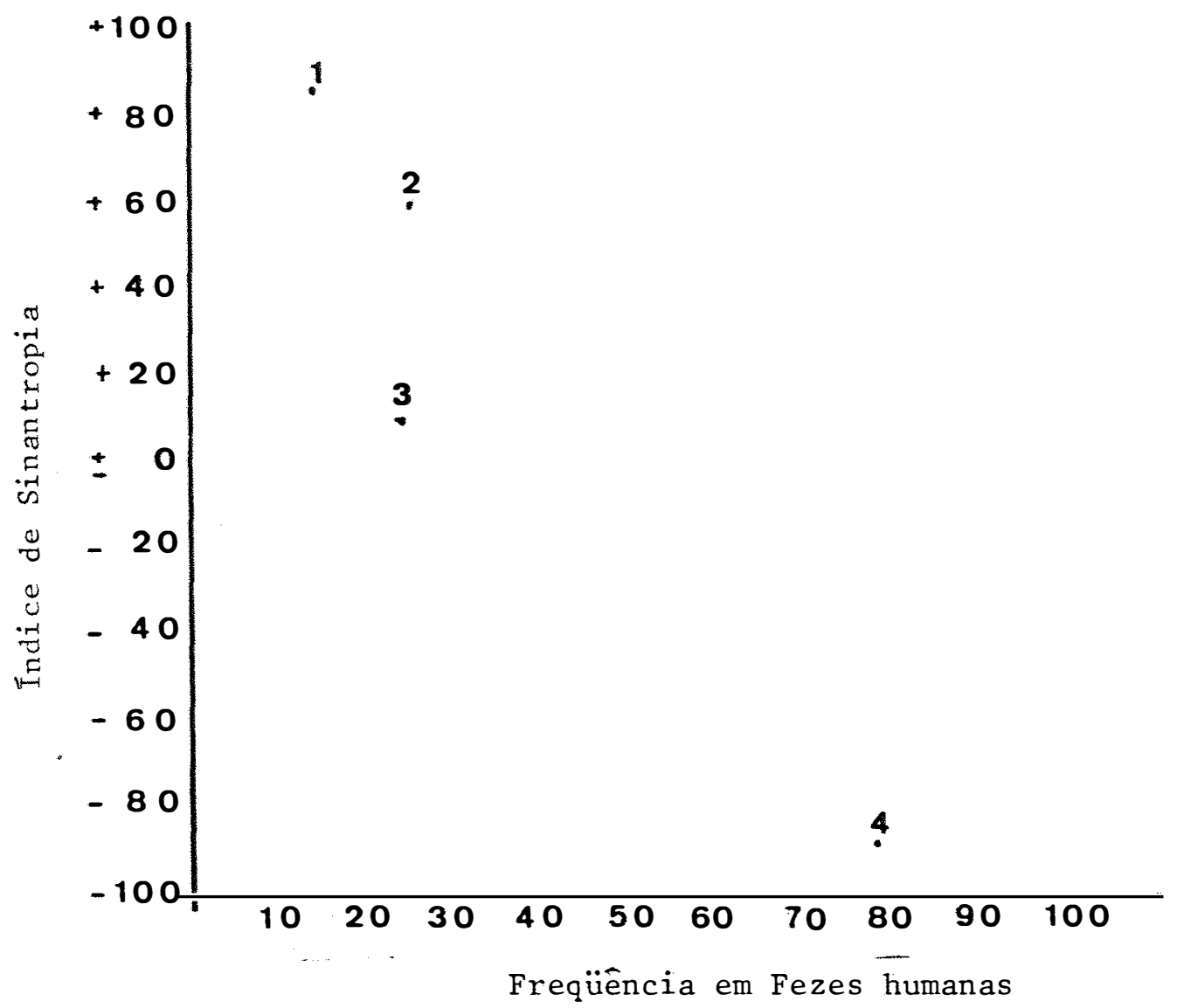

FIG. 23 - Relação entre o Indice de Sinantropia e o Grau de Preferência por Fezes humanas, das espécies de Calliphoridade de Goiânia, no período de julho e dezembro de 1978 e janeiro e fevereiro de 1979. 1 - C. chloropyga; 2 - C. macellaria; 3 - P. eximia; 4 - H. segmentaria 
58.

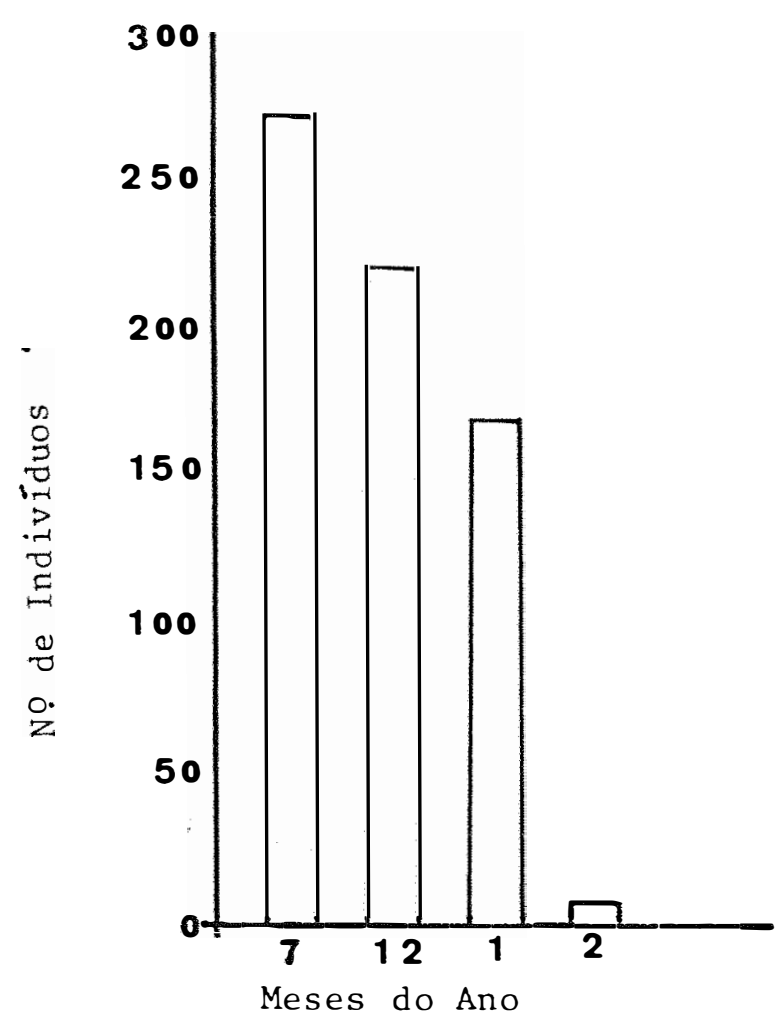

FIG. 27 - Variação na ocorrência de C. macellaria no período de julho e de zembro de 1978 e janeiro-fevereiro de 1979, em Goiânia, Goiás.

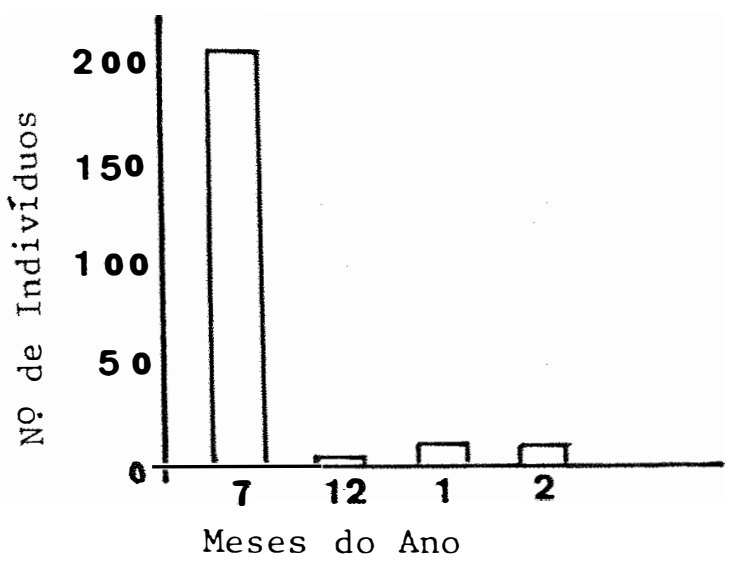

FIG. 28 - Variação na ocorrência de H. segmentaria no período de julho e de zembro de 1978 e janeiro-fevereiro de.1979, em Goiânia, Goiás. 
P. eximia

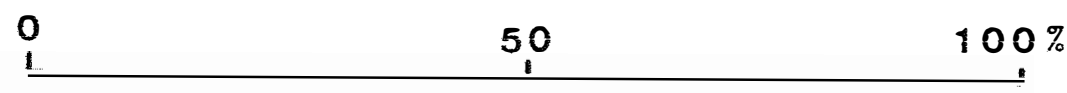

P. sericata

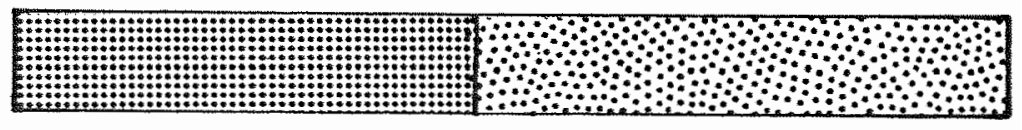

C. macellaria

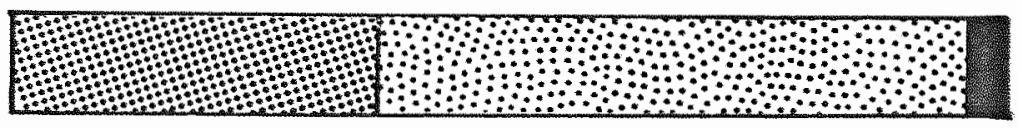

C. chloropega

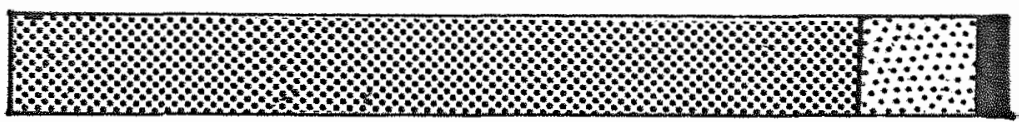

H. segmentaria

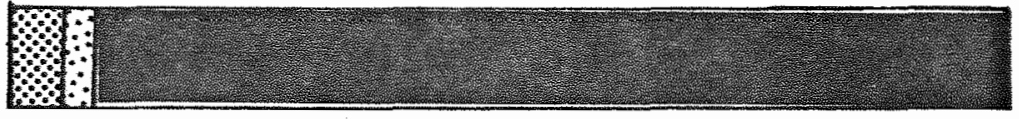

H. flavifacies
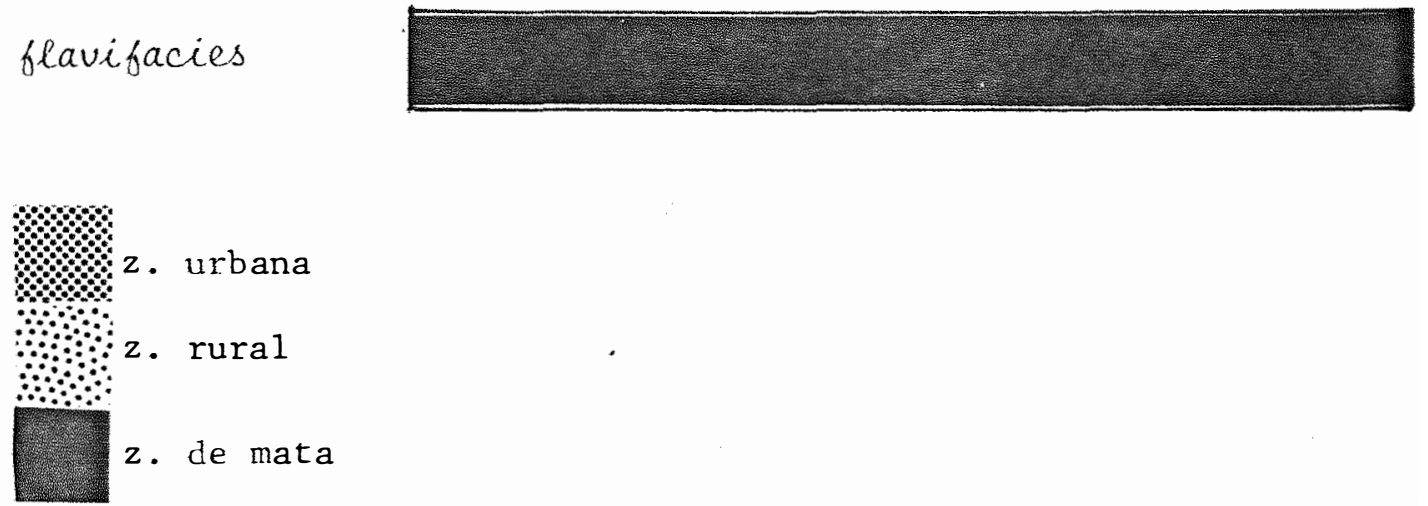

FIG. 30 - Frequência relativa (\%) das espécies de Calliphoridae, coleta dos na z. urbana; z. rural e z. de mata no período de 1978-1979 em Goiânia - Goiās. 


\section{$-$ \\ P. eximia}

P. sericata

C. macellaria

C. chloropyga

H. segmentaria

H. Glavifacies
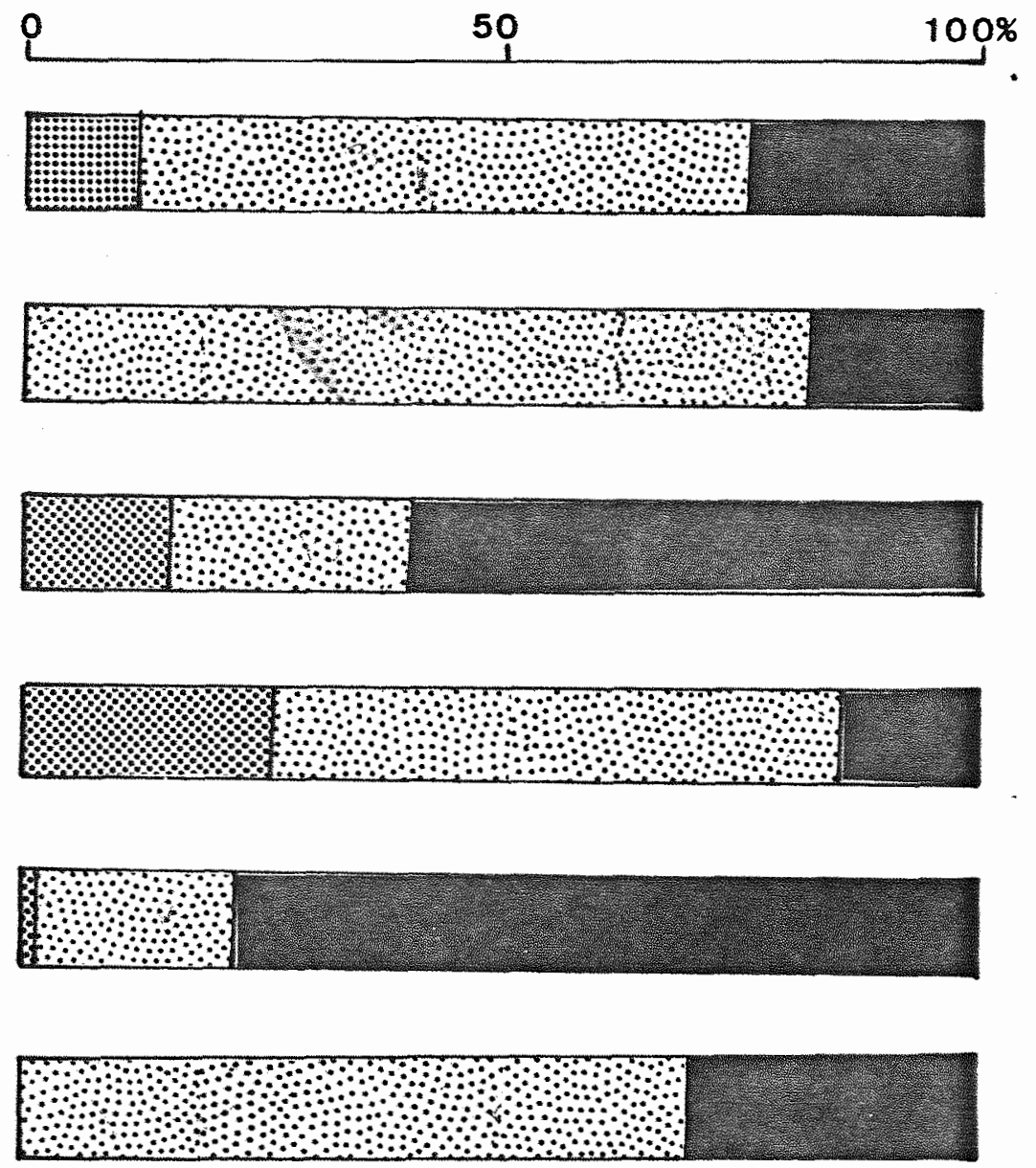

Fígado de aves
Fezes

humanas

FIG. 31 - Frequêencia relativa (\%) das espëcies de Calliphoridae em iscas de: (A) Peixe cru, (B) Fígado de aves e (C) Fezes humanas, no pe ríodo de julho-dezembro 1978 e janeiro-fevereiro 1979 em Goiânia - Goiās. 


P. eximia
P. sericata
C. macellaria
C. chloropuga
H. segmentaria
H. flavifacies
P. eximia
P. sericata
C. macellaria
C. chloropyga
H. segmentaria
H. flavifacies

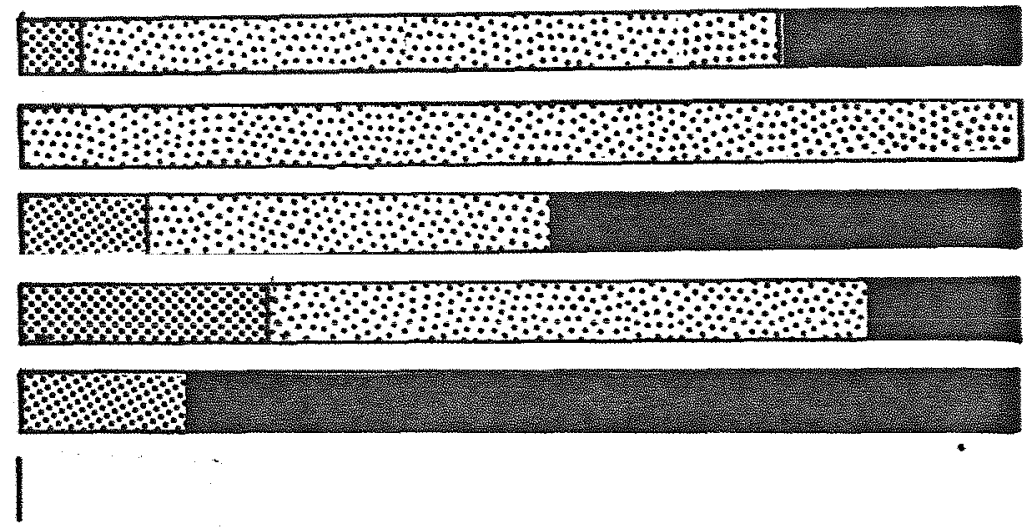

Z. urbana
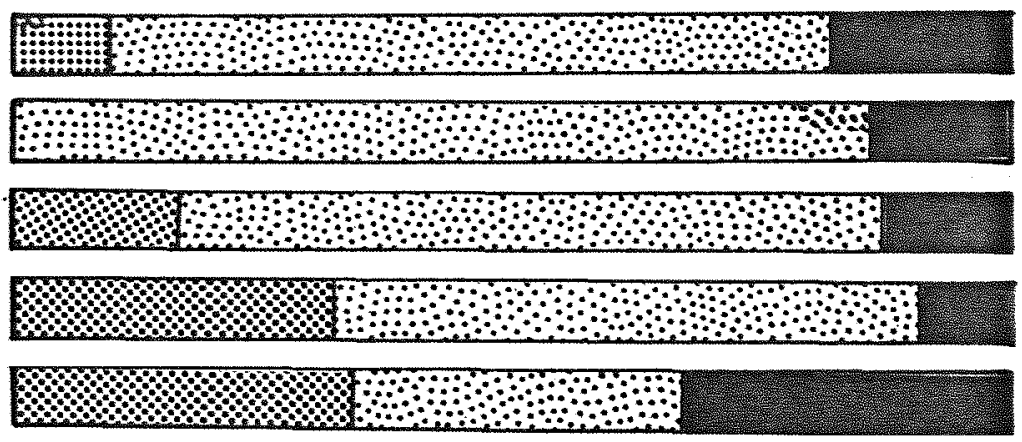

Z. rural

P. eximia

P. sericata

C. macellaria

C. chloropyga

H. segmentaria

H. flavifacies
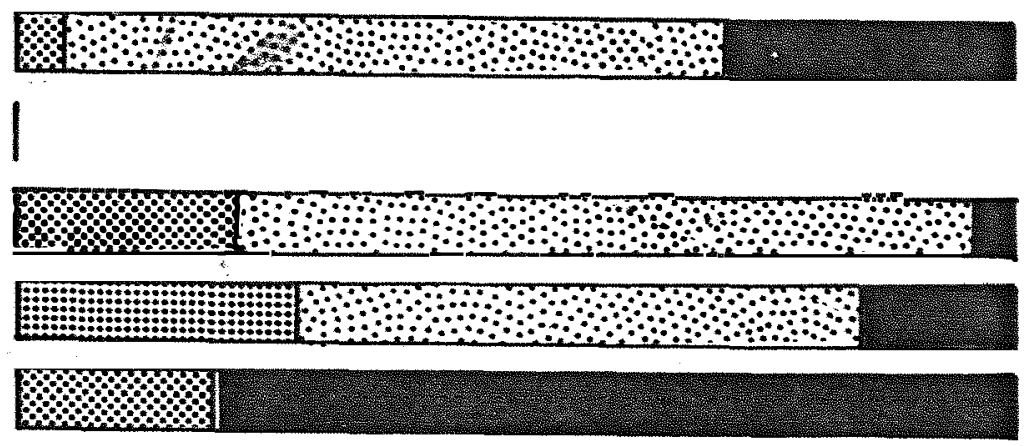

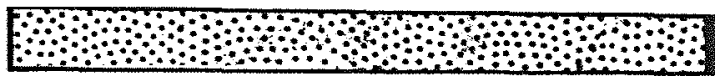

Z. de mata

8. Peixe cru

::: Fígado de ave

FIG. 32 - Frequêencia relativa (\%) das espécies de Calliphoridae, coletadas e iscas de: (A) Peixe cru, (B) Fígado de aves e (C) Fezes humanas, na $z$. urbana, $z$. rural e $z$. de mata, no período de julho-de zembro de 1978 e janeiro-fevereiro 1979, em Goiânia - Goiás. 
P. eximia
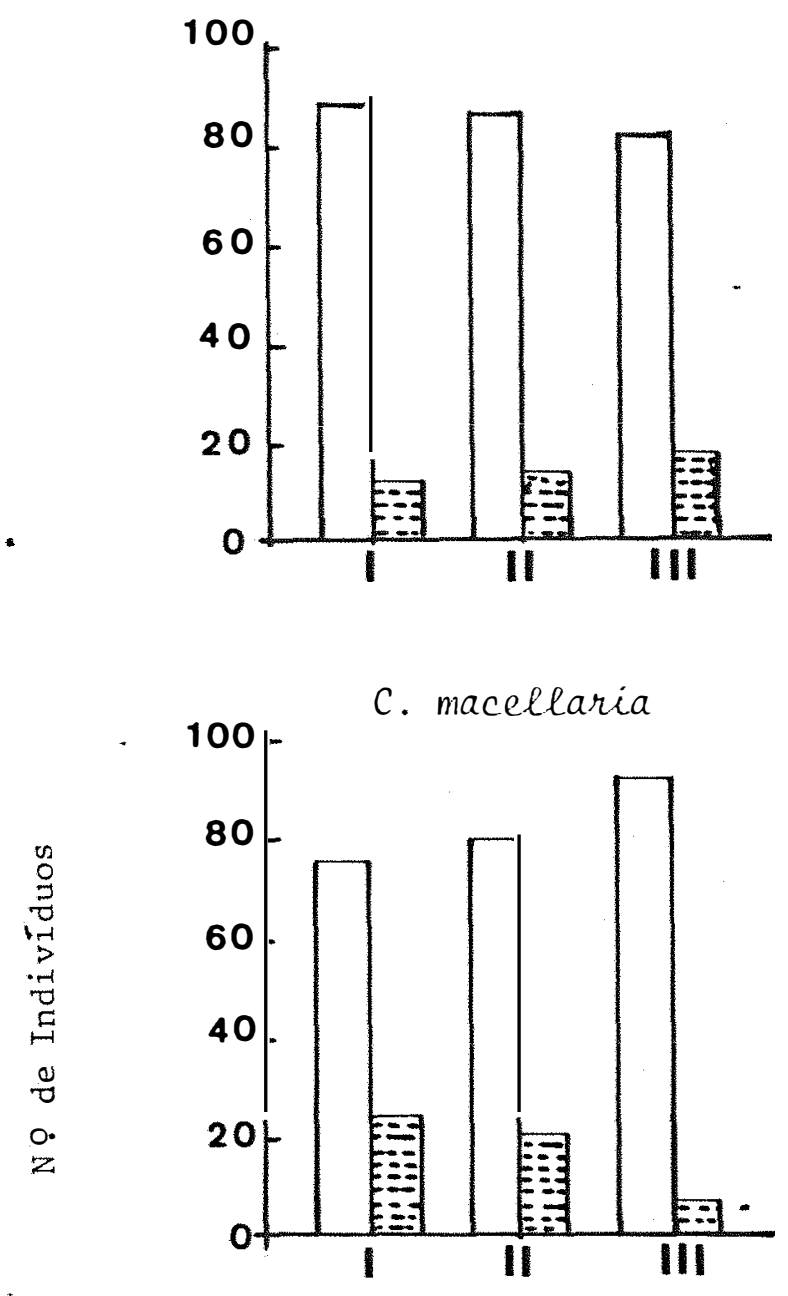

H. segmentaria

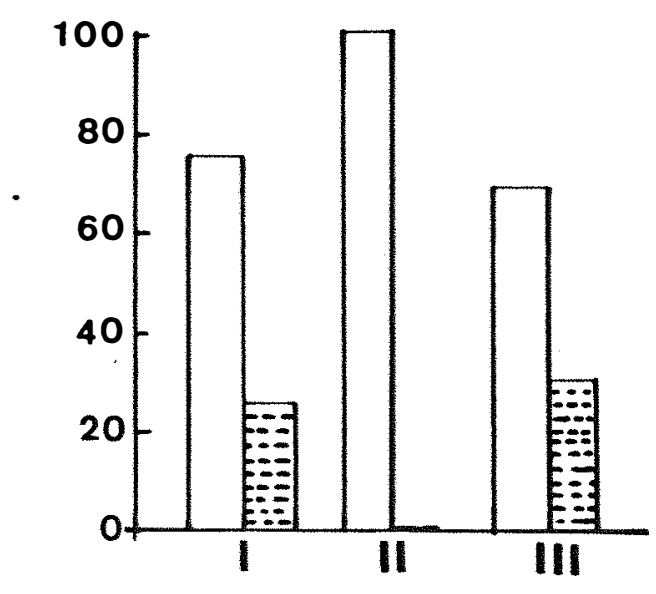

P. sericata

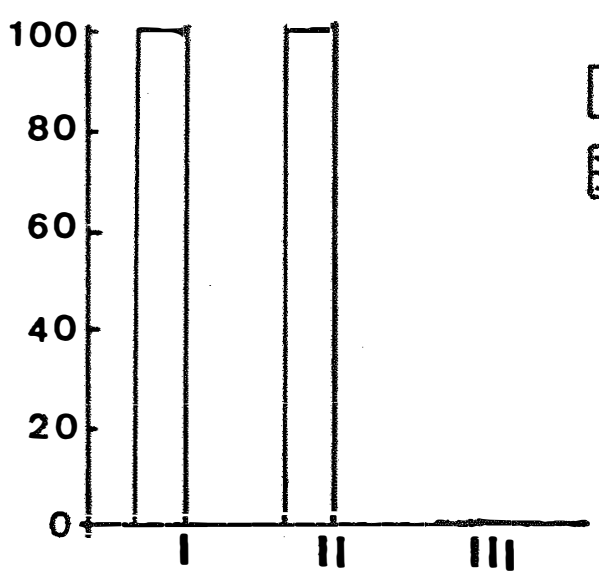

c. chloropyga

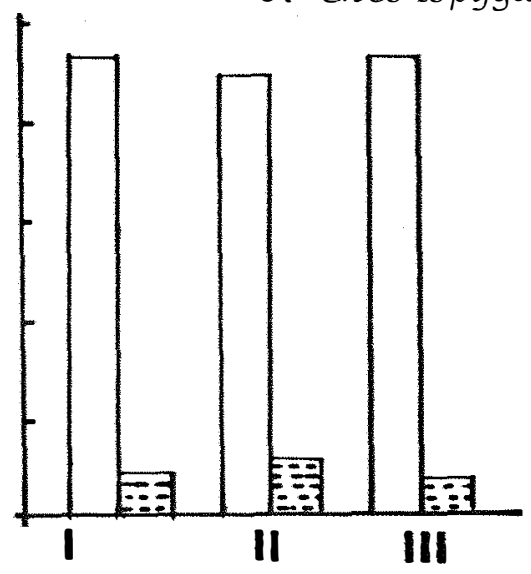

H. blavifacies

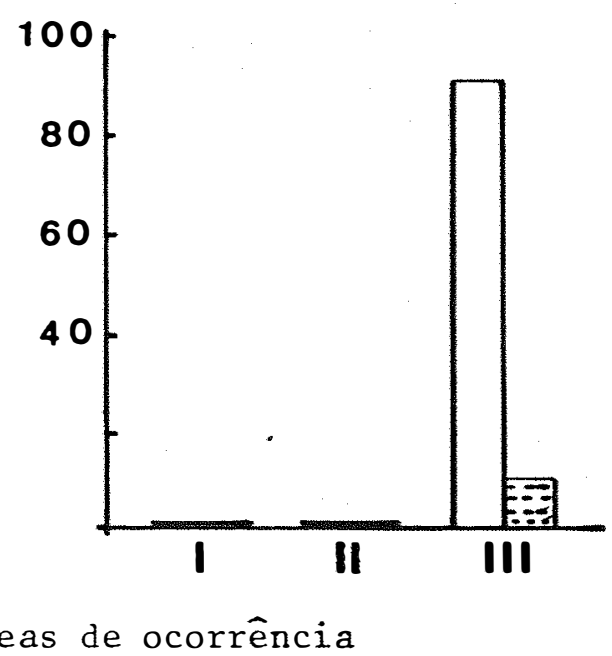

FIG. 33 - Variação na frequência do sexo das espécies de Calliphoridae, co letadas na $z$. urbana (I); z, rural (II) e z. de mata (III), no período de julho-dezembro de 1978 e janeiro-fevereiro de 1979 , em Goiânia - Goiás. 


\section{DISCUSSÃO}

No que diz respeito a variação anual na frequiência das espé cies, não se pode estabelecer um paralelo entre os dois períodos, uma vez que, na primeira etapa as coletas foram realizadas mensalmente, durante to do o ano, e na segunda, apenas durante quatro meses. Observa-se, entretan to, que, em ambos os períodos, a maior incidência populacional ocorreu no mês de janeiro (Figs. 5 e 20). Quando se considera as espécies separada mente, também não se evidenciou nenhuma correlação de predominância das espécies com condições meteorológicas mensais.

Com relação às iscas atrativas, houve sempre preferência por fígado de aves, isca esta que diferiu estatisticamente ao nível de $5 \%$ de probabilidade das iscas de peixe e fezes (Tabelas 5 e 10). Estes dados coincidem com aqueles obtidos por FERREIRA $(1975,1978)$ em Curitiba e LINHARES (1979) em Campinas. Acredita-se assim, ser este substrato fundamen tal para o desenvolvimento dos califorídeos em estudo. NORRIS (1965) considerou que restos de animais, sobretudo carcaças, constituíam o substra- 
to fundamental para o desenvolvimento desse grupo de moscas.

$$
\text { Quanto a frequência dos sexos, fêmeas foram sempre dominantes }
$$

em todas as coletas. Isto deve ter ocorrido porque as fêmeas procuram sem pre o substrato para obtenção de alimento e realização de postura.

A variação do índice de sinantropia das espécies, nos dois períodos estudados, pode ser atribuída às modificações faunísticas, resul tantes da introdução de uma espécie exótica no sistema ecológico. Uma comparação entre os índices, nas duas etapas, è mostrada na Fig. 35. 0 aumento do I.S. de C. macellaria, por exemplo, deve ter ocorrido em virtude da forte pressão sobre esta espécie pela competição de C. Chloropyga. Na zona rural, C. macellaria teve sua população fortemente reduzida. Na zona urbana, apesar da grande ocorrência de C. chloropyga, C. macellaria conse guiu ainda manter-se mesmo com pequena população, daí justificar-se o aumento do seu I.S. Fato semelhante ocorreu com P. eximia, que sofreu forte pressão na zona urbana, tendo seu I.S. sido modificado de +42.9 para +12.2 .

Com relação a sinantropia, pelos resultados obtidos nas duas etapas do trabalho pode-se inferir que, além de variações climáticas e geo grāficas que atuam no comportamento sinantrópico das espécies, outros fatores, como a alteração da fauna local por introdução de um elemento exótico pode também afetar este comportamento do ponto de vista puramente ecológico.

GREGOR (1972, 1975) critica a aplicação do índice de sinantro pia de NUORTEVA para as regiões tropicais. Entretanto, estas críticas não podem ser aceitas totalmente, uma vez que, o índice é baseadoem dados per centuais de ocorrência de espécies em três áreas ecológicas, poderā ser 
66.

aplicado em quaisquer condições climāticas e geogrā́ficas, desque que as coletas sejam simultāneas e sujeitas às mesmas variāveis (como por exem plo, iscas e armadilhas). Contudo, pode-se concordar com LINHARES (1979) no que diz respeito a necessidade de conhecimentos mais profundos sobre hābitos e características fenológicas das espécies. Também se torna importante o conhecimento de seus locais de criação, uma vez que os califorídeos apresentam grande capacidade de dispersão e alcançam pontos distantes de sua ārea de criação.

Este índice também não leva em consideração as grandes modifica ções existentes dentro da ārea rural, que é bastante enfatizada por PoVOLNY in Greenberg (1971). FERREIRA (1975) adota na íntegra a classificação de NUORTEVA (1963) para definir as moscas sinantrópicas. No presente trabalho, apesar de ter sido usada a metodologia de NUORTEVA, foi feita $\underline{u}$ ma tentativa de adaptação dos critérios de sinantropia de NUORTEVA e POVOLNÝ. Assim, surgiu a seguinte combinação: as espécies que mostram alta preferência por āreas habitadas ocupam a antropobiocenose. Aquelas que apresentam independência por āreas habitadas, ocupam tanto a antropobiocenose como a agrobiocenose, e aquelas ausentes em āreas habitadas (assinan trópicas), ocupam exclusivamente a eubiocenose (Fig. 36).

Na primeira etapa do trabalho, C. macellaria foi a espécie dominante, com $77,13 \%$ da população, diferindo significativamente a nível de $5 \%$ de probabilidade de todas as outras espécies que ocorriam na região.Na segunda etapa, portanto, no período de 1978-1979, por causa do aparecimen to de C. Chloropyga, aquela foi deslocada, passando a representar apenas 3,88\% da população (Fig. 34). Em Campinas, C. macellaria é citada por LINHARES (1979) como sendo a segunda espécie em nível populacional, supera- 
da apenas por C. chloropyga. FERREIRA (1975, 1978) mostrou que C. macella ria foi pouco representativa em Curitiba, revelando-se intolerante às bai xas temperaturas de inverno, e por isso totalmente ausente nesta estação do ano. Este comportamento poderia ser explicado pelo fato de ser ela uma espécie essencialmente neotropical. Estes dados coincidem com aqueles obtidos por LINHARES (1979) em Campinas, DEONIER (1942), SCHOOF et ali (1954), STEWART e ROESSLER (1942), WILLIAMS (1954) nos Estados Unidos e por GREGOR (1975) em Cuba. Em Goiânia não se observou variação sazonal na ocorrência da espécie,pois, aí não ocorrem variações extremas de temperatura. Em Cuba, GREGOR (1975) considerou C. macellaria uma espécie hemissinantrōpica, preferindo fezes humanas. Em Campinas, seu I.S. de +42.1 indica associação com o homem, vivendo, preferencialmente, em ambientes ur banos. Em Goiânia, O I.S. de +47.9 , na primeira etapa, e de +62.0 na segunda, indica um comportamento semelhante àquele apresentado em Campinas. Assim, de acordo com a classificação de POVOLNY in Greenberg (1971) podese classificá-la como eusinantrópica nas duas regiões. Na Tabela 12 encon tram-se os indices sinantrōpicos comparativos para os diversos locais.

Phaenicia eximia foi a segunda espécie mais freqüente nos dois períodos de coleta. Assim, em termos proporcionais, a competição de $C$. chloropyga parece que ainda não está afetando a população de $P$. eximia, mas existe evidência de que está havendo um deslocamento da população por ārea de ocorrência. Isto é evidenciado quando se compara o I.S. para as duas etapas. No primeiro período, O I.S. de +42.9 demonstra ser P. eximia uma espécie preferente por áreas habitadas e no segundo período, o I.S. de +12.0 , indica que ela apresentou independência por ärea habitada. Portanto, uma espécie dominante na zona urbana, em certo período, em face da 
pressão de deslocamento por outra espécie, nesta ārea, pode ter sua população diminuída, alterando assim, o seu I.S.

Por tratar-se de uma espécie neotropical, não se constatou dife renças marcantes em sua ocorrência anual, mas em locais com variações extremas de temperatura, como Curitiba (PR), FERREIRA (1975, 1978), obser vou que nos períodos mais frios do ano havia uma queda brusca na popula ção. Nestes períodos, houve uma substituição da população de P. eximia por $P$. sericata, que prefere temperaturas mais baixas. Em Campinas, segundo LINHARES (1979), esta espécie não é dominante e se distribui pelas três āreas, porém, com certa preferência por āreas habitadas.

GREGOR (1975) fez referência a P. eximia como sendo uma espécie hemissinantrōpica.

- Com relação a P. sericata, sua ocorrência foi muito baixa em am bos os períodos de coleta. O indice de sinantropia resultou bastante controvertido, sendo o pequeno número de indivíduos coletados insuficiente pa ra uma análise representativa. Na Tabela 12 pode-se observar o I.S. desta espécie nos diversos locais do Brasil e do Mundo. Nota-se que nos locais de ocorrência é sempre altamente sinantrópica, provavelmente por ser uma espécie cosmopolita.

DEONIER (1942) concluiu que alta temperatura é fator limitante para esta espécie.

LINHARES (1979) concluiu que $P$. sericata não tem significado epidemiológico em Campinas, pois, sua população foi sempre muito baixa, havendo sido encontrado aí seu equivalente ecológico $P$. cuprina. Também em Curitiba e Goiânia suas populações não apresentam significado epidemiológico. Entretanto, na Hungria (MIHÁLYI, 1967a) esta espécie é a mais abun- 
dante em ambientes urbanos, sendo considerada importante na transmissão de doenças entéricas. HAVLIK e BATOVÁ (1961) também concordam com estas considerações, pertinentes à cidade de Praga.

Durante o segundo período de coleta, C. Chloropyga mostrou-se dominante, havendo provocado o deslocamento de $C$. macellaria e de $P$. eximia na zona urbana. Seu alto I.S. evidencia uma íntima relação com a antropobiocenose, e alta preferência por āreas densamente habitadas. Sendo uma espécie exótica, ocorrendo no Continente Africano, apresenta um longo período de associação com o homem, e sendo assim, era de se esperar este comportamento, altamente sinantrópico, no Continente Sul Americano. Portanto, é uma espécie de grande importância, do ponto de vista epidemiológico, como vetor em potencial de microrganismos patógenos ao homem e animais domésticos. ZUMPT (1965) atribuiu-1he ainda importância, como causadora de miíases.

Tambēm em Campinas, C. chloropyga revelou-se dominante, apresen tando preferência por áreas habitadas e uma certa tendência à hemissinantropia (LINHARES, 1979). Esta classificação coincide com a de POVOLNY in Greenberg (1971).

E uma espécie fortemente atraída por fígado de ave, seguido por peixe. Em Campinas ocorreu em depósitos de lixo urbano, tanto na forma lar val como na forma adulta, além de haver. sido encontrada em diversos outros substratos. Também em Goiânia ocorreu em matadouros, feiras - livres, lixo urbano e dentro de residências.

Trata-se de uma espécie de dispersão muito rápida, pois, havendo sido introduzida no Brasil nos fins de 1975, jā se encontra distribuída em pontos distantes de seu provável referencial de introdução (Paraná 
ou São Paulo), estabelecendo-se preferencialmente, em äreas urbanas. 0 mapa da Fig. 37 assinala os pontos em que foi constatada a sua.presença $\underline{a}$ té setembro de 1979. Acredita-se que sua dispersão esteja sendo feita pelo homem, através de rodovias importantes do país, como ocorreu na Belém-Brasília, desde que sua presença foi registrada em Goiânia (GO), Be lém (PA) e Imperatriz (MA). Quanto aos outros pontos de ocorrência, deve ter sido levada também através de transportes rodoviários. Entretanto, na mesma época em que a espécie jā ocorria no Sul. Centro e Norte do País,ain da não estava presente no Nordeste.

SAILER (1978) mostrou que barreiras ecológicas e geogräficas são quebradas devido aos meios de comunicação entre regiões diferentes pro porcionando, pelo intenso comércio, a entrada de espécies exōticas. Assim, as espécies seriam levadas de uma área para outra proporcionando sua fixação e consequiente adaptação.

GUIMARÃES et alii (1979) tentaram correlacionar a introdução de C. chloropyga em território brasileiro, com a época da imigração de portu gueses provenientes de Angola. Acreditam assim que isto possa explicar o evento, pois a espécie é largamente distribuída por todo Continente Africano.

Duas outras espécies, Chrysomya albiceps e C. megacephala, tam bém introduzidas no Brasil, possivelmente na mesma época que $C$. chloropyga e constatadas em São Paulo por GUIMARÃES et alii (1979), ainda não ocorria em Goiânia até à época da realização do presente levantamento. $H$. segmentaria, H. flavifacies e $U$. fulvinota, todas com I.S. negativo, portanto, ocorrendo em ambientes naturais, são designadas de acordo com POVOLNY in Greenberg (1971) como assinantrópicas. Estas espē - 
cies não apresentam, ainda, indícios de associação com o homem. Do ponto de vista sinantrópico, M. fulvinota é citada agora, pela primeira vez em Goiânia.

Esta espécie não foi registrada em nenhuma coleta durante a segunda etapa. Isto pode se justificar uma vez que, ela não ocorreu durante os meses de julho, dezembro e fevereiro, e ocorreu em baixa frequência em janeiro durante o primeiro levantamento (Fig. 15).

Os resultados obtidos nos levantamentos qualitativo e quantitativo procedidos aos califorídeos sinantrópicos de Goiânia apresentam variações marcantes. Podem-se atribuir este fenômeno, sobretudo às alterações ecológicas, decorrentes da introdução de um elemento exótico, C. chlọ ropyga, que afetou, sobremaneira, a população da espécie nativa dominante, C. macellaria. Os efeitos oriundos da introdução de um elemento exótico no: ambiente natural ou no agroecossistema foram estudados por ELTON (1958), que adotou o termo "explosão ecológica" para definir estes efeitos. Sendo a "explosão" uma conseqüência da necessidade de a espécie invasora explorar com maior agressividade o ambiente (competição por alimento e local de postura) e os recursos disponíveis, espera-se, portanto, que haja, pelo menos inicialmente, sucesso no desenvolvimento das populações da espécie invasora.

Dados percentuais da frequiência das espécies estão representa dos naFig. 34, onde se tenta estabelecer um paralelo da ocorrência das es pécies, durante os dois períodos em que se desenvolveu a pesquisa. Como se observa, a espécie C. macellaria foi dominante na primeira etapa, porém, quase não existindo na segunda. Deste modo, pode-se acreditar que es tá se processando o "deslocamento competitivo", definido por DeBACH (1966). 
Ainda que este caso não tenha sido estudado com profundidade, existe evidência de que C. chloropyga e C. macellaria são verdadeiros homólogos eco lógicos e assim sendo uma das espécies não poderá sobreviver por muito tem po no mesmo habitat. Este "deslocamento" também manifesța que a espécie e xótica C. Chloropyga encontrou (pelo menos até o presente) vantagens em relação à espécie autōctone.

$\mathrm{Na}$ literatura existem alguns casos clássicos e bem documentados de "deslocamento competitivo": A "mosca de frutas do Mediterrâneo", Ceratitis capitata (Wied.), foi substituída nas proximidades de Sydney, Aus trália, pela "mosca de frutas de Queensland", Dacus tryoni (Froggat), que invadiu a Austrália pelo norte (ANDREWARTHA e BIRCH, 1964). Outro caso se melhante ocorreu com C. capitata, espécie já estabelecidano litoral do Hawaí, que foi deslocada por Dacus dorsalis Hendel. Atualmente C. capitata está restrita às partes mais elevadas, com clima mais frio (CHRISTENSON e FOOTE, 1960).

Entretanto, para C. Chloropyga ainda é muito precoce se fazer qualquer afirmação em relação a seu estabelecimento definitivo em Goiâ nia - Goiás. Somente levantamentos qualitativos e quantitativos posteriores, da fauna local, poderão comprovar tal fenômeno. 
TABELA 12 - Indice sinantrópico de califorídeos coletados em Goiânia, nos períodos de 1975-1976 (agosto a julho) e 1978-1979 (julho e de zembro, janeiro e fevereiro), para comparação com os índices de espécies que ocorrem em Curitiba, Campinas e o índice de $P$. sericata calculado por NUORTEVA (1963), relativo à Finlândia, Tchecoslováquia, Hungria e Suécia.

\begin{tabular}{|c|c|c|c|c|c|c|c|c|}
\hline \multirow[t]{2}{*}{ Espécies } & \multicolumn{2}{|c|}{ Goiânia } & \multirow{2}{*}{$\begin{array}{c}\text { Curi- } \\
\text { tiba }\end{array}$} & \multirow{2}{*}{$\begin{array}{c}\text { Campi } \\
\text { nas }\end{array}$} & \multirow{2}{*}{$\begin{array}{c}\text { Finlân } \\
\text { dia }\end{array}$} & \multirow{2}{*}{ Tech. } & \multirow{2}{*}{$\begin{array}{l}\text { Hun- } \\
\text { gria }\end{array}$} & \multirow{2}{*}{ Suēcia } \\
\hline & 19 & 29 & & & & & & \\
\hline P. eximia & +42.9 & +12.2 & +14.2 & +27.1 & - & - & - & - \\
\hline P. sericata & +27.5 & +73.0 & +79.0 & - & +98.2 & +89.0 & +33.0 & +92.0 \\
\hline C. macellaria & +47.9 & +62.0 & -2.4 & +42.6 & - & - & - & - \\
\hline C. chloropyga & - & +88.3 & - & +31.7 & - & - & - & - \\
\hline $\begin{array}{l}\text { H. } \\
\text { segmentaria }\end{array}$ & -83.4 & -85.6 & -50.0 & -93.4 & - & - & - & - \\
\hline flavifacies & -93.8 & -100.0 & - & -99.4 & - & - & - & - \\
\hline M. fulvinota & -87.5 & - & - & - & - & - & - & - \\
\hline M. Lyrcea & - & - & -93.5 & -100.0 & - & - & - & - \\
\hline
\end{tabular}



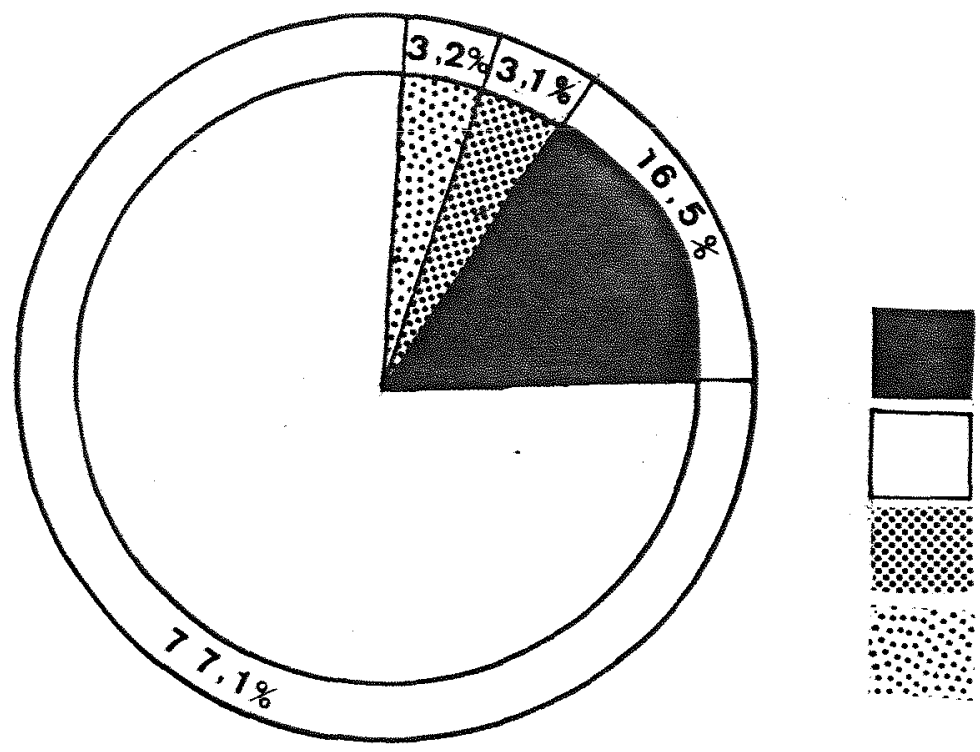

P. eximia

C. macellaria

M. fulvinota

P. sericata

H. segmentaria

H. flavifacies
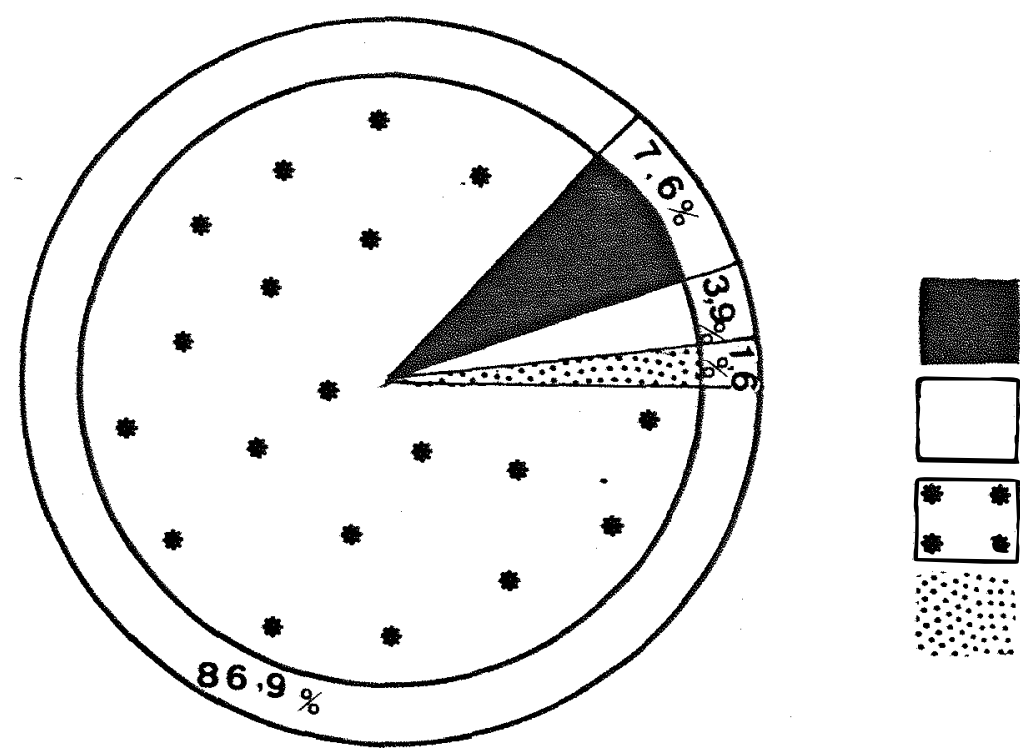

P. eximia

C. macellaria

C. chloropyga

P. sericata

H. segmentaria

H. flavifacies

FIG. 34 - Comparação de freqüencia relativa (\%) das espécies de Calliphoridae, no período de 1975-1976 e 1978-1979, em Goiânia, Goiās. 


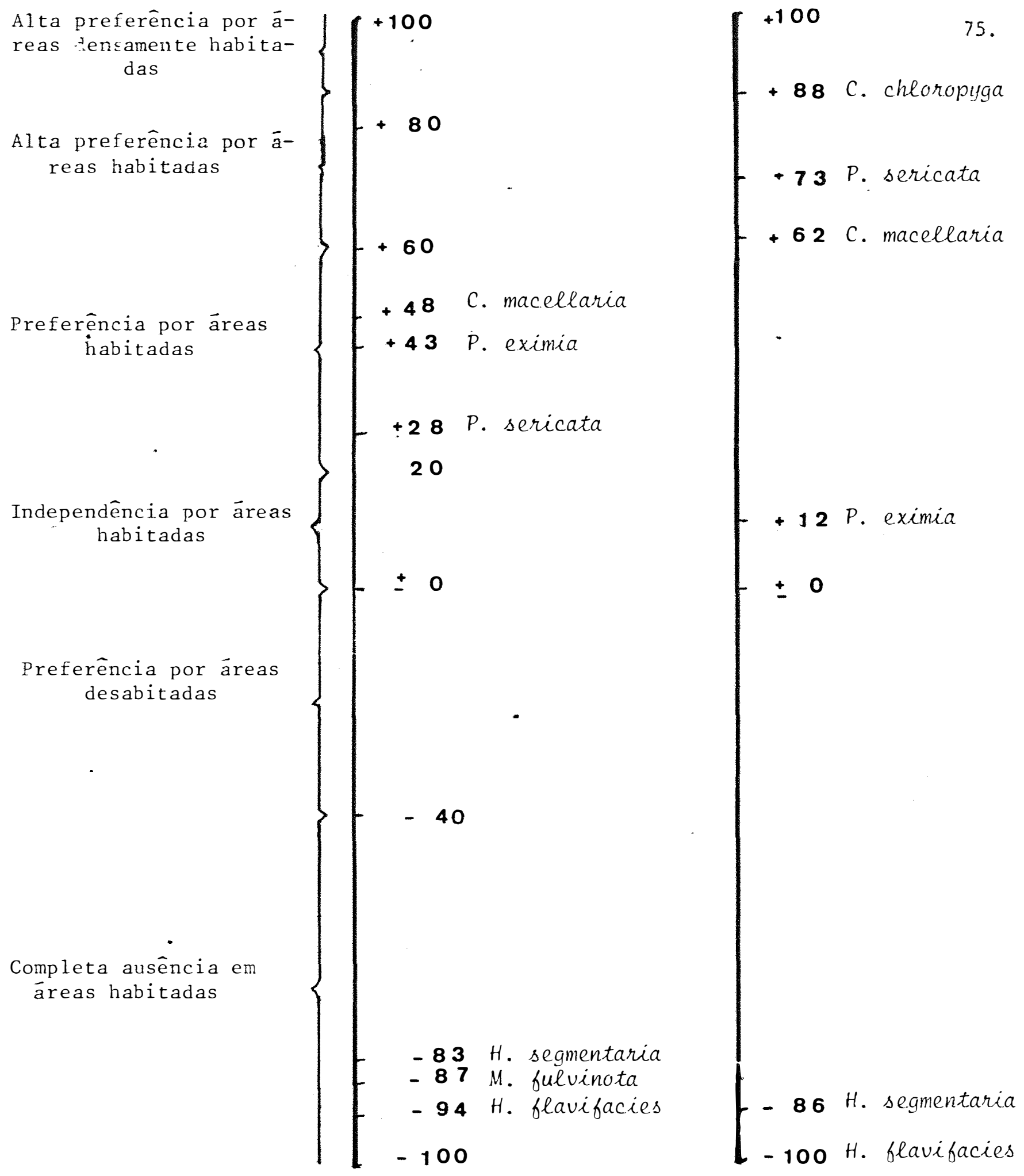

FIC. 35 - Comparação entre o Indice de Sinantropia das espécies de Calliphoridae encontrados em Goiânia - Goiàs, nos períodos de 1975 1976 e 1978-1979. 


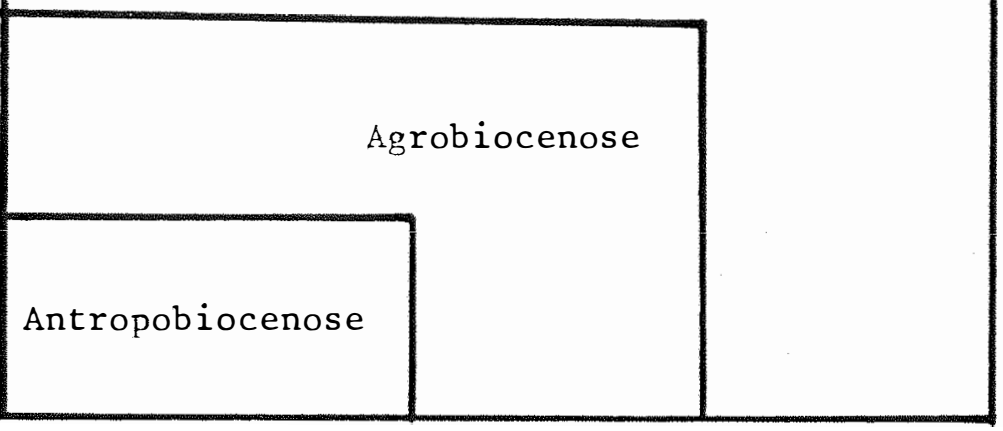

1975-1976

P. eximia

P. sericata

C. macellaria

H. segmentaria

H. flavifacies

11. fulvinota

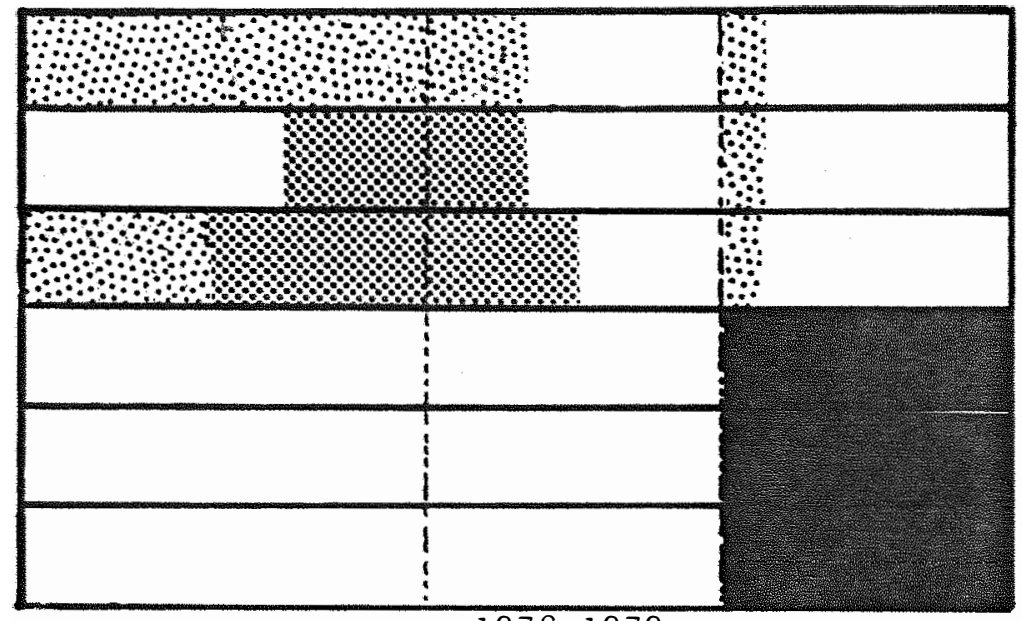

1978-1979

P. eximia

P. sericata

c. macellaria

C. chloropega

H. segmentaria

H. heavifacies

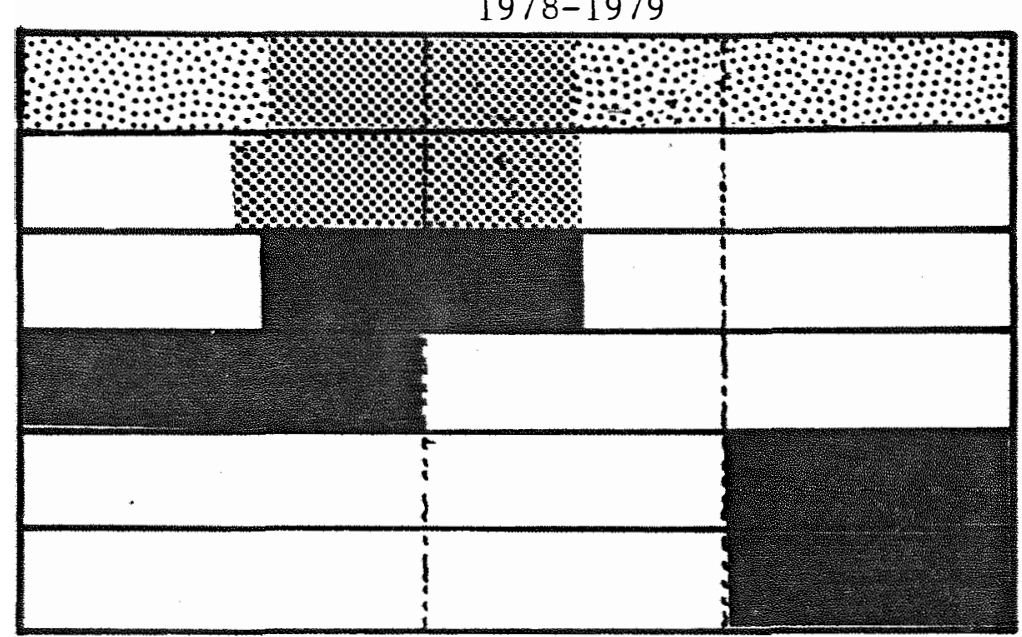

FIG. 36 - Distribuição das espécies de Calliphoridae encontradas em Goiânia-GO, nos períodos de 1975-1976 e 1978-1979, na Eubiocenose, Agrobiocenose e Antropobiocenose (Esquema baseado nos critérios de densidade populacional de NUORTEVA, 1963 e POVOLNȲ, 1971). 


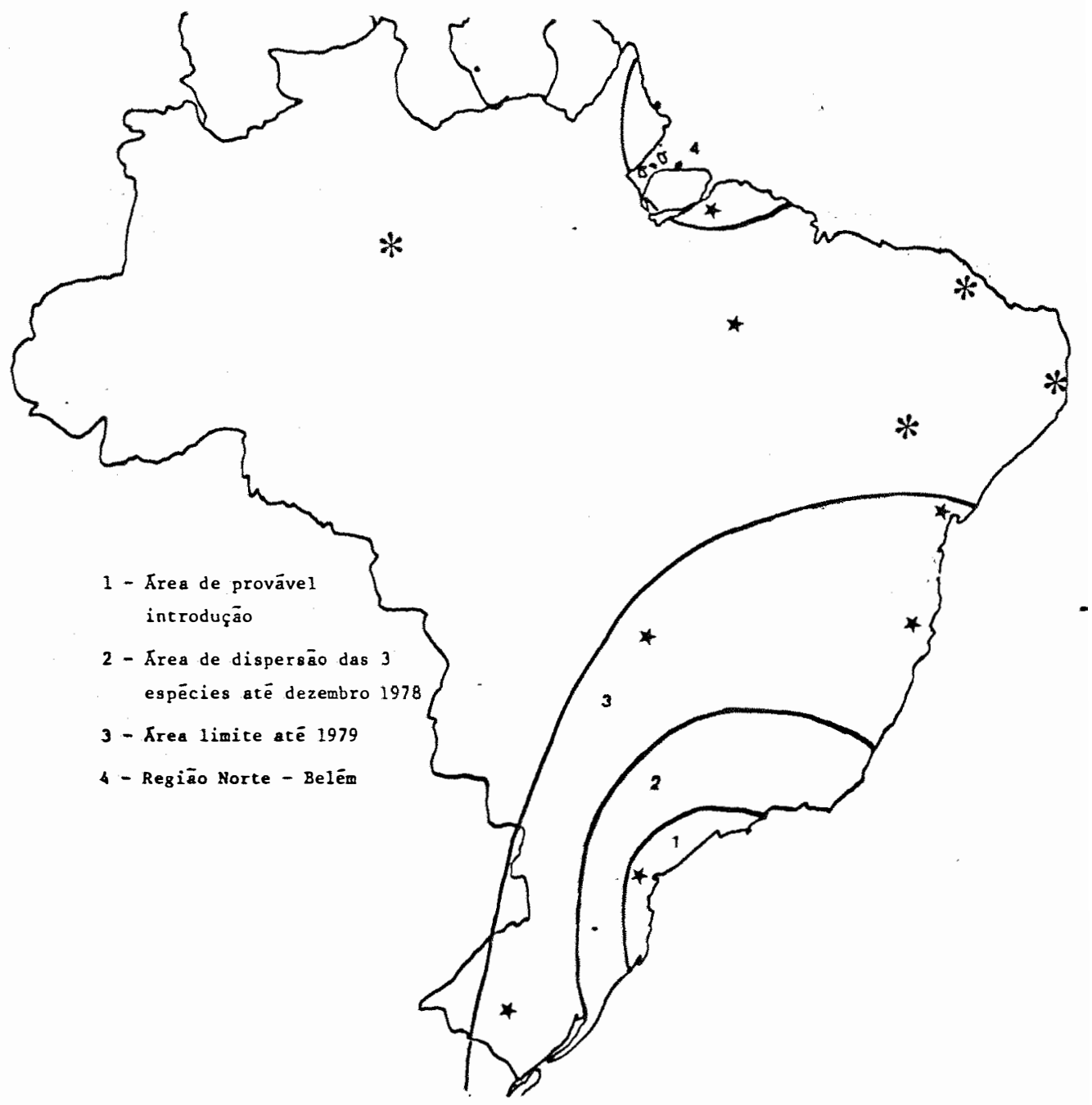

* Locais onde ocorrem C. Chloropyga.

* Locais onde não ocorren C. chloropyga.

FIG. 37 - Dispersão de C. Chloropyga, no Brasil, atē setembro de 1979. 
6. CONCLUSÕES

De acordo com os resultados obtidos no presente levantamento,em Goiânia, concluiu-se que:

19) A espécie Chrysomya chloropyga, introduzida em Goiânia - Goiás, apresenta maior Indice de sinantropia do que as espécies autóctones.

29) O Indice de sinantropia das espécies nativas pode variar com as modificações provocadas pelo"deslocamento competitivo"de uma espécie introduzida.

39) A composição faunística dos califorídeos sinantrópicos de Goiânia sofreu modificações por causa da introdução de uma espécie exótica c. chloropyga.

49) A espécie C. Chloropyga, recentemente introduzida no Brasil, já se en contra amplamente distribuída em nosso território.

59) Existe um "deslocamento competitivo" de C. macellaria por C. chloropy ga a partir de 1978 . 
69) C. Chloropyga tornou-se espécie dominante na zona urbana em Goiânia Goiàs .

79) A isca de fígado de ave é preferida por todas as espécies sinantrópicas e hemissinantrōpicas.

80) As espécies assinantrópicas preferem iscas de fezes humanas.

99) Hā variação anual, em número de indivíduos, na ocorrência das espé cies estudadas. 


\section{LITERATURA CITADA}

ANDREWARTHA, H.G. e L.C. BIRCH, 1964. The distribution and abundance of animals. Univ. Chicago Press, Chicago, 782pp.

ARADI, M.P. e F. MIHĀLYI, 1971. Seasonal investigations of flies visiting food markets in Budapest. Acta zool. Hung., Budapest, 17: 1-10.

BISHOPP, F.C. e E.W. LAAKE, 1921. Dispersion of flies by flight. J. agric. Res., Washington D.C., 21: $726-766$.

CHRISTENSON, L.D. e R.H. FOOTE, 1960. Biology of fruit flies. A. Rev. Ent., Stanford, 5: 171-192.

DeBACH, P., 1966. The competitive displacement and coexistence principles. A. Rev. Ent., Stanford, 11: 183-212.

DEONIER, C.C., 1942. Seasonal abundance and distribution of certain blowflies in southern Arizona and their economic importance. J. econ. Ent., New York, 35: 65-70. 
DERBENEVA-UKHOVA, V.P., 1962. On the ecological classification of synanthropic flies of the families Muscidae and Calliphoridae (Diptera). Verh. XI int. Kongr. Ent., 2: 422-426.

ELTON, C.S., 1958. The ecology of Invasions by Animals and Plants. Methuen and Co. Ltd., London, 181pp.

FERREIRA, M.J.M., 1975. Sinantropia de Dípteros Muscóideos de Curitiba (Calliphoridae e Sarcophagidae). Curitiba, UFP, 106pp. (Tese de Mestrado).

FERREIRA, M.J.M., 1978. Sinantropia de Dípteros Muscóideos de Curitiba, Paranā. I. Calliphoridae. Rev. bras. Biol., Rio de Janeiro, 38: 445-454.

FERREIRA, M.J.M., 1979. Sinantropia de Dípteros Muscóideos de Curitiba, Paranā. II. Sarcophagidae. Rev. bras. Biol., Rio de Janeiro, 39(4): 773-781 .

FRANKIE, G.W. e EHLER, L.E., 1978. Ecology of insects in urban environments. A. Rev. Ent., Stanford, 23: 367-387.

GREENBERG, B., 1971. Flies and Diseases vol. I: Ecology classifications and biotic associations. Princeton Univ. Press., Princeton, N.J., 16-54.

GREENBERG, B., 1973. Flies and Disease vol. II: Biology and disease. transmission. Princeton Univ. Press, Princeton, N.J., X+447pp, 54 figs. 
GREGOR, F., 1972. Sinanthropy of Sarcophaginae (Diptera) from Cuba. Folia parasit., Praha, 19: 155-163.

GREGOR, F., 1975. Sinanthropy of Muscidae and Calliphoridae (Diptera) in Cuba. Folia parasit., Praha, 22: 57-71.

GREGOR, F. e D. POVOLNY, 1958. Versuch einer Klassifikation der synantropen Fliegen. J. Hyg. Epidem. Microbio. Immun., Prague, $\underline{2}$ : 205-216.

GUIMARĀES, J.H.; A.P. PRADO e A.X. LINHARES, 1978. Three newly introduced blowfly species in Southern Brazil (Diptera, Calliphoridae). Rev. bras. Ent., São Paulo, 22: 53-60.

GUIMARÃES, J.H.; A.P. PRADO e G.M. BURALLI, 1979. Dispersal and distribution of three newly introduced species of Chrysomya Robineau-Desvoidy in Brazil (Diptera, Calliphoridae). Rev. bras. Ent., São Paulo, 23(4): 245-255.

HAVLIK, B. e B. BATOVA, 1961. A study of the most abundant synanthropic flies in Prague. Acta Soc. Ent. Cechoslov., Praha, 20: 1-11.

IMBIRIBA, A.; D.T. IZUTANI; I.T. MILHORETTO e E. LUZ, 1977. Introdução de Chrysomya chloropyga (Wiedemann, 1818) na região neotropical (Diptera, Calliphoridae). Arq. Biol. Tecnol., Curitiba, 20(1-2): 35-39. 
JAMES, M.T., [1948.] The flies that causes myiasis in man. Misc. Publis. U.S. Dept. Agric., (1947), Washington, 631: 1-175, 98 figs.

JAMES, M.T., 1970. Family Calliphoridae in: A Catalogue of the Diptera of the Americas South of the United States, São Paulo, Museu de Zoologia da Universidade de São Paulo, Fasc. 102, 28pp.

KAWAI, S. e O. SUENAGA, 1960. Studies of the methods of collecting flies. III. On the effect of putrefaction of baits (fish). Endem. Dis. Bull. Nagasaki Univ., Nagasaki, $\underline{2}:$ 61-66.

LINDQUIST, A.W.; W.W. YATES; R.D. HOFFMAN e J.S. BUTTS, 1951. Studies of the flight habits of three species of flies tagged with radioctive phosphorous. J. econ. Ent., New York, 44: 397-400.

LINDSAY, A.W. e H.I.SCUDDER, 1956. Nonbiting flies and diseases. A. Rev. Ent., Stanford, $\underline{1}: 323-346$.

LINHARES, A.X., 1979. Sinantropia de Dípteros Muscóideos de Campinas, Campinas-UNICAMP, . 129pp. (Tese de Mestrado).

MacLEOD, J. e J. DONELLY, 1958. Local distribuition and dispersal paths of blowflies in hill country. J. Anim. Ecol., Cambridge, 27: 349-374. MELLO, R.P., 1961. Contribuição ao estudo do gênero Phaenicia (R.D., 1863) (Diptera, Calliphoridae). Mems. Inst. Oswaldo Cruz, Rio de Janeiro, 60: 263-274.

MIHÁLYI, F., 1965. Rearing flies from faeces and meat infected under natural condition. Acta zool. Hung., Budapest, 11: 153-164. 
MIHALYY, F., 1967a. Seasonal distribuition of the synanthropic flies in Hungary. Ann. hist. nat. Mus. natn. hung., Budapest, 59: 327-344.

MIHĀLYI, F., 1967c. Separating the rural and urban synanthropic fly faunas. Acta zool. Hung., Budapest, 13: 379-383.

NORRIS, K.R., 1965. The bionomics of blowflies. A. Rev. Ent., Stanford, 10: $47-68$.

NUORTEVA, P., 1958. Some peculiarities of the seasonal occurrence of polı́lomyelitis in Finland. Annls. Med. exp. Biol. Fenn., Helsinki, 36: 335-342.

NUORTEVA, P., 1959. Studies on the significance of flies in the transmission of poliomyelitis. I. The occurrence of the Lucilia species (Dipt., Calliphoridae) in relation to the occurrence of poliomyelitis in Finland. Annls. ent. Fenn., Helsinki, 25: 1-24.

NUORTEVA, P., 1959b. Studies on the significance of flies in the transmission of poliomyelitis. II. The composition of the annual blowflies population as compared with the incidence of poliomyelitis in England during the years 1949-1952. Annls. ent. Fenn., Helsinki, 25: 25-27.

NUORTEVA, P., 1959c. Studies on the significance of flies in the transmission of poliomyelitis. III. The composition of the blowfly fauna and activity of the flies in relation to the weather during the epidemic season of poliomyelitis in South Finland. Annls. ent. Fenn., Helsinki, 25: $121-136$ 
NUORTEVA, P., 1959d. Studies of the significance of flies in the transmission of poliomyelitis. IV. The composition of the blowfly fauna in different parts of Finland during the year 1958. Annls. ent. Fenn., Helsinki, 25: 137-162.

NUORTEVA, P., 1960. Studies of the significance of flies in the transmission of poliomyelitis. VI. On the influence of icosaconic climatic flutuation on the incidence of poliomyelitis and the occurrence of Lucilia species in Finland. Annls. ent. Fenn., Helsinki, 29: 1-40.

NUORTEVA, P., 1963. Synanthropy of blowflies (Dipt., Calliphoridae) in Finland. Annls. ent. Fenn., Helsinki, 29: 1-49.

NUORTEVA, P., 1966. Local distribuition of blowflies in relation to human settlement in an area around the town of Forsa in South Finland. Annls. ent. Fenn., Helsinki, 32: 218-137.

NUORTEVA, P., 1971. The synanthropy of birds as an expression of the ecological cycle disorder caused by urbanization. Ann. zool. Fenn., Helsinki, 8: 547-553.

NUORTEVA, P. e E. LAURIKAINEN, 1964. Synanthropy of blowflies (Dipt., Calliphoridae) on the island of Gotland, Sweden. Annls. ent. Fenn., Helsinki, 30: 187-190.

NUORTEVA, P. e T. RÄSÄNEN, 1968. The occurrence of blowflies (Dipt., Calliphoridae) in the archipelago of the lake Kallavesi, central Finland. Ann. zool. Fenn., Helsinki, 5: 188-193. 
NUORTEVA, P. e U. SKAREN, 1960. Studies on the significance of flies in the transmission of poliomyelitis. V. Observations on the attraction of blowflies to the carcasse of micro-mammals in the commune of Kuhmo, East Finland. Annls. ent. Fenn., Helsinki, 26: 221-226.

NUORTEVA, P. e T. VESIKARI, 1966. The synanthropy of blowflies (Dipt., Calliphoridae) on the coast of the Arctic Ocean. Annls. Med. exp. Fenn., Helsinki, 44: 544-548.

ORI, S.; T. SHIMOGAMA e Y. TAKATSUKI, 1960. Studies of the methods of collecting flies. IV. On the effect of colored cage traps. Endem. Dis. Bull. Nagasaki Univ., Nagasaki, 2: 229-235.

PETERS, H., 1960. Uber den Begriff der Synanthropie. Z. angew Zool., Berlin, 47: 35-42.

POVOLNÝ, D., 1959. Gesichtspunkte der Klassifikation von synanthropen Fliegen. Internationales Symposion uber schadliche Fliegen. 324-328.

QUARTERMAN, K.D.; W.C. BAKER e J.A. JENSEN, 1949. The importance of sanitation in municipal fly control. J. trop. Med. Hyg., London, 29 : 973-982.

QUARTERMAN, K.D.; W. MATHIS e J.W. KILPATRICK, 1954a. Urban fly dispersal in the area of Savannah, Georgia. J. econ. Ent., New York, 47: 405412. 
QUARTERMAN, K.D.; W. MATHIS e J.W. KILPATRICK, 1954b. Fly dispersal in a rural area near Savannah, Georgia. J. econ. Ent., New York, 47: 413419.

RIZZO, J.A.; G.M. BARROSO; A.J. CENTENO; J.S. LOUSA E T.S. FILGUEIRAS, 1972. Levantamento de dadós em ārea de Cerrado e de Floresta Caducifó lia Tropical do Planalto Centro-Oeste - Parte II. XXIII Cong. Nac. Bo tânica, Garanhuns, 16-23.

SAILER, R.I., 1978. Our Immigrant Insect Fauna. Bull. ent. Soc. Am., Washington, 24(1): 3-11.

SAVAGE, E.P. e H.F. SCHOOF, 1955. The species composition of fly populations at several types of problems sites in urban areas. Ann. ent. Soc. Am., Columbus, 48: 251-257.

SCHOOF, H.F. E E.P. SAVAGE, 1955. Comparative studies of urban fly population in Arizona, Kansas, Michigan, New York, and West Virginia. Ann. ent. Soc. Am., Columbus, 48: 1-12.

SCHOOF, H.F.; E.P. SAVAGE e H.R. DODGE, 1956. Comparative studies of urban fly populations in Arizona, Kansas, Michigan, New York and West Virginia. II. Seasonal abundance of minor species. Ann. ent. Soc. Am., Columbus, 49: $59-66$.

SCHOOF, H.F.,; R.E. SIVERLY e J.A. JENSEN, 1952. House fly dispersion studies in metropolitan areas. J. econ. Ent., New York, 45: 675-683. 
SCHOOF, H.F. e G.A. MAIL, 1953. Dispersal habits of Phormia regina in Charleston, West Virginia. J. econ. Ent., New York, 46: 258-262.

SCHOOF, H.F.; G.A. MAIL e E.P. SAVAGE, 1954. Fly production sources in urban communities. J. econ. Ent., New York, 47: 245-253.

SIVERLY, R.E. e H.F. SCHOOF, 1955a. Utilization of various production media by muscoid flies in a metropolitan area. I. Adaptability of different flies for infestation of prevalent media. Ann. ent. Soc. Am., Columbus, 48: 258-262.

SIVERLY, R.E. e H.F. SCHOOF, 1955b. Utilization of various production media by muscoid flies in a metropolitan area. II. Seasonal influence by population. Ann. ent. Soc. Am., Columbus, 48: 320-324.

SIVERLY, R.E. e H.F. SCHOOF, 1955c. Utilization of various production media by muscoid flies in metropolitan area. III. Fly productions in relation to city block environment. Ann. ent. Soc. Am., Columbus, 48: $325-329$.

STEWART, M.A. E E.B. ROESLER, 1942. The seasonal distribuition of myiasis producing Diptera. J. econ. Ent., New York, 35: 408-411.

TRASK, J.D.; J.R. PAUL e J.L. MELNICK, 1943. The detection of poliomyelitis virus in flies collected during epidemics of poliomyelitis. I. Methods results and types of flies envolved. J. exp. Med., New York, 77: $531-544$. 
WILLIAMS, R.W., 1954. A study of the filth flies in New York city. J. econ. Ent., New York, 47: 556-563.

WILTON, D.P., 1961. Refuse containers as a source of flies in Honolulu and nearby comunities. Proc. Hawaii. ent. Soc., Honolulu, 17: 477481 .

ZUMPT, F., 1965. Myiasis in man and animals in the 01d World. Butterworths (London), $267 \mathrm{pp}$. 


\section{8 - APÊNDICES}


APÊNDICE I - Condições meteorológicas de Goiânia, durante os anos de 1960 a 1979.

\begin{tabular}{|c|c|c|c|c|c|}
\hline \multirow{3}{*}{ ANO } & \multicolumn{3}{|c|}{ Temperatura Ar $\left({ }^{\circ} \mathrm{C}\right)$} & \multirow{3}{*}{$\begin{array}{l}\text { U.R. } \\
(\%) \\
\text { Média }\end{array}$} & \multirow{3}{*}{$\begin{array}{l}\text { Precipitação } \\
(\mathrm{mm}) \\
(\text { altura total) }\end{array}$} \\
\hline & Média & Média & Média & & \\
\hline & Compens ada & . Máxima & Mínima & & \\
\hline 1960 & 24,0 & 29,1 & 16,8 & 68 & $1.364,0$ \\
\hline 1961 & 23,0 & 30,0 & 16,9 & 65 & $1.400,0$ \\
\hline 1962 & 22,4 & 29,3 & 16,2 & 69 & $1.451,6$ \\
\hline 1963 & 24,2 & 30,7 & 16,2 & 61 & $1.073,9$ \\
\hline 1964 & 22,2 & 28,2 & 17,0 & 71 & $1.621,5$ \\
\hline 1965 & 23,0 & 29,8 & 17,4 & 70 & $1.718,0$ \\
\hline 1966 & 22,9 & 29,7 & 17,2 & 68 & $1.611,2$ \\
\hline 1967 & 22,9 & 30,0 & 17,4 & 66 & $1.403,5$ \\
\hline 1968 & 22,3 & 29,8 & 16,9 & 66 & $1.848,1$ \\
\hline 1969 & 23,4 & 30,2 & 17,6 & 64 & $1.699,4$ \\
\hline 1970 & 23,2 & 29,5 & 17,9 & 66 & $1.613,4$ \\
\hline 1971 & 22,8 & 29,3 & 17,4 & 66 & $1.757,6$ \\
\hline 1972 & 23,1 & 29,7 & 17,8 & 66 & $1.706,5$ \\
\hline 1973 & 23,8 & 30,4 & 18,4 & 64 & $1.667,2$ \\
\hline 1974 & 23,1 & 29,7 & 21,2 & 64 & $1.303,7$ \\
\hline 1975 & 23,2 & 29,7 & 17,9 & 64 & $1.443,0$ \\
\hline 1976 & 22,9 & 29,3 & 17,8 & 66 & $1.812,5$ \\
\hline 1977 & 23,7 . & 30,0 & 18,5 & 66 & $1.394,4$ \\
\hline 1978 & 23,3 & 29,4 & 18,0 & 68 & $1.481,7$ \\
\hline 1979 & 23,2 & 29,1 & 18,3 & 69 & $1.660,2$ \\
\hline
\end{tabular}

Dados fornecidos pelo Ministério da Agricultura - Estação Climatológica principal de Goiânia, Estado de Goiás. 
APENDICE II - Condições meteorológicas de Goiânia, durante o período de jạ neiro de 1975 a setembro de 1976 .

\begin{tabular}{|c|c|c|c|c|c|}
\hline \multirow{3}{*}{ MESES } & \multicolumn{3}{|c|}{ Temperatura Ar $\left({ }^{\circ} \mathrm{C}\right)$} & \multirow{3}{*}{$\begin{array}{c}\text { U.R. } \\
(\%) \\
\text { Média }\end{array}$} & \multirow{3}{*}{$\begin{array}{c}\text { Precipitação } \\
\text { (mm) } \\
\text { (altura total) }\end{array}$} \\
\hline & Média & Média & Média & & \\
\hline & Compensada & Máxima & , Mínima & & \\
\hline janeiro & 23,7 & 29,9 & 19,4 & 74 & 202,9 \\
\hline fevereiro & 24,1 & 29,7 & 20,1 & 78 & 217,3 \\
\hline março & 24,2 & 30,7 & 19,5 & 72 & 135,6 \\
\hline abril & 23,3 & 29,2 & 18,7 & 72 & 182,8 \\
\hline maio & 21,6 & 28,5 & 15,9 & 64 & 17,7 \\
\hline junho & 20,9 & 28,5 & 14,4 & 56 & 1,3 \\
\hline julho & 19,8 & 27,5 & 12,6 & 52 & 15,3 \\
\hline agosto & 23,5 & 31,3 & 15,9 & 38 & 0,0 \\
\hline setembro & 25,5 & 32,2 & 19,2 & 40 & 53,3 \\
\hline outubro & 23,9 & 30,0 & 19,4 & 66 & 161,4 \\
\hline ñovembro & 23,5 & 28,7 & 20,0 & 77 & 249,1 \\
\hline dezembro & 23,9 & 29,8 & 19,5 & 72 & 206,3 \\
\hline janeiro & 24,2 & 30,3 & 19,7 & 52 & 149,0 \\
\hline fevereiro & 23,7 & 28,6 & 19,9 & 76 & 158,1 \\
\hline março & 23,5 & 29,7 & 19,2 & 76 & 295,2 \\
\hline abril & 23,6 & 30,0 & 18,1 & 68 & 143,7 \\
\hline maio · & 22,0 & 28,6 & 16,3 & 70 & 113,2 \\
\hline junho & 20,8 & 28,8 & 13,4 & 59 & 16,0 \\
\hline julho & 20,8 & 29,0 & 13,7 & 53 & 3,2 \\
\hline agosto & 23,0 & 30,8 & 16,1 & 49 & 5,5 \\
\hline setembro & 22,8 & 29,0 & 17,4 & 1 & 148,3 \\
\hline
\end{tabular}

Dados fornecidos pelo Ministério da Agricultura - Estação Climatológica principal de Goiânia, Estado de Goiās. 
APÊNDICE III - Condições meteorológicas de Goiânia, durante o período de janeiro de 1978 a julho de 1979 .

\begin{tabular}{|c|c|c|c|c|c|}
\hline \multirow{3}{*}{ MESES } & \multicolumn{3}{|c|}{ Temperatura Ar (OC) } & \multirow{3}{*}{$\begin{array}{c}\text { U.R. } \\
(\%) \\
\text { Média }\end{array}$} & \multirow{3}{*}{$\begin{array}{l}\text { Precipitação } \\
\text { (mm) } \\
\text { (altura total) }\end{array}$} \\
\hline & Média & Média & Média & & \\
\hline & Compens ada & Māxima & Mínima & & \\
\hline janeiro & 24,4 & 29,2 & 20,2 & 75 & 275,3 \\
\hline fevereiro & 24,1 & 29,6 & 20,3 & 78 & 287,1 \\
\hline março & 23,9 & 29,3 & 19,4 & 76 & 221,7 \\
\hline abril & 23,4 & 29,0 & 18,9 & 84 & 125,8 \\
\hline maio & 22,2 & 28,7 & 16,4 & 69 & 45,1 \\
\hline junho & 21,0 & 27,6 & 24,3 & 64 & 0,2 \\
\hline julho & 21,8 & 28,6 & 15,0 & 62 & 25,5 \\
\hline agosto & 22,3 & 29,7 & 14,6 & 50 & 185,0 \\
\hline setembro & 24,1 & 30,9 & 18,4 & 53 & 20,2 \\
\hline outubro & 25,0 & 31,2 & 20,1 & 63 & 78,0 \\
\hline novembro & 23,8 & 28,8 & 20,2 & 82 & 148,2 \\
\hline dezembro & 23,3 & 28,4 & 19,9 & 80 & 218,8 \\
\hline janeiro & 23,4 & 28,4 & 20,5 & 83 & 418,0 \\
\hline fevereiro & 23,7 & 28,7 & 20,2 & 78 & 291,0 \\
\hline março & 24,0 & 30,1 & 19,7 & 75 & 218,4 \\
\hline abril & 23,2 & 29,6 & 18,4 & 72 & 54,7 \\
\hline maio & 22,2 & 28,9 & 16,7 & 67 & 80,8 \\
\hline junho & 20,2 & 27,5 & 13,1 & 60 & 0,0 \\
\hline julho & 20,9 & 28,6 & 14,1 & 61 & 40,3 \\
\hline
\end{tabular}

Dados fornecidos pelo Ministério da Agricultura - Estação Climatológica principal de Goiânia, Estado de Goiās. 
APÊNDICE IV - Condições meteorológicas diärias, de todo período de coleta (agosto de 1975 a julho de 1976, e julho e dezembro de 1978, e janeiro-fevereiro de 1979) em Goiânia - Goiās.

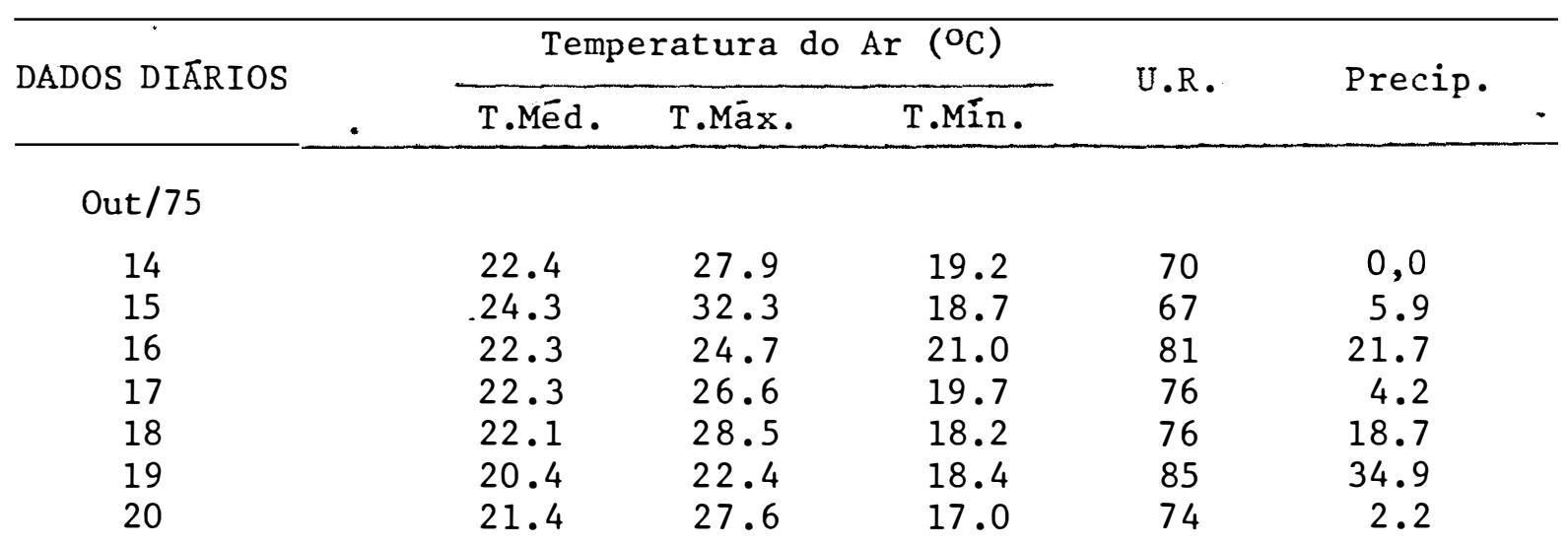

Nov/75

$\begin{array}{rrrrrr}12 & 24.0 & 30.9 & 19.2 & 71 & 0.8 \\ 13 & 24.7 & 30.9 & 20.2 & 69 & 2.7 \\ 14 & 24.2 & 29.0 & 20.7 & 72 & 1.8 \\ 15 & 23.6 & 27.2 & 20.4 & 74 & 0.0 \\ 16 & 23.1 & 30.3 & 19.5 & 74 & 24.5 \\ 17 & 23.0 & 28.6 & 19.4 & 74 & 4.5 \\ 18 & 24.1 & 29.4 & 20.4 & 75 & 0.7\end{array}$

Dez/75

13

14

15

16

17

18

19
24.5

22.6

19.8

21.0

21.9

23.4

23.8
30.5

29.5

22.8

24.4

24.7

27.9

29.5
20.4

19.9

18.2

17.6

19.2

18.6

19.8
2.7

1.8

0.0

.

0.7 
Continuação ...

\begin{tabular}{cccccc}
\hline \multirow{2}{*}{ DADOS DIĒRIOS } & \multicolumn{3}{c}{ Temperatura Ar $\left({ }^{\circ} \mathrm{C}\right)$} & U.R. & Precip. \\
\cline { 2 - 3 } & & & & & \\
\hline \multirow{2}{*}{ T.Méd. } & & & & & \\
15 & 23.6 & 28.8 & $21: 2$ & 68 & 0.0 \\
16 & 23.5 & 31.6 & 17.2 & 57 & 0.0 \\
17 & 24.3 & 30.7 & 19.2 & 74 & 0.1 \\
18 & 26.5 & 33.0 & 19.1 & 64 & 0.0 \\
19 & 25.3 & 31.6 & 20.2 & 65 & 0.0 \\
20 & 26.4 & 33.6 & 20.8 & 59 & 0.5 \\
21 & 23.7 & 29.5 & 21.2 & 70 & 0.2
\end{tabular}

Fev/76

$\begin{array}{rrrrrr}25 & 22.9 & 26.8 & 19.2 & 82 & 6.2 \\ 26 & 21.3 & 25.0 & 18.2 & 84 & 0.8 \\ 27 & 21.8 & 25.8 & 19.2 & 80 & 6.5 \\ 28 & 21.2 & 25.4 & 19.2 & 85 & 32.4 \\ 29 & 21.6 & 27.2 & 19.1 & 80 & 50.9\end{array}$

Mar/76

$\begin{array}{rrrrrr}15 & 24.0 & 29.4 & 20.2 & 79 & 26.2 \\ 16 & 25.0 & 31.2 & 19.7 & 67 & 0.0 \\ 17 & 24.2 & 29.5 & 20.2 & 78 & 0.0 \\ 18 & 25.1 & 32.0 & 20.1 & 71 & 0.0 \\ 19 & 24.7 & 31.8 & 19.8 & 65 & 0.0 \\ 20 & 23.2 & 30.0 & 19.2 & 72 & 4.3 \\ 21 & 24.3 & 30.3 & 19.8 & 72 & 4.0\end{array}$

$\mathrm{Abr} / 76$

$\begin{array}{rrrrrr}07 & 24.4 & 31.2 & 18.6 & 66 & 0.0 \\ 08 & 23.4 & 31.5 & 19.2 & 69 & 0.0 \\ 09 & 21.3 & 26.0 & 19.1 & 87 & 0.0 \\ 10 & 23.0 & 29.0 & 19.2 & 76 & 77.6 \\ 11 & 24.5 & 30.5 & 19.5 & 69 & 1.5 \\ 12 & 22.9 & 29.4 & 19.7 & 91 & 0.0 \\ 13 & 22.7 & 29.9 & 20.2 & 79 & 1.0\end{array}$


Continuação ...

\begin{tabular}{|c|c|c|c|c|}
\hline \multirow[t]{2}{*}{ DADOS DIĀRIOS } & \multicolumn{2}{|c|}{ Temperatura $\operatorname{Ar}\left({ }^{\circ} \mathrm{C}\right)$} & \multirow{2}{*}{ U.R. } & \multirow{2}{*}{ Precip. } \\
\hline & T.Max. & T.Mín. & & \\
\hline
\end{tabular}

$\mathrm{Mai} / 76$.

$\begin{array}{rrrrrr}14 & 21.3 & 27.0 & 15.7 & 58 & 0.0 \\ 15 & 20.6 & 27.9 & 16.2 & 76 & 0.0 \\ 16 & 22.0 & 28.7 & 15.6 & 66 & 13.5 \\ 17 & 21.9 & 29.6 & 15.2 & 64 & 0.0 \\ 18 & 22.6 & 30.6 & 15.2 & 61 & 0.0 \\ 19 & 21.6 & 30.8 & 15.8 & 67 & 0.0 \\ 20 & 22.1 & 27.6 & 18.2 & 75 & 20.0\end{array}$

Jun/76

$\begin{array}{llllll}10 & 21.0 & 29.2 & 14.2 & 57 & 0.0 \\ 11 & 20.2 & 28.2 & 13.2 & 64 & 0.0 \\ 12 & 20.4 & 27.9 & 13.2 & 65 & 0.0 \\ 13 & 21.0 & 28.5 & 14.8 & 64 & 0.0 \\ 14 & 21.4 & 28.2 & 13.8 & 64 & 0.0 \\ 15 & 20.7 & 29.1 & 13.4 & 66 & 0.0 \\ 16 & 21.0 & 30.2 & 13.6 & 63 & 0.0 \\ 17 & 22.8 & 30.4 & 19.1 & 56 & 0.0\end{array}$

Jul/ 76

01

02

03

04

05

06

07

08
20.9

21.2

19.3

19.0

18.3

18.0

18.4

20.0
28.0

27.0

26.4

26.0

27.0

27.8

29.8

31.2
15.0

16.2

14.4

13.4

10.7

10.2

9.2

10.7
62

61

69

59

54

53

53

47
0.0

0.8

1.2

0.0

0.0

0.0

0.0

0.0 
Continuação ...

\begin{tabular}{|c|c|c|c|c|c|}
\hline \multirow{2}{*}{ DADOS DIARRIOS } & \multicolumn{3}{|c|}{ Temperatura $\operatorname{Ar}\left({ }^{\circ} \mathrm{C}\right)$} & \multirow{2}{*}{$\mathrm{U} \cdot \mathrm{R} \cdot$} & \multirow{2}{*}{ Preci } \\
\hline & T.Méd. & T.Māx. & T.Mín. & & \\
\hline $\mathrm{Ju} 1 / 78$ & & & & - & \\
\hline $\begin{array}{l}13 \\
14 \\
15 \\
16 \\
17 \\
18 \\
19\end{array}$ & $\begin{array}{l}20.9 \\
20.5 \\
21.1 \\
19.8 \\
21.6 \\
20.0 \\
21.4\end{array}$ & $\begin{array}{l}29.6 \\
29.4 \\
30.0 \\
24.4 \\
30.6 \\
23.2 \\
28.8\end{array}$ & $\begin{array}{l}11.2 \\
10.7 \\
11.2 \\
17.2 \\
13.4 \\
15.8 \\
14.7\end{array}$ & $\begin{array}{l}55 \\
57 \\
56 \\
75 \\
62 \\
72 \\
65\end{array}$ & $\begin{array}{l}0.0 \\
0.0 \\
0.0 \\
0.4 \\
0.6 \\
0.2 \\
8.0\end{array}$ \\
\hline
\end{tabular}

Dez/78

12

13

14

15

16

17

18
23.5

22.5

23.7

23.5

22.9

22.4

24.3
26.6

28.0

28.4

28.2

28.0

26.4

30.0
19.3

19.6

20.2

21.7

20.0

20.6

20.0
74

79

86

84

88

89

70
16.2

14.4

5.6

0.8

1.9

13.7

6.8

$\mathrm{Jan} / 79$

22

23

24

25

26

27

28
24.2

24.2

24.6

22.7

23.2

22.8

22.6
29.6

29.6

29.6

27.8

29.8

27.4

25.8
20.6

21.2

20.8

21.2

20.2

20.2

20.2
75

77

75

87

77

79

86
0.0

0.0

7.8

0.0

41.9

9.0

9.2

(continua) 
Continuação ...

\begin{tabular}{|c|c|c|c|c|c|}
\hline \multirow{2}{*}{ DADOS DIARIOS } & \multicolumn{3}{|c|}{ Temperatura Ar $(\mathrm{OC})$} & \multirow{2}{*}{ U.R. } & \multirow{2}{*}{ Precip. } \\
\hline & T.Méd. & T.Māx. & T.Mín. & & \\
\hline
\end{tabular}

Fev/79
06
07
08
09
10
11
12

$\begin{array}{rrrrr}22.7 & 28.4 & 19.2 & 78 & 6.3 \\ 23.8 & 27.8 & 21.2 & 83 & 0.4 \\ 24.2 & 31.4 & 20.2 & 77 & 2.0 \\ 24.5 & 29.0 & 20.2 & 72 & 18.7 \\ 24.3 & 30.0 & 21.2 & 75 & 0.0 \\ 24.1 & 28.0 & 21.0 & 88 & 14.7 \\ 24.6 & 31.2 & 20.2 & 71 & 0.0\end{array}$




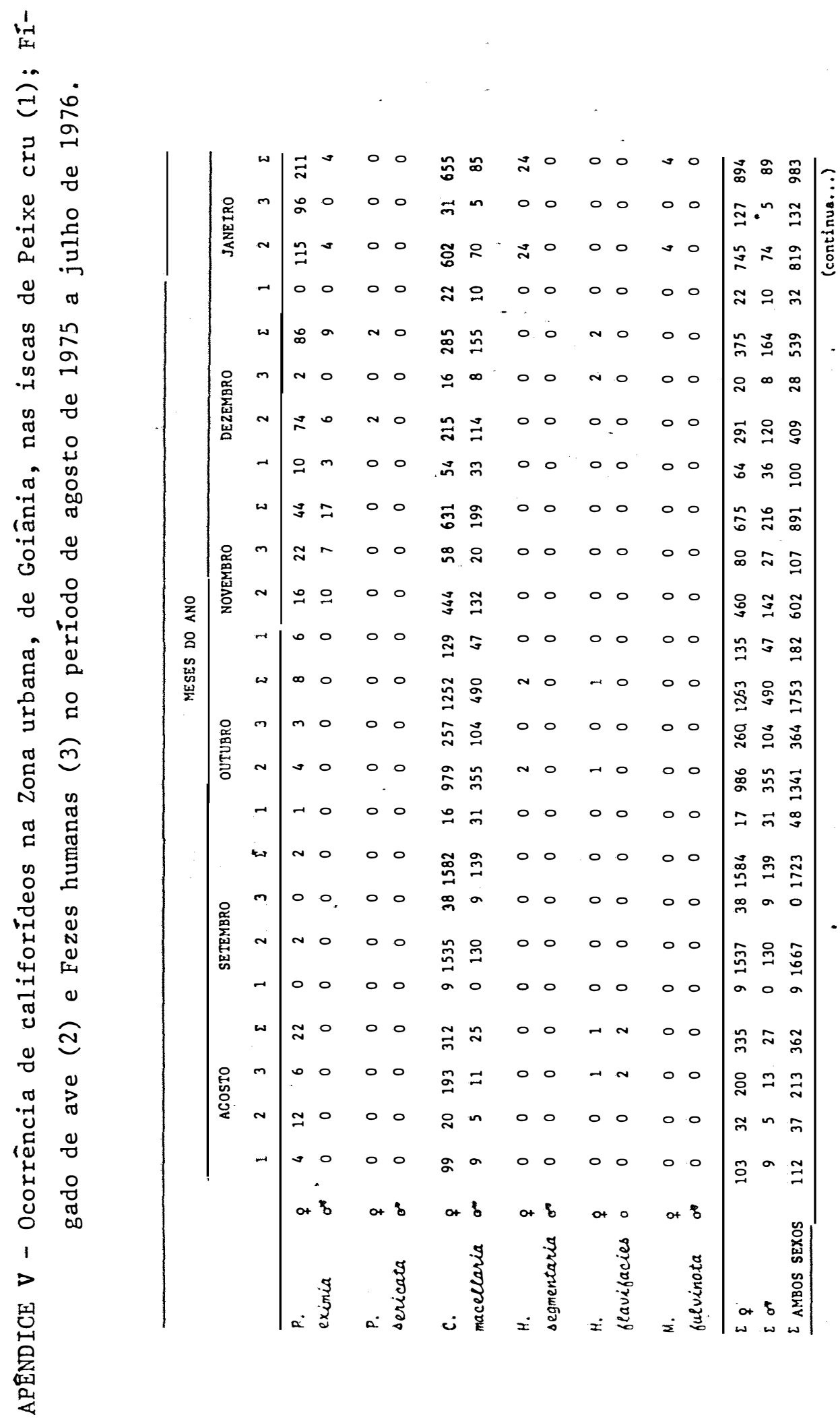




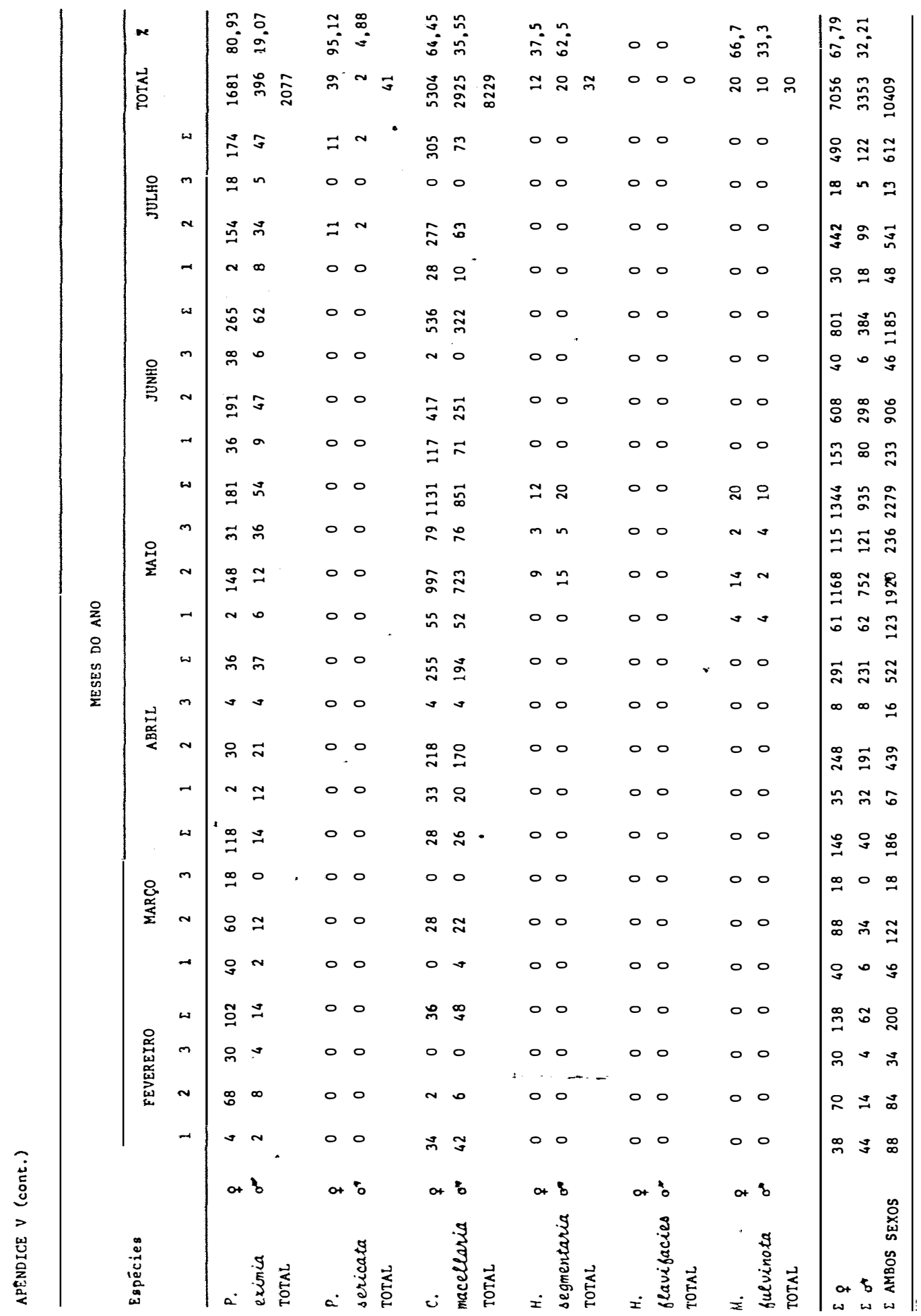




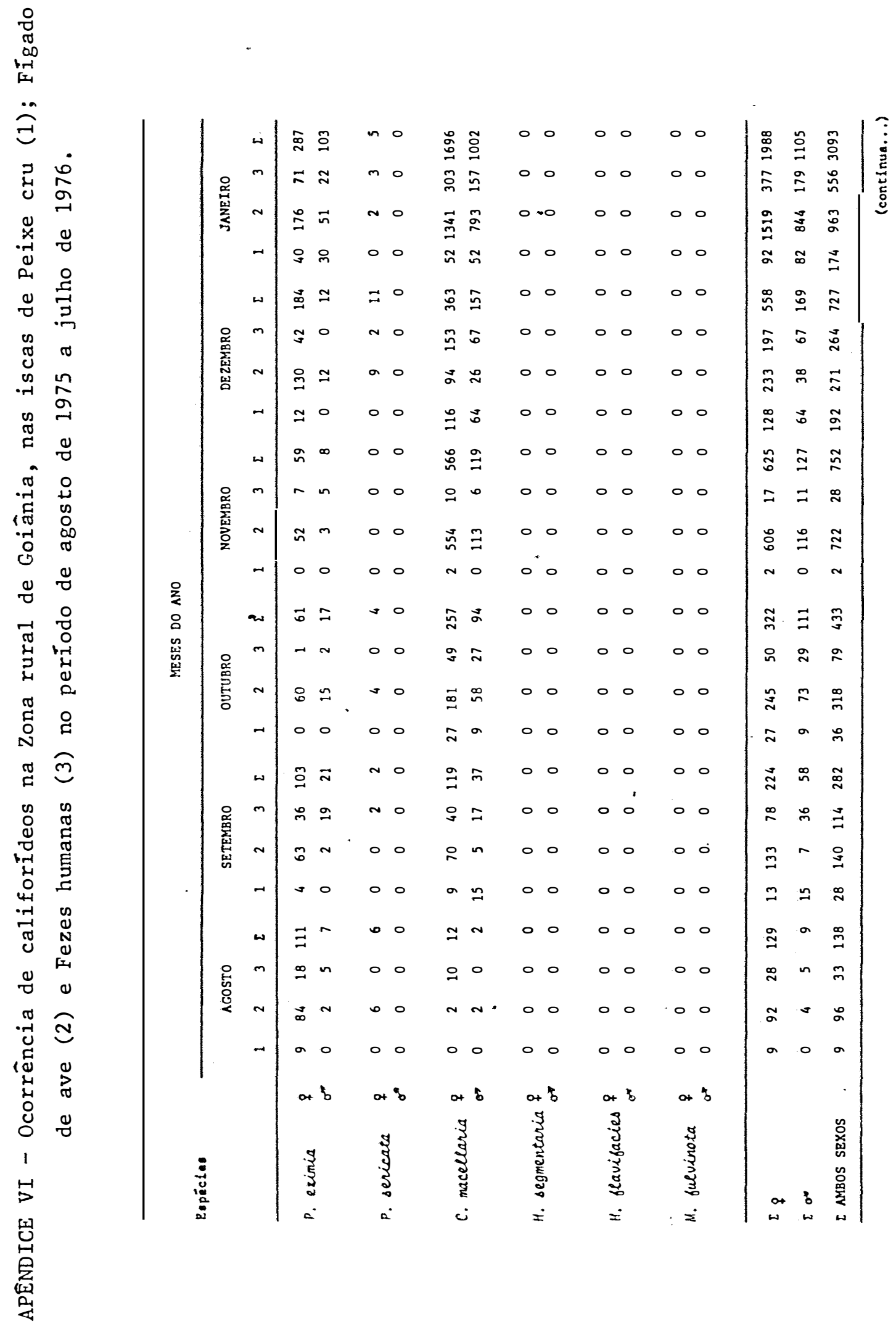




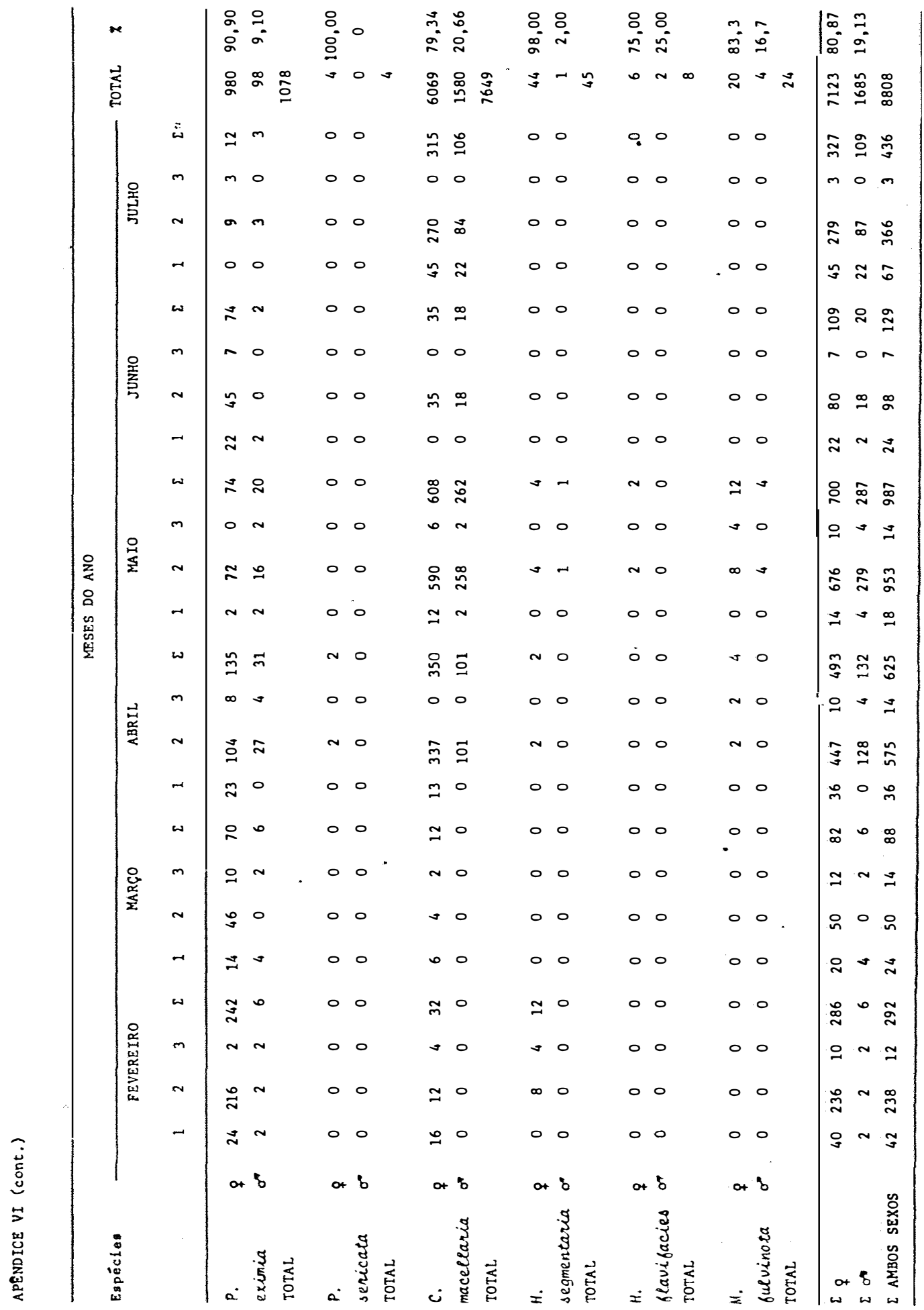




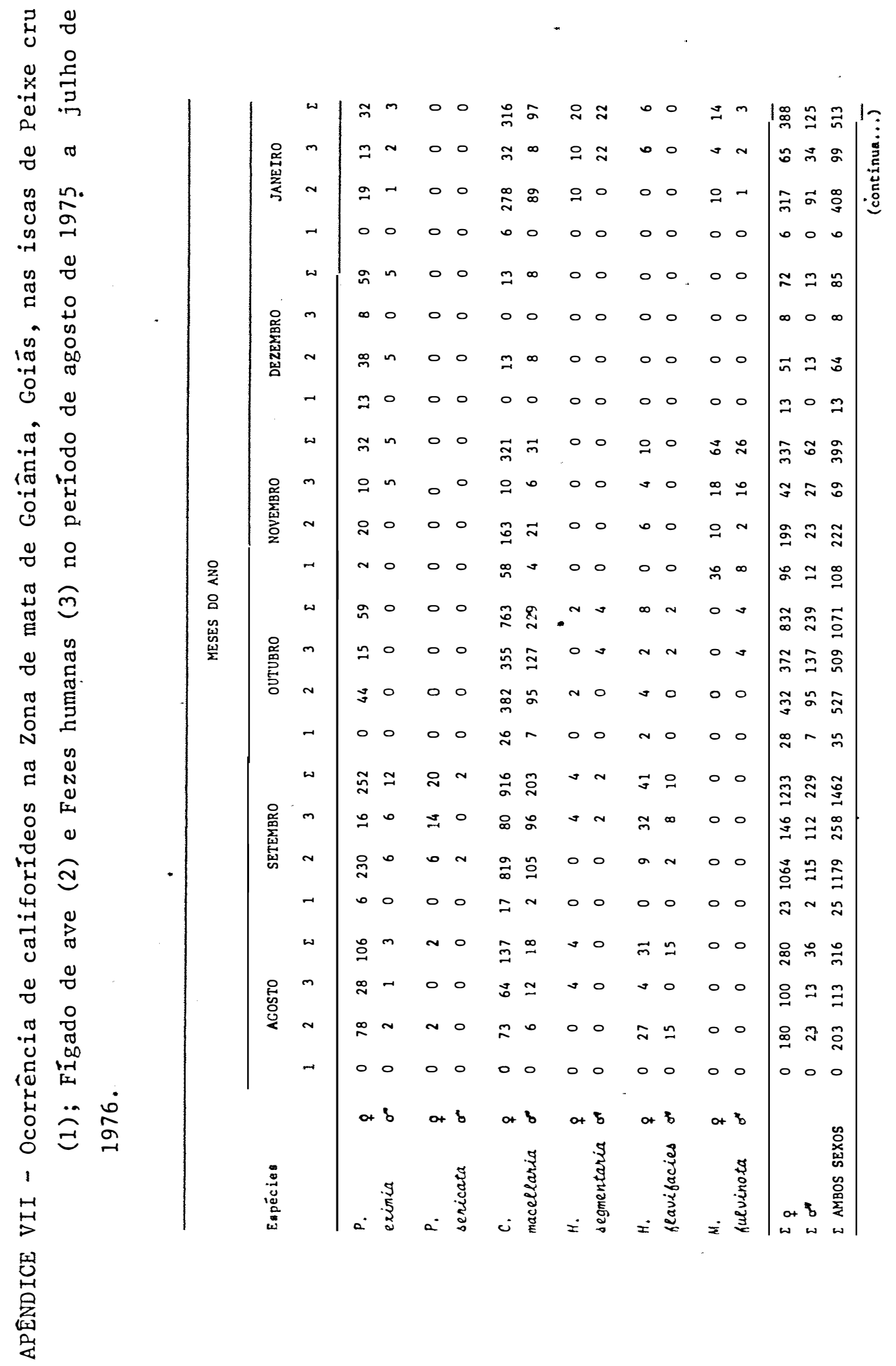




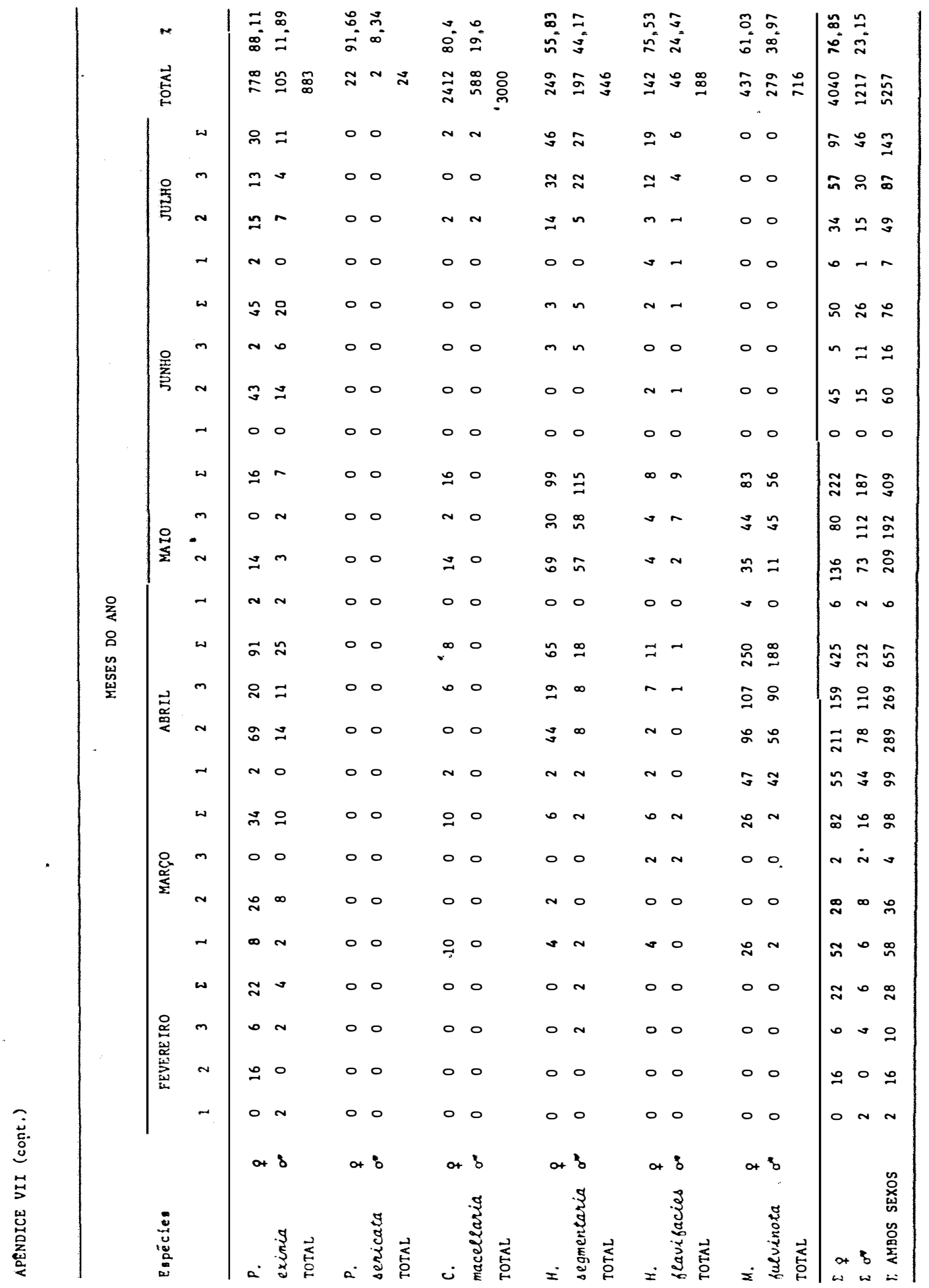




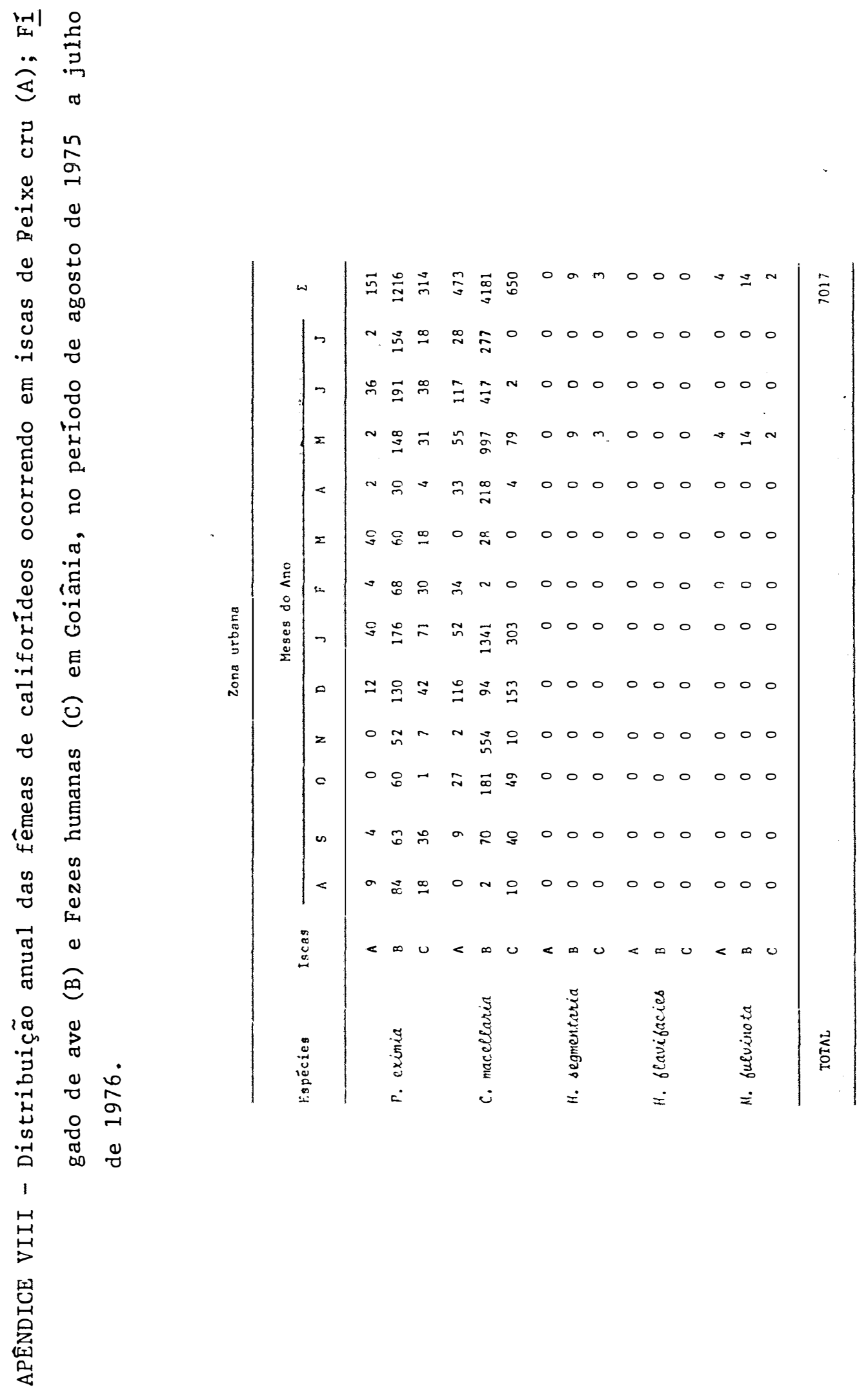




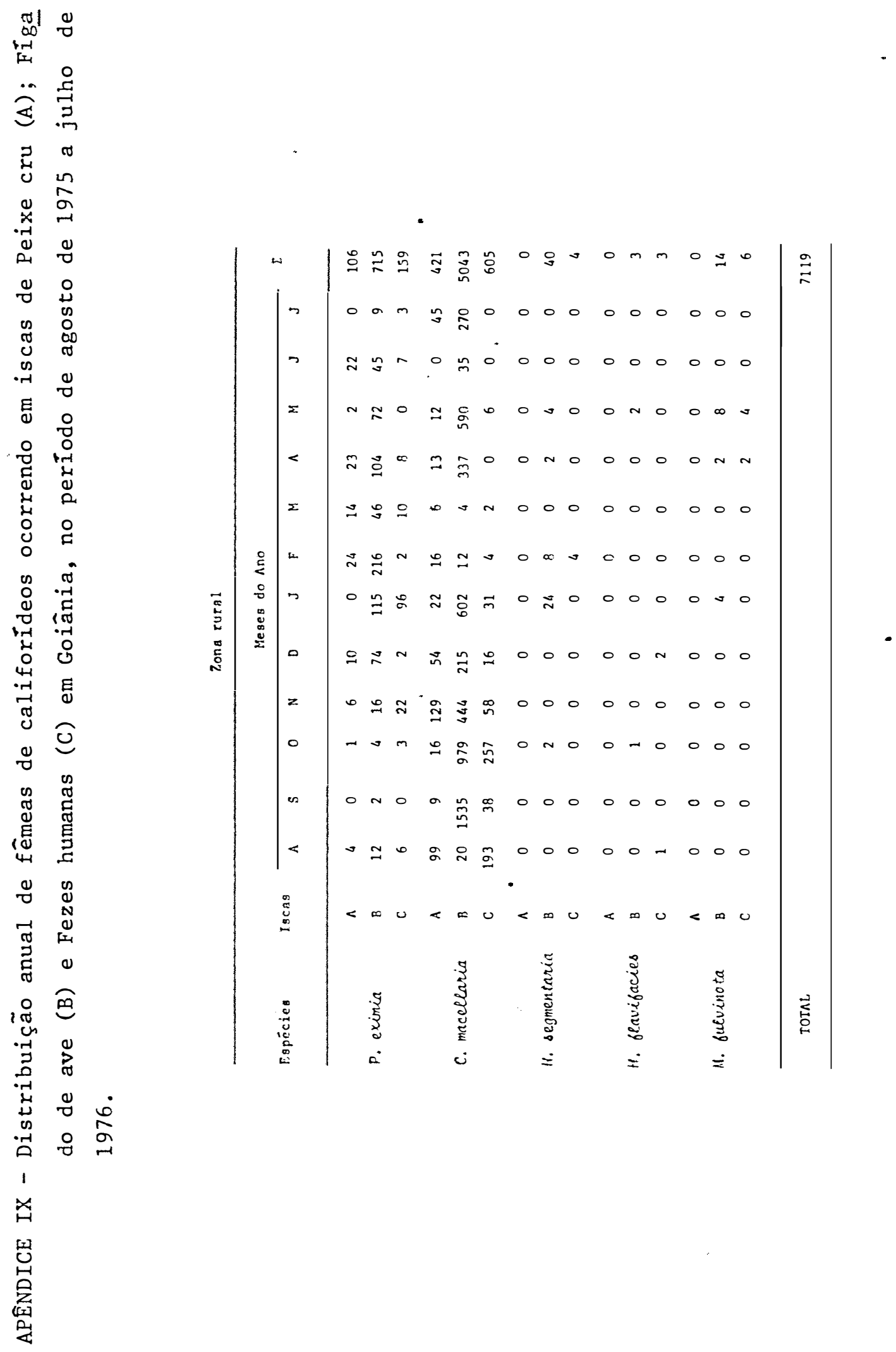




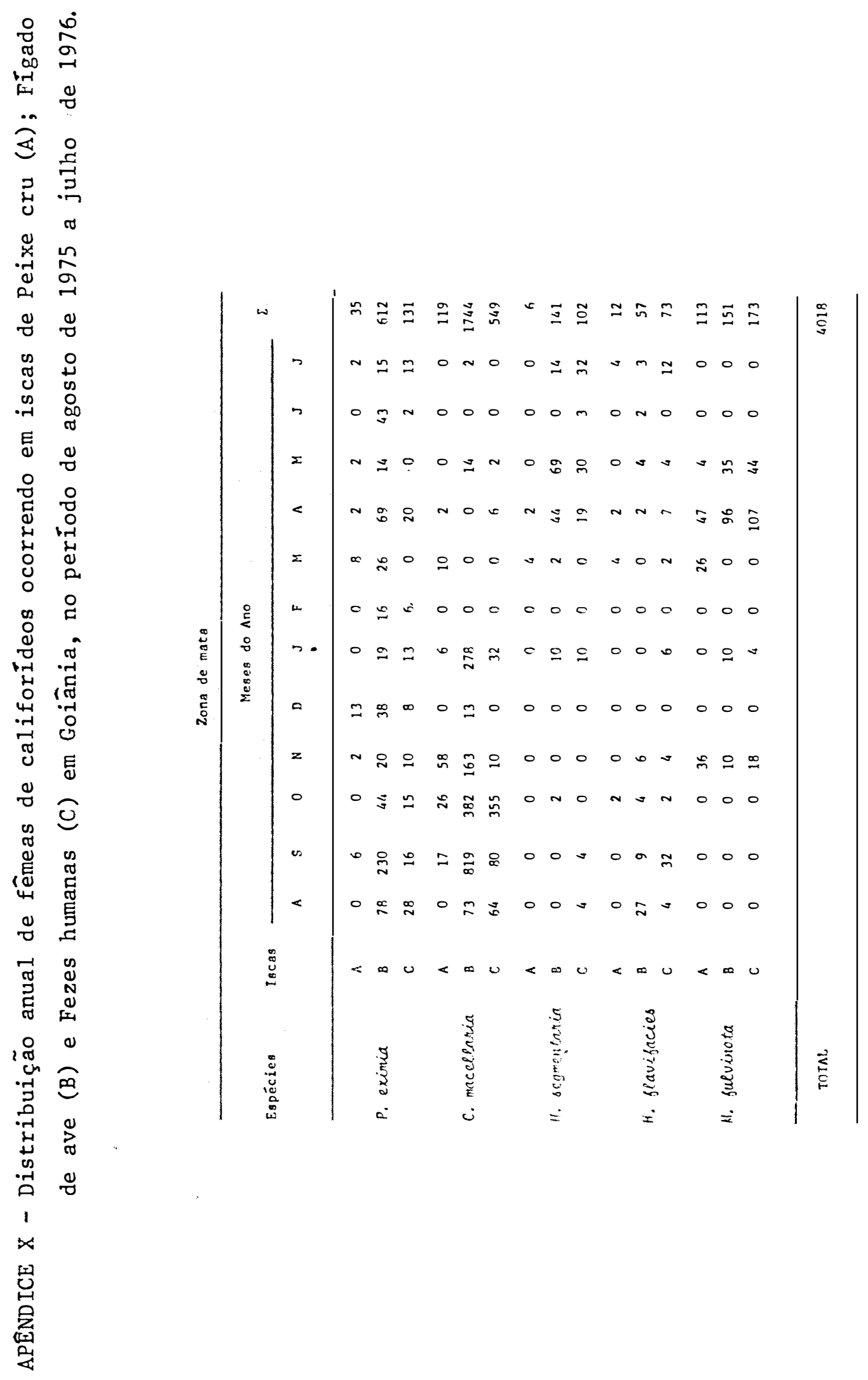


APENDICE XI - Indice de Sinantropia de califorídeos coletados em Goiânia no período de agosto de 1975 a julho de 1976.

\begin{tabular}{|c|c|c|c|c|c|c|c|c|}
\hline \multirow{3}{*}{ Espécies } & \multicolumn{7}{|c|}{ Areas de Coleta } & \multirow{3}{*}{ I.S. } \\
\hline & Zona & & Zona & & Zona & & & \\
\hline & urbana & $\%$ & rural & $\%$ & mata & $\%$ & Total & \\
\hline P. eximia & 2077 & 51,44 & 1078 & 26,70 & 883 & 21,86 & 4038 & +42.93 \\
\hline P. sericata & 41 & 59,42 & 4 & 5,80 & 24 & 34,78 & 69 & +27.64 \\
\hline c. macellaria & 8229 & $4,, 59$ & 7649 & 40,52 & 3000 & 15,89 & 18878 & +47.96 \\
\hline H. segmentaria & 32 & 6,12 & 45 & 8,60 & 446 & 85,28 & 523 & -83.46 \\
\hline H. flavifacies & 0 & 0 & 8 & 4,08 & 188 & 95,92 & 196 & -93.88 \\
\hline M. fulvinota & 30 & 3,90 & 24 & 3,12 & 716 & 92,98 & 770 & -87.53 \\
\hline TOTAL & 10409 & & 8808 & & 5257 & & 24474 & \\
\hline
\end{tabular}


APENDICE XII - Frequência (\%) de califorídeos em iscas de peixe, fígado e fezes, coletados nas zonas urbana, rural e de mata, em Goiâa nia, no período de agosto de 1975 a julho de 1976.

\begin{tabular}{|c|c|c|c|c|c|c|}
\hline \multirow{3}{*}{$\begin{array}{l}\text { Espécies } \\
\text { - Iscas - }\end{array}$} & \multicolumn{6}{|c|}{ Locais de Coleta } \\
\hline & \multicolumn{2}{|c|}{ 2. urbana } & \multicolumn{2}{|c|}{ 2. rural } & \multicolumn{2}{|c|}{ 2. mata } \\
\hline & Total & $\%$ & Total & $\%$ & Total & $\%$ \\
\hline
\end{tabular}

P. eximia

$\begin{array}{lrrrrrr}\text { Peixe } & 220 & 10,59 & 119 & 11,04 & 41 & .4,64 \\ \text { Fígado } & 1435 & 69,09 & 783 & 72,63 & 672 & 76,10 \\ \text { Fezes } & 422 & 20,32 & 176 & 16,33 & 170 & 19,25\end{array}$

P. sericata

$\begin{array}{lrccccc}\text { Peixe } & 0 & 0 & 0 & 0 & 0 & 0 \\ \text { Fígado } & 34 & 82,90 & 4 & 100,00 & 10 & 41,66 \\ \text { Fezes } & 7 & 17,10 & 0 & 0 & 14 & 58,34\end{array}$

c. macellaria

$\begin{array}{lrrrrrr}\text { Peixe } & 812 & 9,87 & 575 & 7,52 & 132 & 4,40 \\ \text { Fígado } & 6413 & 77,93 & 6310 & 82,50 & 2070 & 69,00 \\ \text { Fezes } & 1004 & 12,20 & 764 & 9,98 & 798 & 26,60\end{array}$

H. segmentaria

$\begin{array}{lrcrrrr}\text { Peixe } & 0 & 0 & 0 & 0 & 10 & 2,24 \\ \text { Fígado } & 24 & 75,00 & 41 & 91,00 & 211 & 47,31 \\ \text { Fezes } & 8 & 25,00 & 4 & 9,00 & 225 & 50,45\end{array}$

H. flavifacies

$\begin{array}{llllcrr}\text { Peixe } & 0 & 0 & 0 & 0 & 13 & 6,91 \\ \text { Fígado } & 0 & 0 & 3 & 37,50 & 78 & 41,49 \\ \text { Fezes } & 0 & 0 & 5 & 62,50 & 97 & 51,60\end{array}$

M. fulvinota

$\begin{array}{lrrrcrl}\text { Peixe } & 8 & 26,66 & 0 & 0 & 165 & 23,04 \\ \text { Fígado } & 16 & 53,34 & 18 & 75,00 & 221 & 30,87 \\ \text { Fezes } & 6 & 20,00 & 6 & 25,00 & 330 & 46,09\end{array}$

\begin{tabular}{|c|c|c|c|}
\hline TOTAL & 10409 & 8808 & 5257 \\
\hline
\end{tabular}


APÊNDICE XIII - Variação na frequência dos sexos nas zonas urbana, rural e de mata, em Goiânia - Goiás, no período de 1975 a 1976.

\begin{tabular}{|c|c|c|c|c|c|c|c|}
\hline \multirow{3}{*}{ Espécies } & \multicolumn{7}{|c|}{ Locais de coleta } \\
\hline & \multirow[t]{2}{*}{ - } & \multicolumn{2}{|c|}{ Z. urbana } & \multicolumn{2}{|c|}{ Z. rural } & \multicolumn{2}{|c|}{ Z. mata } \\
\hline & & Total & $\%$ & Total & $\%$ & Total & $\%$ \\
\hline & $q$ & 1681 & 80,93 & 980 & 90,90 & 778 & 88,11 \\
\hline \multirow[t]{3}{*}{ P. eximia } & $\infty$ & 396 & 19,07 & 98 & 9,10 & 105 & 11,89 \\
\hline & $\Sigma$ & 2077 & & 1078 & & 883 & \\
\hline & 8 & 39 & 95,12 & 4 & 100,00 & 22 & 91,66 \\
\hline \multirow[t]{3}{*}{ P. sericata } & $\infty$ & 2 & 4,78 & 0 & 0 & 2 & 8,34 \\
\hline & $\Sigma$ & 41 & & 4 & & 24 & \\
\hline & $\$$ & 5304 & 64,45 & 6069 & 79,34 & 2412 & 80,40 \\
\hline \multirow[t]{3}{*}{ C. macellaria } & $\infty$ & 2925 & 35,55 & 1580 & 20,66 & 588 & 19,60 \\
\hline & $\Sigma$ & 8229 & & 7649 & & 3000 & \\
\hline & 8 & 12 & 37,50 & 44 & 98,00 & 249 & 55,83 \\
\hline \multirow[t]{3}{*}{ H. segmentaria } & $\infty$ & 20 & 62,50 & 1 & 2,00 & 197 & 44,17 \\
\hline & $\Sigma$ & 32 & & 45 & & 446 & \\
\hline & 8 & 0 & 0 & 6 & 75,00 & 142 & 75,53 \\
\hline \multirow[t]{3}{*}{ H. flavifacies } & $\sigma$ & 0 & 0 & 2 & 25,00 & 46 & 24,47 \\
\hline & $\Sigma$ & 0 & & 8 & & 188 & \\
\hline & q & 20 & 66,66 & 20 & 83,30 & 437 & 61,03 \\
\hline \multirow[t]{2}{*}{ M. fulvinota } & $\sigma^{\prime}$ & 10 & 33,33 & 4 & 16,70 & 279 & 38,97 \\
\hline & $\Sigma$ & 30 & & 24 & & 716 & \\
\hline
\end{tabular}




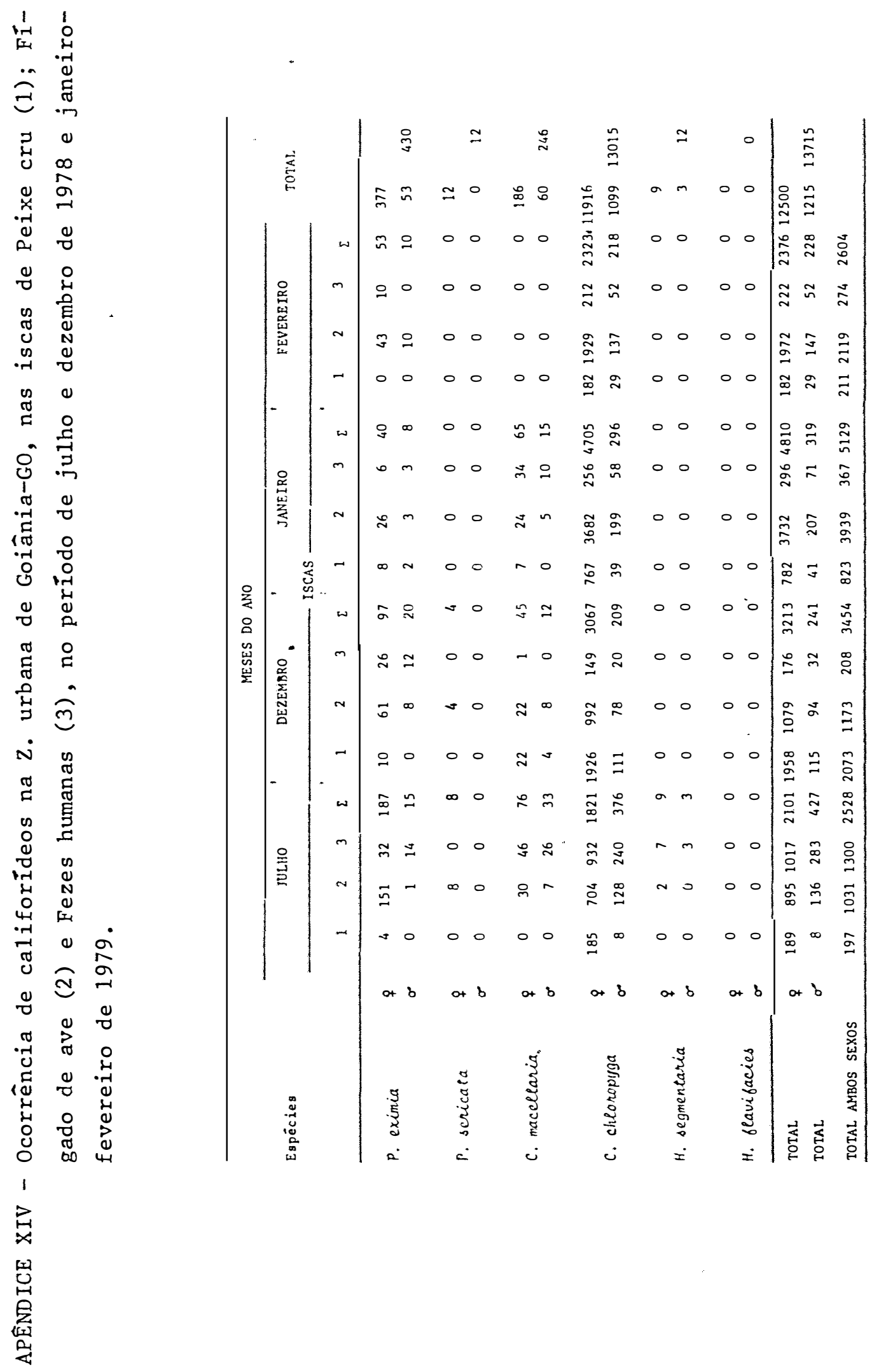




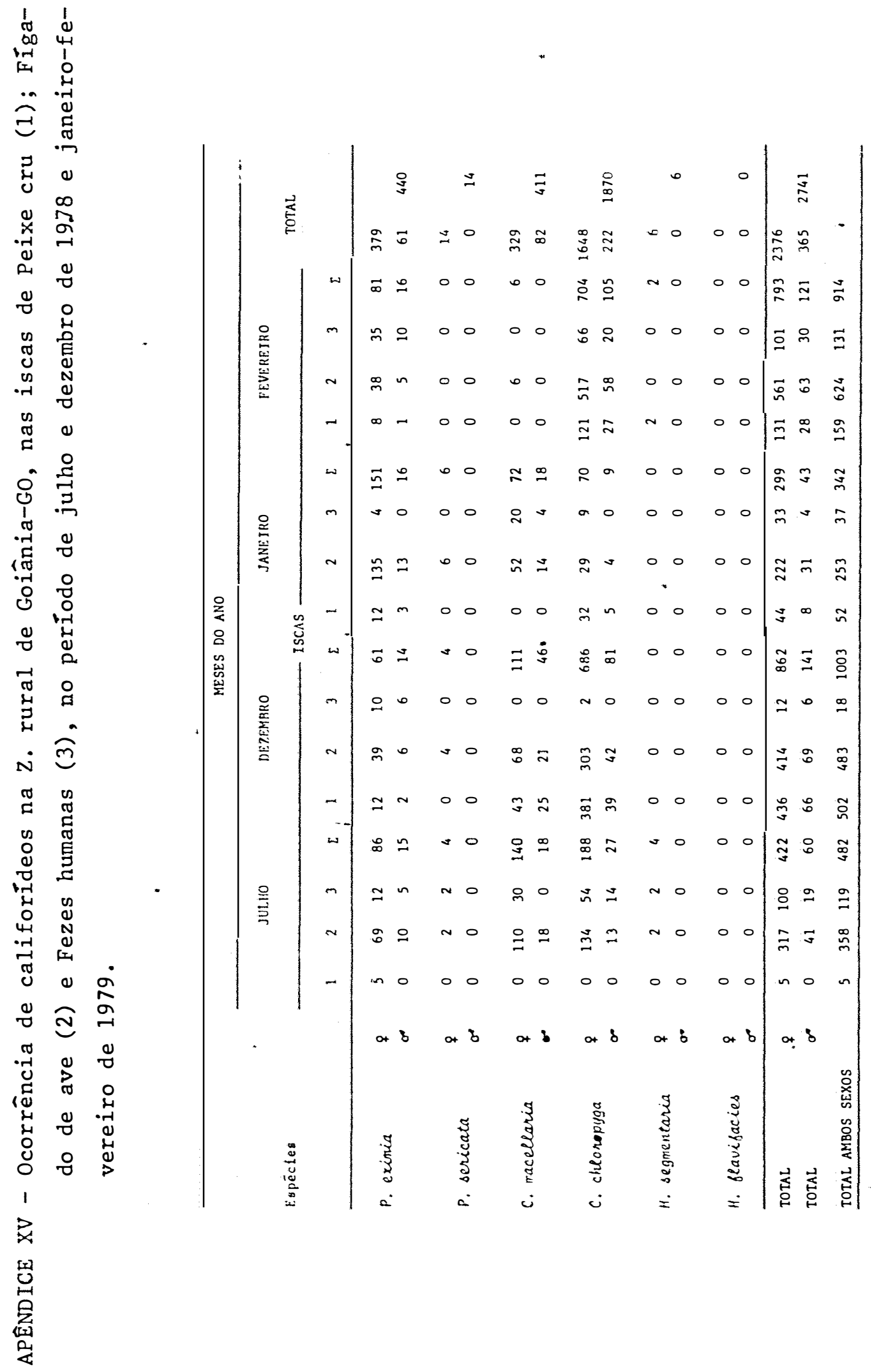




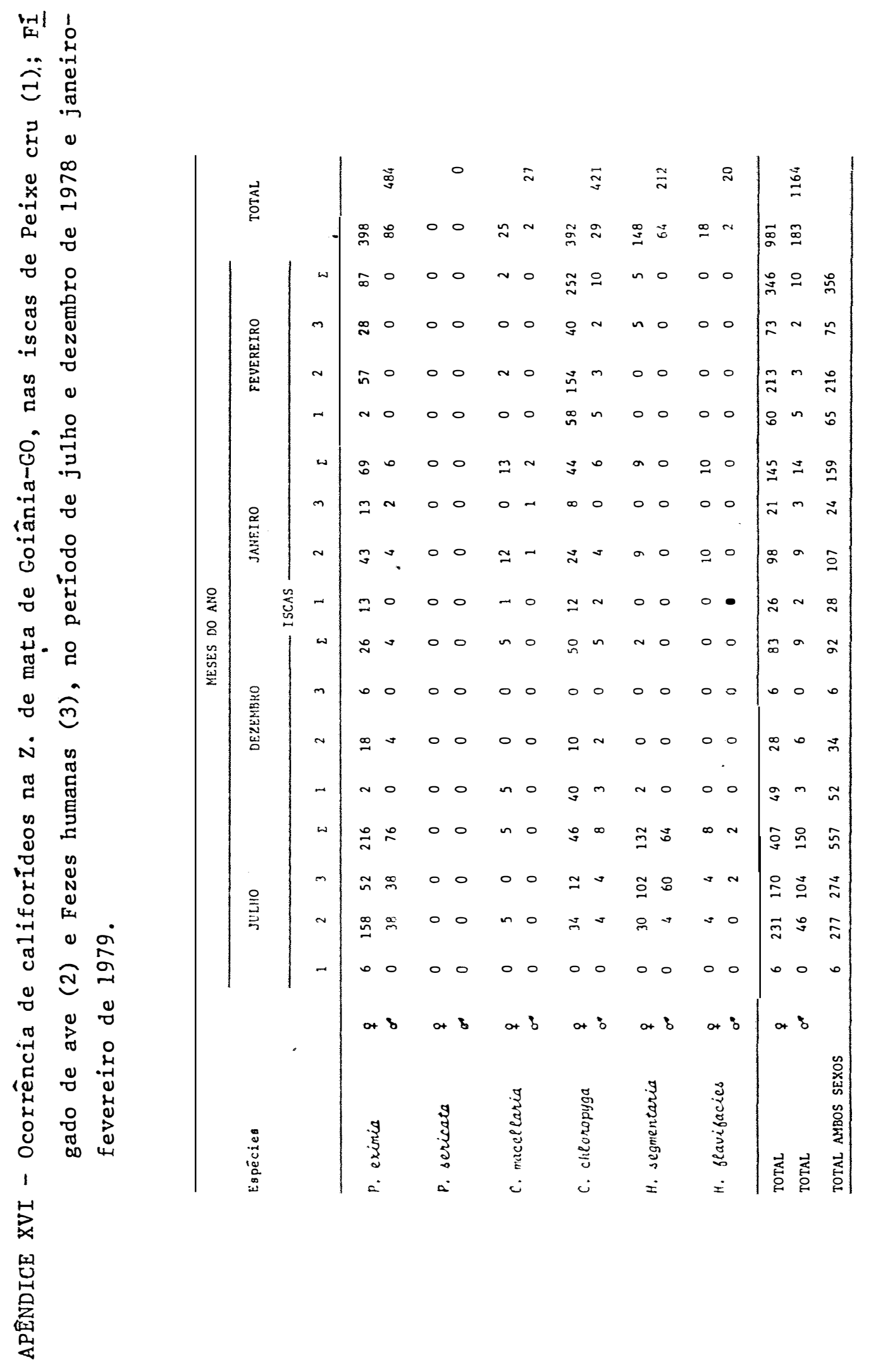


APENDICE XVII - Distribuição anual de fêmeas de califorídeos ocorrendo em iscas de peixe (A); fígado de ave (B) e fezes humanas (C) em Goiânia no período de julho e dezembro de 1978 e jane ro-fevereiro de 1979.

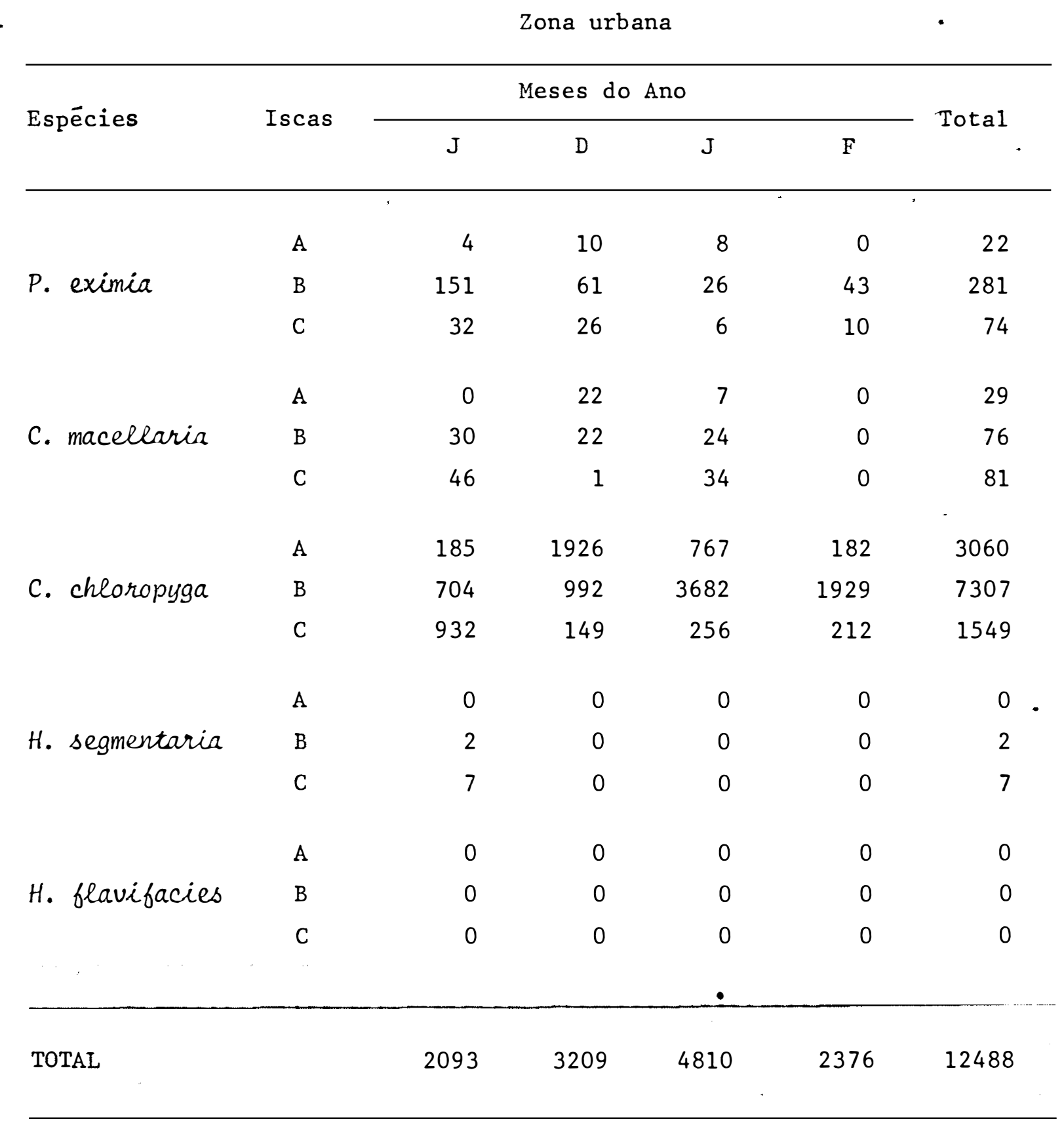


APENDICE XVIII - Distribuição anual de fêmeas de califorídeos ocorrendo em iscas de peixe (A); fígado de ave (B) e fezes humanas (C) em Goiânia no período de julho e dezembro de 1978 e janeiro-fevereiro de 1979.

Zona rural

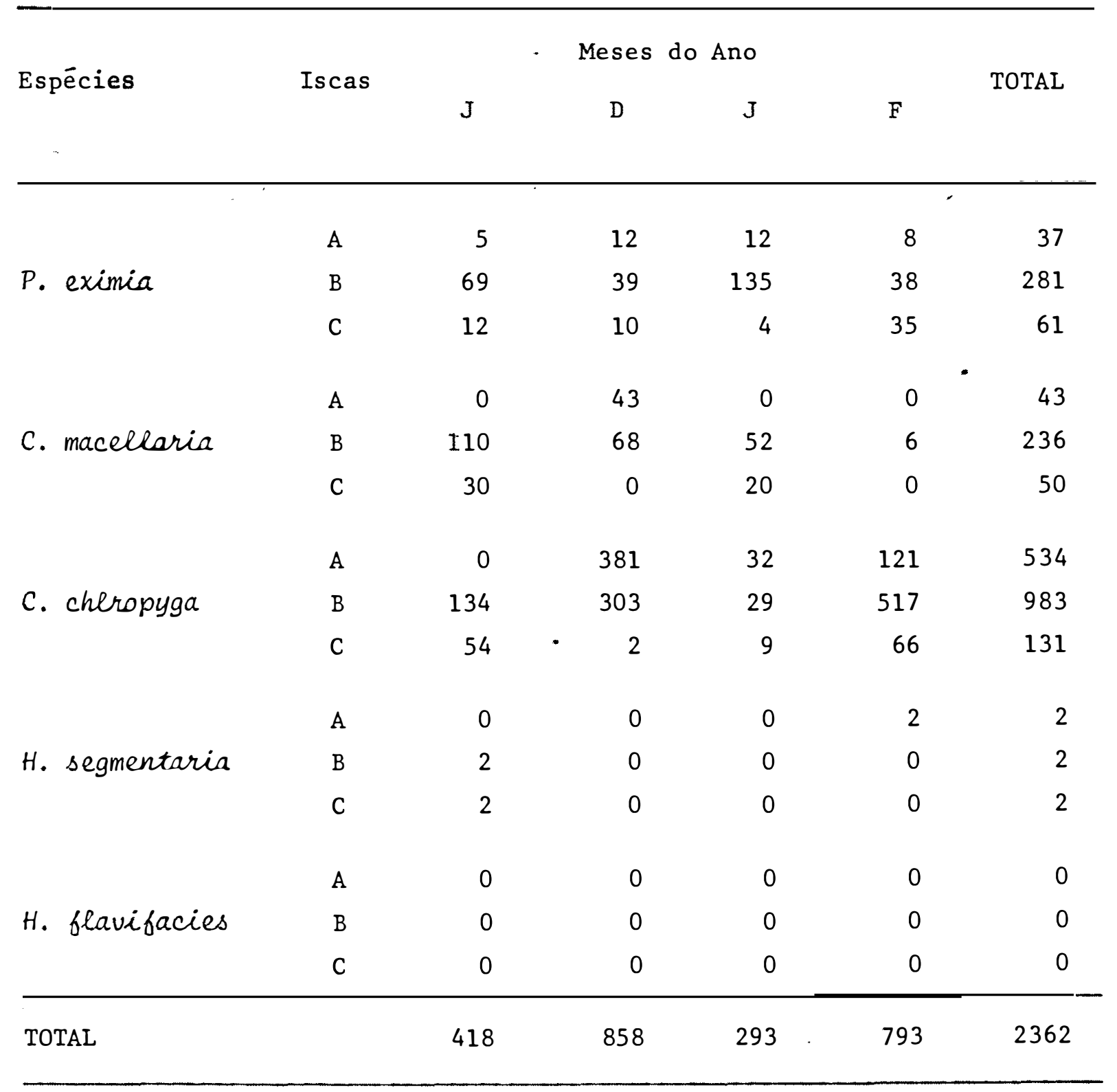


APENDICE XIX - Distribuição anual de fêmeas de califorídeos ocorrendo em iscas de peixe (A); fígado de ave (B) e fezes humanas (C) em Goiânia no período de julho e dezembro de 1978 e janeiro-fevereiro de 1979 .

Zona de Mata.

\begin{tabular}{|c|c|c|c|c|c|c|}
\hline \multirow{2}{*}{ Espécies } & \multirow{2}{*}{ Iscas } & \multicolumn{4}{|c|}{ Meses do Ano } & \multirow[b]{2}{*}{ TOTAL } \\
\hline & & $\mathrm{J}$ & D & $\mathrm{J}$ & $\mathrm{F}$ & \\
\hline & $\mathrm{A}$ & 6 & 2 & 13 & 2 & 23 \\
\hline \multirow[t]{3}{*}{ P. eximia } & B & 158 & 18 & 43 & 57 & 276 \\
\hline & $\mathrm{C}$ & 52 & 6 & 13 & 28 & 99 \\
\hline & A & 0 & 5 & 1 & 0 & 6 \\
\hline \multirow[t]{3}{*}{ C. macellaria } & B & 5 & -0 & 12 & 2 & 19 \\
\hline & $\mathrm{C}$ & 0 & 0 & 0 & 0 & 0 \\
\hline & A & 0 & 40 & 12 & 58 & 110 \\
\hline \multirow[t]{3}{*}{ C. chloropyga } & B & 34 & 10 & 24 & 154 & 222 \\
\hline & $\mathrm{C}$ & 12 & 0 & 8 & 40 & 60 \\
\hline & A & 0 & 2 & 0 & 0 & 2 \\
\hline \multirow[t]{3}{*}{ H. segmentaria } & B & 30 & 0 & 9 & 0 & 39 \\
\hline & C & 102 & 0 & 0 & 5 & 107 \\
\hline & $A$ & 0 & 0 & 0 & 0 & 0 \\
\hline \multirow[t]{2}{*}{ H. flavifacies } & B & 4 & 0 & 10 & 0 & 14 \\
\hline & $\mathrm{C}$ & 4 & 0 & 0 & 0 & 4 \\
\hline TOTAL & & 407 & 83 & 145 & 346 & 981 \\
\hline
\end{tabular}




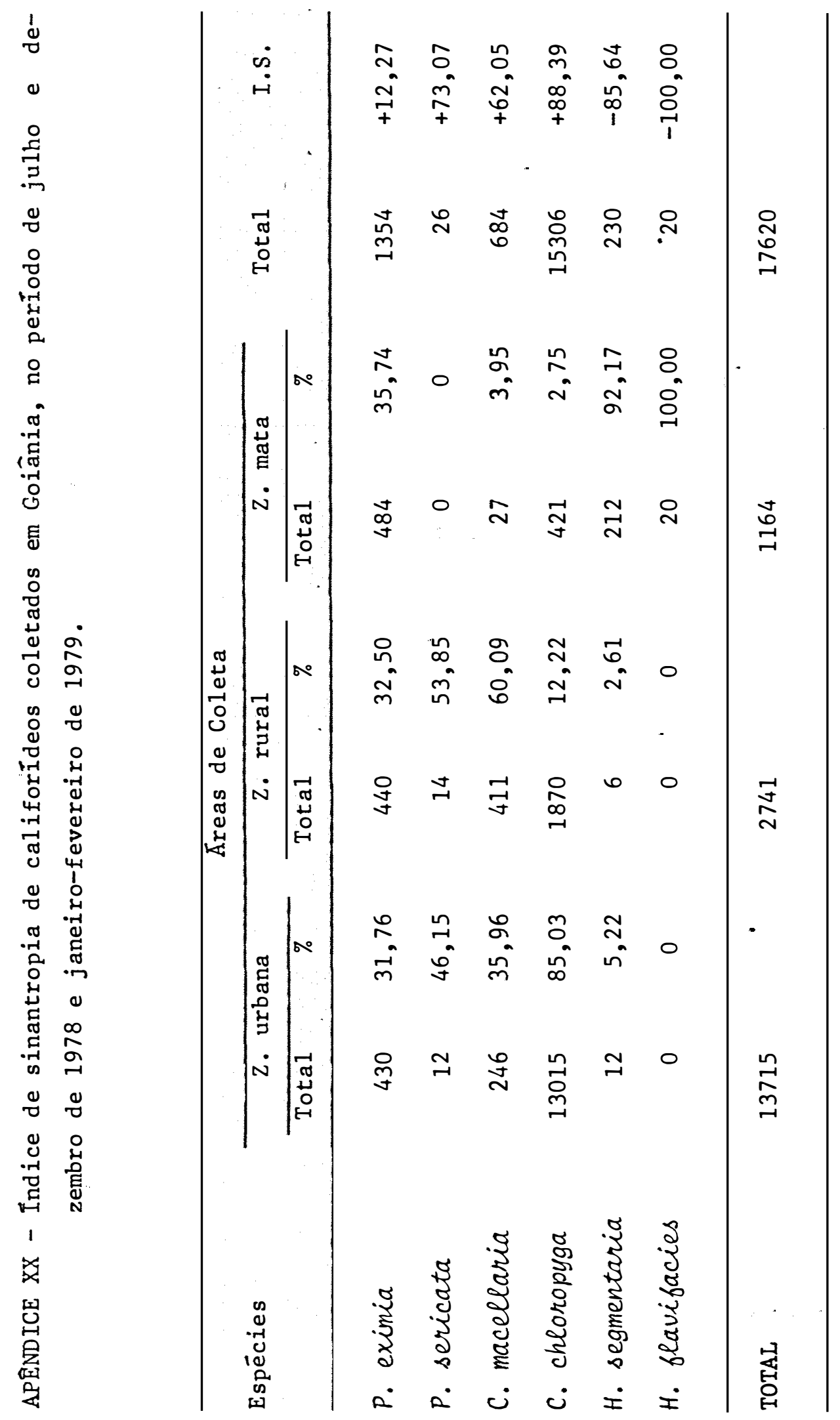


APÊNDICE XXII - Variação na frequêencia dos sexos de califorídeos na $z$. urbana, z. rural e z. de mata - Goiânia-Goiās, no período de $1978-1979$.

\begin{tabular}{|c|c|c|c|c|c|c|c|}
\hline \multirow{3}{*}{ Espēcies } & \multicolumn{7}{|c|}{ Locais de coleta } \\
\hline & \multicolumn{3}{|c|}{ Z. urbana } & \multicolumn{2}{|c|}{ 2. rural } & \multicolumn{2}{|c|}{ Z. mata } \\
\hline & & Total & $\%$ & Total & $\%$ & Total & $\%$ \\
\hline & $q$ & 377 & 87,67 & 379 & 86,14 & 398 & 82,23 \\
\hline \multirow[t]{3}{*}{ P. eximia } & $\sigma^{\circ}$ & 53 & 12,33 & 61 & 13,86 & 86 & 17,77 \\
\hline & $\Sigma$ & 430 & & 440 & & 484 & \\
\hline & $q$ & 12 & 100,00 & 14 & 100,00 & 0 & 0 \\
\hline \multirow{3}{*}{ P. sericata } & or & 0 & 0 & 0 & 0 & 0 & 0 \\
\hline & $\Sigma$ & 12 & & 14 & & 0 & \\
\hline & ㅇ & 186 & 75,61 & 329 & 80,00 & 25 & 92,60 \\
\hline \multirow[t]{3}{*}{ C. macellaria } & or & 60 & 24,39 & 82 & 20,00 & 2 & 7,40 \\
\hline & $\Sigma$ & 246 & & 411 & & 27 & \\
\hline & 우 & 11916 & 91,56 & 1648 & 88,13 & 392 & 93,11 \\
\hline \multirow[t]{3}{*}{ C. chloropyga } & $\infty$ & 1099 & 8,44 & 222 & 11,87 & 29 & 6,89 \\
\hline & $\Sigma$ & 13015 & & 1870 & & 421 & \\
\hline & $q$ & 9 & 75,00 & 6 & 100,00 & 148 & 69,80 \\
\hline \multirow{2}{*}{ H. segmentaria } & or & 3 & 25,00 & 0 & 0 & 64 & 30,20 \\
\hline & $\Sigma$ & 12 & & 6 & & 212 & \\
\hline \multirow{3}{*}{ H. flavifacies } & $q$ & 0 & 0 & 0 & 0 & 18 & 90,00 \\
\hline & $\sigma$ & 0 & 0 & 0 & 0 & 2 & 10,00 \\
\hline & $\Sigma$ & 0 & & 0 & & 20 & \\
\hline
\end{tabular}

